Portland State University

PDXScholar

1981

\title{
Environmental and psychological factors surrounding children of cancer patients : an exploratory study
}

Joan Strong Buell

Portland State University

Follow this and additional works at: https://pdxscholar.library.pdx.edu/open_access_etds

Part of the Child Psychology Commons, and the Family, Life Course, and Society Commons Let us know how access to this document benefits you.

Recommended Citation

Buell, Joan Strong, "Environmental and psychological factors surrounding children of cancer patients : an exploratory study" (1981). Dissertations and Theses. Paper 3196.

https://doi.org/10.15760/etd.3187

This Thesis is brought to you for free and open access. It has been accepted for inclusion in Dissertations and Theses by an authorized administrator of PDXScholar. Please contact us if we can make this document more accessible: pdxscholar@pdx.edu. 
AN ABSTRACT OF THE THESIS OF Joan Strong Buell for the Master of Arts in Psychology presented May 22, 1981.

Title: Environmental and Psychological Factors Surrounding Children of Cancer Patients: An Exploratory study

APPROVED BY MEMBERS OF THE THESIS COMMITTEE:

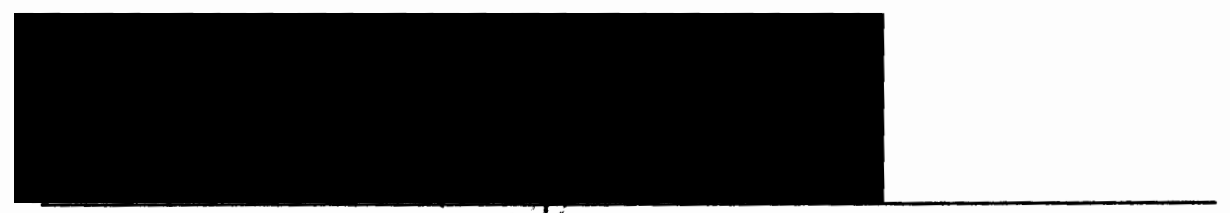

walter G. Klopfer, Chaipthan

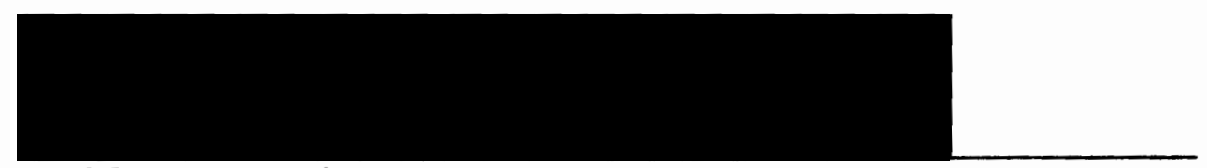

Cathleen L. Smith

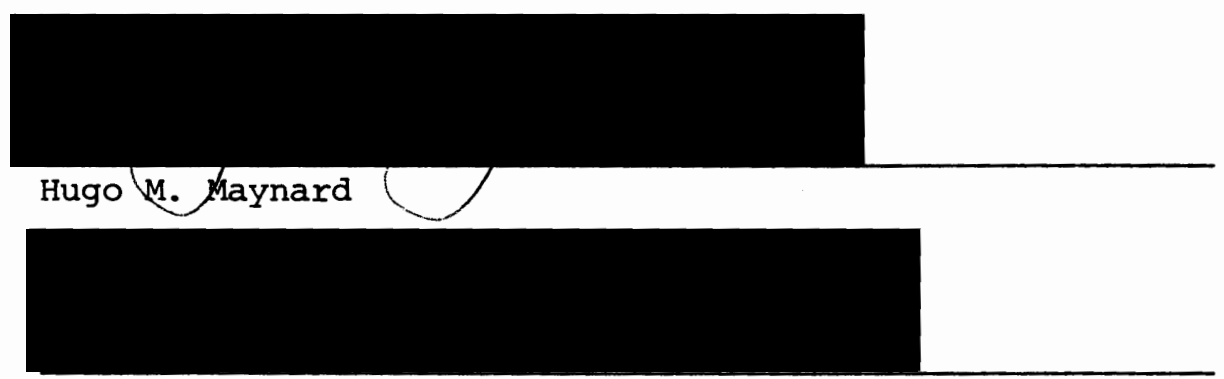

David L. Cressler

This exploratory study examines five families in which one parent was ill with cancer and in which there was a 5-to 8-year-old child. To understand the adaptation to the illness (and, in the case of three families, to the death of the ill parent) of the focus child was the principal aim of the study. The circumstances existing around the time of the illness and death of the parent were seen as particularly important in determining how the child viewed these events. Areas such as 
substitute caregivers, family routines, information given to the child, and the child's participation in, apparent understanding of and preparation for occurrences were some of the areas studied.

over a period of a $1-1 / 2$ years, interviews, home visits, a school visit and telephone conversations took place. The patterns varied for each family depending on individual characteristics and family convenience. Interviews were conducted with one parent in each family (either well or ill), while conversations during participant observations and telephone conversations were the chief mode of gathering data otherwise. The advantages and disadvantages of participant observation are discussed.

The young child's ability to foresee future events is limited, and that lack of foresight seems crucial in how the child views the death of the parent. Adults' views of the child's loss comprehend the loss of the life between the parent and child that would have taken place had the parent not died. The child views the loss from quite a different perspective.

The child's view of the permanency of death may be quite as complete as the adults'. It is the full implication of that loss that the child does not grasp. Hence, the child's fears for personal security and grief for the known parent may be acute. But only as the child grows older and sees the other elements that he or she did not encompass at the time of death will the whole picture be complete.

The rationale for examining the events surrounding the death is based on the premise that if there are aversive conditions existing (besides the death itself) these may prevent the growing child from reviewing and remembering the event in later years and grieving for the 
newly understood components of the loss. Under aversive conditions we would group fear, in particular fear for personal security, physical pain, deception of which the child is aware, isolation and extreme disruption of familiar patterns of routines and people.

The families in this study showed many similarities in ways of explaining the illness and of preparing the children for the death of the parent. Home and hospital care were factors for all of them, separation from the ill parent occurring most noticeably during hospitalization. Parent fatigue, anger, and grief were factors in interparental stress, all of which influenced the child's daily life to some extent. The child's increasing awareness of observable disease progression was also a factor.

It is hoped that in isolating and in allowing these families to describe their experiences centering on these and other factors, we may help lay the groundwork for preventive therapy with children undergoing the experience of the illness and death of a parent. 
ENVIRONMENTAL AND PSYCHOLOGICAL FACTORS SURROUNDING CHILDREN OF CANCER PATIENTS:

AN EXPLORATORY STUDY

by

JOAN STRONG BUELL

A thesis submitted in partial fulfillment of the requirements for the degree of

\author{
MASTER OF ARTS \\ in \\ PSYCHOLOGY
}

Portland State University

1981 
TO THE OFFICE OF GRADUATE STUDIES AND RESEARCH:

The members of the Committee approve the thesis of Joan strong Buell presented May 22, 1981.

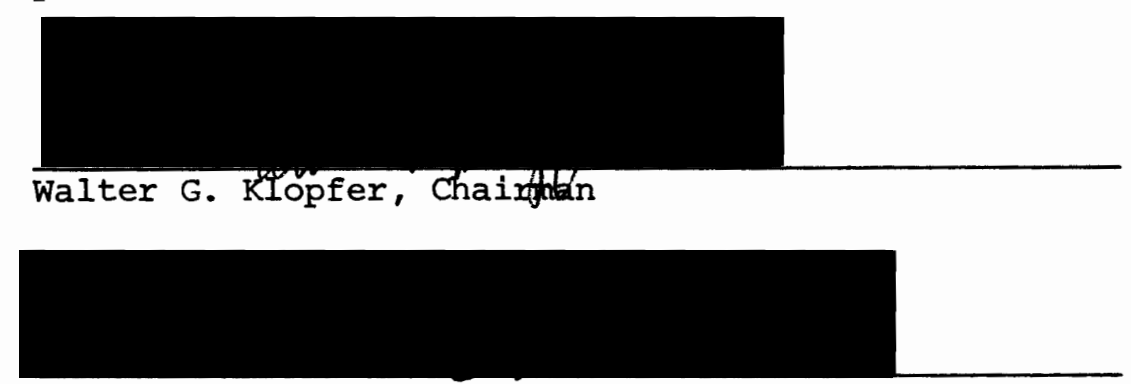

Cathleen I. Smith

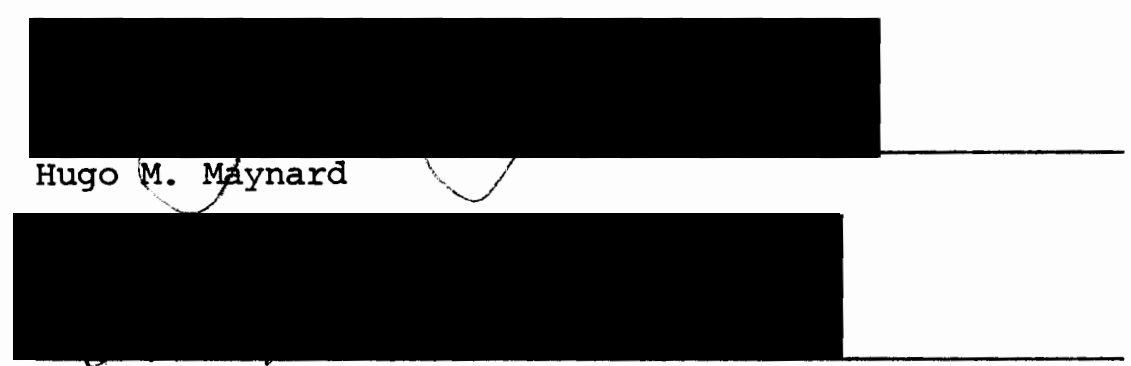

David I. Cressler

APPROVED :

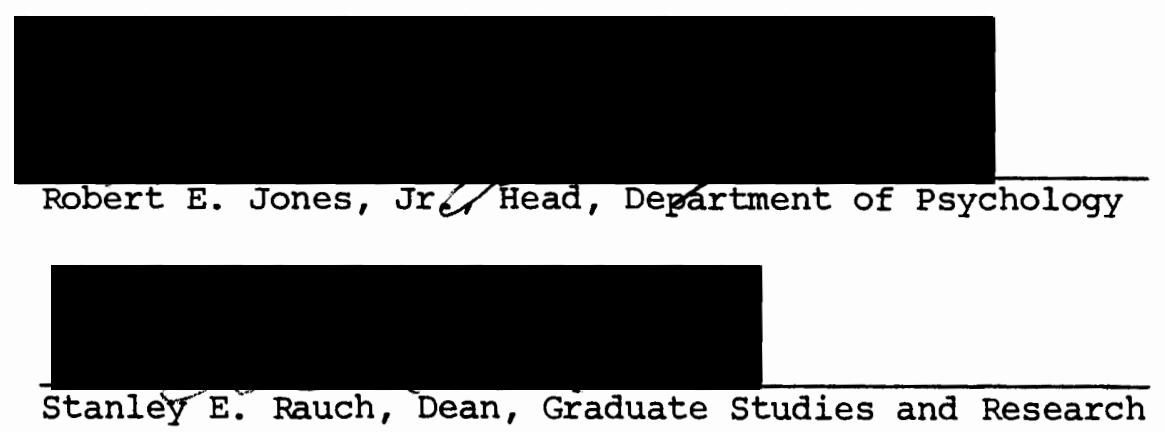




\section{ACKNOWLEDGEMENTS}

To the families whose voices speak in this study I give my most loving thanks. For them, the months were often full of strain and sadness, and that they allowed me to work with them speaks for their deep generosity. I want to express my appreciation to the caregivers who referred me to the families, understanding the problem and obligation this imposed but feeling that the effort was important.

I am grateful, too, to the members of my committee for their patient and encouraging support. They gave sound advice and helped me find my way when the waters seemed, at least, uncharted. And last, I thank my husband, Tom, for taking on double his share of our shared responsibilities so that I could bring the writing to a close. From the start, he had said it was a job worth doing, and thanks to him, I never felt otherwise. 
TABLE OF CONTENTS

PAGE

ACKNOWLEDGEMENTS. . . . . . . . . . . . . . . . . . . . $i i i$

IIST OF TABLES. . . . . . . . . . . . . . . . . . . . . vii

LIST OF FIGURES . . . . . . . . . . . . . . . . . . . . . viii

\section{CHAPTER}

I INTRODUCTION. . . . . . . . . . . . . . . . 1

II REVIEW OF THE IITERATURE. . . . . . . . . . . . 6

Cognitive Development and the Child's

Understanding of Death. . . . . . . . . . 6

Pre-death Procedures. . . . . . . . . . 13

Factors Influencing the Effects of Illness

and Death on the Child. . . . . . . . . . 18

Childhood Mourning. . . . . . . . . . . 24

Intervention and Therapy. . . . . . . . . 28

Aims of Present Study . . . . . . . . . . 29

III METHOD. . . . . . . . . . . . . . . . . 34

Selection of subjects . . . . . . . . . . 34

The Arrangement of Visits . . . . . . . . . 34

Procedures. . . . . . . . . . . . . 35

Stipulations Self-imposed by the Researcher . . . 38

Data Sorting. . . . . . . . . . . . . 39

IV PROFILES. . . . . . . . . . . . . . . 40

Family 1: Garrison ................ 40 
Family 2: Lindstrom. . . . . . . . . . .

Family 3: McAllister ............. 45

Family 4: Reutter. . . . . . . . . . . 48

Family 5: Neether. . . . . . . . . 50

V RESULTS . . . . . . . . . . . . . . . 53

Practicalities. . . . . . . . . . . . 53

place of Care . . . . . . . . . . . 53

Routines. . . . . . . . . . . . . 56

Financial Worries . . . . . . . . . . . 58

Caregivers: at Home and Away from Home . . . . . 60

School: The Teacher's Comments, The Parent's

outlook . . . . . . . . . . . . . . 67

The Younger (2- and 3-Year-old) Child...... . 71

Seeking Advice from a Counselor . . . . . . . 72

Mother-Father-Focus Child . . . . . . . . . 75

Mother Ill or Father Ill. . . . . . . . . 75

Father or Mother as the Person Who Talks

Most Easily with the Child. . . . . . . . 79

Interparental Relations .. . . . . . . . 80

Child.... . . . . . . . . . . . . . 84

Child Behaviors . . . . . . . . . . . 84

Child's Understanding of Disease, Medication

and Possibility of Death. . . . . . . . . . 88

Child Behaviors at the Time of Death

and Shortly After . . . . . . . . . . 95

Fears . . . . . . . . . . . . . . 101

The Idealized Dead Parent . . . . . . . . . 104 
Parent. . . . . . . . . . . . . . . 105

Surviving Parent: Time Alone,

Possibilities, and New Relationships. . . . . . 105

Recommendations to others ............ 113

V DISCUSSION. . . . . . . . . . . . . . . 115

BIBLIOGRAPHY . . . . . . . . . . . . . . . . . . . . 125

APPENDICES. . . . . . . . . . . . . . . . . . . . 132 


\section{LIST OF TABLES}

TABLE

PAGE

I Family Data and Timeline of Contacts. . . . . . . . 


\section{LIST OF FIGURES}

\section{FIGURE}

PAGE

1. Conceptual Model: Hypothetical Life-space of Person who Loses a Parent During Childhood. . . . . . . . . 
CHAPTER I

INTRODUCTION

Family members, as a group of people who learn everyday patterns of living together, also develop ways of coping with crisis when it arises. Crises can be sudden, as in the burning down of the house, the breaking of a child's bone through a fall, or a car accident. Or they can take an apparently positive form in the sudden fame of one member of the family or the unexpected acquisition of a large amount of money. On the other hand, a crisis can be an event which is attenuated in obvious ways by the preparatory sequences of smaller events that precede the actual peak of the crisis. The culmination of a series of economic hardships that end in the necessity to leave one's house and move to another might be one such type of crisis. The crisis to be discussed here is that which involves the malignant illness of one parent, a lifethreatening illness which in some cases leads to the death of a parent.

The view of crisis as a time when the people involved are particularly vulnerable and have a heightened potential for growth or deterioration, has been discussed both in the developmental literature and that of crisis theory (Caplan, 1961; Erikson, 1968; Pincus, 1974). The idea of death and bereavement as one such turning point is put in terms of interaction between the individual and the event by Pincus (1974):

A crisis is not an abstract imposition from without but a high point in the life of the person concerned . . . We might say that a crisis is a dynamic interaction between a person and an extreme event, and it would be as fatal to look at each part 
individually as it is to look at the two partners of a marriage crisis individually $(\mathrm{p} .44)$.

It is with the aim of understanding some of the complex occurrences that surround the child during the crisis created by the illness and death of a parent that this exploratory study is undertaken. In observing children who are living through these circumstances and in listening to their parents recount events, statements, questions and behaviors of the children, we hope to see more clearly the pattern of the child's comprehension of and adaptation to these events.

It is not the purpose only to look at a sample of bereaved children. Nor are we interested here in the particular problems caused by sudden death of a parent. Events during an illness may have an important bearing on the nature of the child's experience at and after the parent's death, a fact which has been supported in the literature in a general way but without isolation of specific elements that apply particularly to cancer patients and their children. In other words, the nature of the crisis under study is the long series of events starting with the diagnosis of cancer and continuing through the time when the disease is recognized to be terminal, the death of the parent, and the period of early bereavement.

It may be helpful in understanding the rationale behind the study to look on it as parallel to the study of natural disasters. As in a natural disaster, the illness and death of a parent are events which cannot be predicted accurately. They cannot be replicated or reproduced in facsimile in a laboratory setting. To do so would not only be unethical and grotesque, but if any part of the event could be imitated ethically, it would be robbed of its main characteristic, that of its 
great impact on those around the ill person.

We have then a series of events which must be found and reported on while it is currently taking place, or by retrospective account. Some of the early research in the area of child bereavement was done by psychiatrists who happened to be treating children when a parent died (Barnes, 1964; Bowlby, 1963). Although much rich material has come out of those accounts, it is our aim here to look at average, healthy children who, except for the occurrence of this "natural disaster," do not have any particular distinguishing problems, are living at home, and going through a process of adaptation, along with the other members of the family, to the illness and death of a parent.

Since it is the aim here to describe the environmental and psychological factors surrounding the focus child, it was felt that interviews alone would be insufficient, that observations in a setting removed from home would be artificial and would eliminate the possibility of gathering data on the physical setting. To interviews, an additional method was added, that of participant observation in the home, to give a perspective on parents' reports and a dimension that would otherwise be lacking. Protocols followed by the researcher will be treated in the Methods and Discussion sections. It suffices here to say that during an informal visit, the researcher was observing as a participant in the life of the family and was welcomed and included in current activities.

Participant observation in which the researcher interacts with the child and the parent in the home presents particular advantages and at the same time particular problems. The atmosphere created by natural interaction is a relaxed one. However, through participation the 
researcher becomes a variable in the pattern of family interaction. Since there is no way to determine exactly what changes this participation may cause, one must simply acknowledge the fact that these alterations may exist and describe the procedure as it was carried out (Becker \& Geer, 1970).

The technique of participant observation has been used to examine family interaction largely by anthropologists. Oscar Lewis (1969) has written extensively on one family after prolonged visits. One of the works encompasses three different people's views of one event: the death of an aunt. Lewis confines his comments to the preface, while the other sections consist entirely of quotes by each family member, on The Death, The Wake, and The Burial.

Jules Henry (1965), on the other hand, comments liberally and very subjectively as he presents his transposed notes in Pathways to Madness. (The book is a product of intensive study of five families, each of which had a disturbed child.) His notes, in fact, are quite subjective and edited-in-the-writing. He recorded them in the evenings or in spare moments during his week-to-ten-day stays in several families. He included in the Appendix a very helpful section on the rationale, method, and difficulties in the naturalistic observation of families of disturbed children.

Robert Coles (1967) has used the technique of participant observation to help understand and describe at length a number of families in the south. His work uses considerable commentary and reflection to set off long quotes from the family members. In gathering the data, he visited the families over a period of years, sometimes for quite long stays. 
The writers of the Foxfire series used a technique of taping dialogues, recording descriptive narrative, and taking photographs (Wigginton, 1972). They have compiled these data into a document vividly revealing the thoughts and activities of the people of a certain era and area.

It is hoped that in this present study, by looking at the child's experience from several points of view, we may better be able to see it clearly.

In order to narrow the field of investigation, families in the present study were chosen in which one parent was ill with cancer or had died from cancer within the last six months, and in which there was a child between the ages of 5 and 8 . Five families are included in the study. Data were collected over a period of $1-1 / 2$ years.

After a review of the literature and a description of the methods used to gather data, each child's home situation and family are described in a short profile. Subsequently, the conversations and interviews with the parents and children are presented in such a way as to describe the experience of each family with the focus on the child, preserving in large part the actual words used by the speaker. 
REVIEW OF THE IITERATURE

Cognitive Development and the Child's Understanding of Death

That there are stages in a child's cognitive development which determine his or her capability of understanding causal relationships, abstract concepts and the irreversibility of certain phenomena is heavily documented in the literature (Inhelder \& Piaget, 1958; Flavell, 1977). There have been descriptions, too, of the progression with age of children's understanding of death, a progression that corresponds with the changing levels of the child's cognitive development (Nagera, 1970; Nagy, 1959; Jackson, 1965; Hansen, 1973).

In one view (Nagy, 1959), the 1- to 5-year-old child understands death as separation, as being less alive; the child at that age does not understand either inevitability or irreversibility. For the child from 5 to 9 years, death is personified, understood to be final, although it may still be considered something to be outwitted or eluded. The child may not understand that it is inevitable nor that it has a personal reference. The child from 9 to 13 years, according to Nagy, sees death as final and inevitable.

Fram another point of view (Jackson, 1965), the child's cumulative process of understanding death is described as follows: The 3- to 4year-old experiences a sense of loss but without conceptualization of death; the 4- to 7-year-old adds to this biological interests and the 8- to 12-year-old adds a social dimension, concern for death's 
consequences on the lives of the living. The adult understanding is compounded or compiled in this way, and when any phase of the developmental process is mishandled, it will tend to complicate the adult response.

Jackson is not as concerned as Nagy with whether or not the child understands death as final. The emphasis in Jackson's work is largely on the role adults can play in avoiding emotional complications for the child subsequent to the death of an important person, by acknowledging the importance the child attaches to the death.

There is a wide discrepancy in the ages at which children reach understanding even within the general age ranges outlined in these stages. Some children within an age group grasp the concept of death sooner than others (Kastenbaum, 1974). R. Furman (1970) urges us not to be surprised that a 3-year-old understands what is happening when someone dies and a 5-year-old seems not to.

From very early childhood, both fear of extinction and speculation on means of staving it off are present (Maurer, 1974). Understanding of being vs. non-being is seen as early as 16 months, witnessed by the child who, when seeing a caterpillar crushed by an undnowing adult's foot, stoops and inspects it carefully, saying, "No more!" We also see children using the possibility of being dead in play, pretending to be dead, experimenting, Kastenbaum (1974) feels, with a cognitive level they may not have reached. This type of play is particularly frequent among children in the early school years, the ages of the children under study here.

our criteria for judging a child's understanding of death are clumsy at best. Frequently, our criterion for judging whether a child understands the finality and full impact of the death of a parent is 
whether or not the child weeps and shows emotion. It is possible that the first impact of death is an impact on the frame of reference (Schor, 1974), not an emotional impact. For instance, the child who asked her mother, on coming home from school the day she learned about the death of one of her friends, "Will you die before I do?" was resetting her frame of reference, trying to understand what a death meant to her personally in terms of her own friendships and relationships, and her own probable life span. Rather than seeing this as simply an example of egocentricity, it would be more useful to see it as a question aimed at solving a newly arisen problem, the problem of who is likely to die when. The child may indeed see another child's death as a threat to her own well-being, particularly if she had earlier been told that old people die, not young people. She may have been asking the question hoping for reassurance that she would probably not die soon, even as she, at the same time, exposed herself to the question of how she would feel if her mother did die.

Britchnell (1969) has made an important contribution to our view of the child's loss when a parent dies: The child may have an acute sense of loss but it may not include any perception of the broader role that the parent played in family interaction. In other words, not only is the dead parent lost to the child but the influence that that parent had on all the other interrelationships in the family is now no longer in effect. The young child, however, may not have an awareness either of the complexity of the parent's role nor of the implications of the loss of the person who functioned in that role.

Bauer (1976) discusses the child's deficiency in awareness of genuine physical causality in a study on developmental changes in 
children's fears. Only two out of 19 kindergarten aged children were frightened of actual bodily injury, while 14 of the same group were frightened of monsters and ghosts. Illness has for most children been something from which one recovers. Quite rightly, parents, when children are ill, have often said, "The doctor will make you better," or "If you take your medicine, it will make you all well." without an understanding of how the body functions, it is nearly impossible for most adults, much less children, to understand the actual causality of illness leading to death. Therefore, the child may search for other reasons why the parent is dying and come up with a variety of ideas including the idea that the death may be caused by something the child has done. Klein (1948) sees this guilt as a major component of all childhood mourning.

Continuing an investigation of what comprehension of causality is possible for a very young child, 2-1/2 years old, an anecdotal sequence described by Brent (1978) is illuminating. The child, Brent's son, waked every night several times crying for a bottle of sugarwater. The child was past the bottle stage and the parents, feeling that this was regressive, following the birth of a baby sister, tried to reason him away from it. Finally one night, when the number of wakings had increased to an almost steady waking, the father had gone into the room and had said that that was enough, no more bottles; on leaving, hearing a note of terror in the child's voice, he stopped and returned. He took the child up and sat in a chair with him to talk.

"What will happen if you don't get your bottle?"

"Then I won't make contact."

"What does that mean, 'You can't make contact'?"

"If I run out of gas, I can't make contact,--my engine won't go, you know!" (p. 287) 
Then followed a talk about how people are not like engines. They eat food and they can live for days without eating food. People go on living even when they don't eat for quite a long time. Adding another part of this, feeling that he had only said things which reached part of the cognitive side of the child's terror, the father added that motors have a key, and together they concluded that the child did not have a key. The child went to bed and that was the last time he woke up crying for a bottle.

Brent's discussion of the sequence that had led up to this very complex and logical fear of dying is clear, and, thanks to a very verbal child and very observant parents, the pieces could be fitted together.

(Two parakeets and a grandfather had died. During the child's emotional upset about these deaths, the parents had used the words, ". . it is like when a motor stops running.") (p. 290)

1. Every animal and person has a motor.

2. Dead is when a person's motor stops.

(Three events had occurred in the last year: One, a dead battery with talk of contact; two, running out of gas, once with a car, once with a boat, both with considerable confusion, one with some danger.)

3. Two elements needed to keep the motors running: gas and contact.

4. If your motor stops you'll be dead.

5. Keep filled up with gas so motor will go.

(Baby sister's sugar water bottle had been stopped and the mother had said in that child's hearing, that it had been 'giving her gas.') (p. 289)

6. Bottle with sugar-water will give you gas.

7. The way to keep from dying during the night is to drink sugar-water. 
The intricacy of deduction in the sequence is startling and touching, and that we hear it from a very young child seems to indicate that it may be unwarranted to make too many rigid assumptions about children's lack of understanding of death.

In another retrospective first hand account, a child whose mother had just died was 5 years old. After the funeral, the aunts, seeing her playing and dancing around, said, in her hearing, "Poor little thing, she doesn't know what's happened." The child thought, "Aren't they stupid! of course I know what's happened." (Personal account.) The child was playing, thinking, but perhaps, since she was not sitting and looking bewildered or weeping, the nearby adults assumed that she "didn't understand."

The questions of the frequency of children's thoughts about death, its likelihood, and their affective response to it is related to the proposition that the change in frame of reference caused by the death may be as important for the child as the emotional response to the death. In one study (Menig-Peterson \& McCabe, 1978), 96 children, aged $3-1 / 2$ to $9-1 / 2$ were told a narrative story which the narrator interrupted at some semi-dire point such as a bee sting, a car wreck, a domestic accident, or the taking of a pet to the veterinarian. The children were then asked to continue the stories with narratives of their orn by requests such as one about whether or not the child ever was scared of something similar. In the continuation narratives that the children then told, only 118 of the children aged $3-1 / 2$ to $5-1 / 2$ continued with a narrative involving death, while over 508 of the children aged $5-1 / 2$ to $6-1 / 2$, and 758 of the children aged $7-1 / 2$ to 9-1/2, did so. The investigators noted that the children in the 
younger groups showed little or no affect, although in the older groups the children evinced some empathy with suffering. The investigators looked on this increase with age in the frequency of mention of death as evidence of growing preoccupation with death in older children. They also saw the younger children's lack of affect as evidence that those children had difficulty coping with the emotional impact of death.

The older children's expression of empathy might be said to confirm Jackson's (1965) view that 8- to 9-year-olds have begun to have concerns for the living who are bereaved. It should be pointed out, however, that children of this age are frequently to be heard imitating stereotypic adult phrases and cliches, and could in some part be imitating frequently heard and socially acceptable sayings. It is also possible that the rise in frequency of mention of death was due to the fact that the older children had heard more about death, had seen more deaths on television, and had even had more experience with deaths of people they had known, than had the younger children.

Rather than demonstrating difficulty coping with death in emotional terms, Schor (1974) would support the view that the younger children's lack of emotional behavior in discussing death shows that for them, death is not a highly emotionally charged issue. Bugen (1977) goes further to aver that depression and volatile emotion may never be a response to bereavement, even in a completed adult grieving process. In the impending death of a parent, the child may understand only portions of what is occurring. Misunderstandings on the part of the child may be revealed in direct questions or statements (Brent, 1978; Schnathorst, 1976; Pincus, 1974). These misunderstandings or partial understandings may come to light in non-verbal behavior such as 
paintings and drawings, or avoidance of certain places and types of situations (Kubler-Ross, 1974; Bertman, 1979), difficult for an unpracticed eye and ear to detect.

\section{Pre-death Procedures}

Emerging in the literature are several aspects of the ways in which the adults and children in a family can prepare or not prepare for death.

While the adult's choice of ways to understand and cope with death is largely under that person's own control and that of the person's past history, the child's is linked in a particular way to the behavior of the adults around the child, partly in the sense that the adult models behavior, but also in the sense that the adult can modify the nature and amount of information given to the child. Not only does our society tend to avoid the subject of death and therefore make it unlikely that the child will hear open discussion of the subject, but also within the family the adults control the giving of information and the setting of the tone and attitude. This means that the child can be aided (or thwarted) by adults who may be sad, sometimes afraid and angry and who may find it confusing and difficult to know how to tell the child what is happening even if they themselves recognize all the intricacies of the events (Caine, 1974). They may give the child a constantly changing, not always truthful impression of occurrences and of their own emotional condition (Bok, 1978).

Preparation. Preparation of the child during illness of a parent is advocated by Astrachan (1977). "If something exists, it should be told to children under appropriate circumstances by well-intended people and with emotional support. Information and support are better 
than imagination and fantasy" (p.383). Curiosity and the child's natural reaction facilitate this process, since questions will emerge almost inevitably, in an open atmosphere, and can be answered honestly (Becker \& Margolin, 1967).

Jackson (1965) also advocates open preparation. As he describes it, the child lives in a world of feelings. "The child is almost defenseless against their (adults') feelings. They get to him directly" (p. 34). "To be lied to at the same time that he is faced with an emotional climate he cannot understand is doubly injuring. Even half truths are hard to interpret to a youngster" (p. 38).

Avoidance of Preparation. The well parent and the ill parent may find it very difficult to see the situation from the perspective of the child. Since they are involved in their own fear caused by the illness, anger, and other concerns (e.g., sexual deprivation), they may neglect to prepare the child during the course of illness. Possibly in attempts to protect the child from "roller coaster rides between peaks of hope and valleys of despair" (Hine, 1979, p. 177), some parents may deliberately avoid preparing the children in the family. They may themselves hope that death is not going to be the ultimate outcome, and may feel that it is pointless or even heartless and unnecessary to worry the child. Hine (1979) points out that discussing death was, for her and her husband, not morbid, that at a certain point in his illness it was "heart lightening," and did not violate attempts to keep up a positive attitude (p. 177). This dichotomy seems difficult to understand, but the heart lightening that can indeed occur would seem to be something of which one would not deliberately deprive a child. 
Avoidance can cause a vacuum in which no communication can take place, not only during the illness but after the death. A child, describing a teacher as "mean" who never even bothered to come and say, "I'm sorry your father died," is sensing the same vacuum: No comfort, nor any thanks for comfort can be given in that empty space (R. Furman, 1970).

Assurance might be given to parents, in order to encourage them not to avoid preparation, that childhood bereavement is not, ipso facto, a cause of mental illness (Kliman, 1968; Crook \& Eliot, 1980). Understandably, if parents or other surrounding adults believe that the only alternative to ignorance and cheerfulness is heart-rending anguish, they would avoid preparing the child for the impending death of a parent, possibly to save themselves the pain of having to be a witness to such anguish.

Bowlby (1963) points out that there are risks in lack of preparation. In cases of pathological grief where a "split" occurred, i.e., where the death was both denied and acknowledged by an adult:

the loss had not only occurred in the absence of the bereaved but had been sudden. If, as I suspect, these conditions do promote splits, it may be a step to understanding why such splits are so apt to occur in childhood; for young children are usually banished from the scene of death and since they have little foresight, the event of death is almost bound to be experienced by them as sudden (p. 519).

Bowlby here uses the term "foresight" in the short range sense, indicating that the child does not foresee the death as an outcome of illness.

This view of the way the child may learn about the death of a parent is revealing of the way the death is often presented to the child. The child may be told both that it happened and that it didn't happen, or at least that people are going to pretend that it didn't 
happen.

Anticipatory Grief. Preparation is a sine qua non for a process known as anticipatory grief, although the latter may not occur in a family even though there is a perception that death will soon occur. As a partial defense against eventual intense grief, anticipatory grief is seen as an adaptive mechanism (Lindemann, 1944). The manner in which the family and the dying person deal with grief or deny it among themselves and the reactions of doctors and other caregivers will affect the family members' anticipatory grief and may have long-term implications for their post-loss adjustment (Fulton \& Gottesman, 1980). E. Furman (1974) points out that there are reasons, perhaps having to do with post-death guilt and feelings of responsibility, that it may be disadvantageous to grieve too completely before the person has died. In other words, anticipatory grief can only be healthy if it is partial, preparatory and incomplete. It is not unusual in caring for the terminally ill to see families where the relatives are ready and more than ready for a person to die. The child in the family, sensing this, may be puzzled by the confusing messages coming from the adults.

The period before the death, the time when preparation and anticipatory grief can be accomplished, is a time when preventive intervention can take place (Caplan, 1961). Caplan sees this as a time when relatively little effort will produce proportionately large results in weighting the child's experience in a positive direction, for the very reason that the family balance and the interpersonal network is out of kilter. It may be that the reason for the effectiveness of this intervention is that any well-organized series of contingencies will be noticeable in an otherwise confused, fragmented scene. 
Immunization and Fortification as a Form of Preparation. Another longer range kind of preparation which may occur fortuitously is that which occurs when the child has an experience with the death of a pet or a distant relative, or experience with temporary separation from parents. There may be advantages to living through sadness: "Actual experience in withstanding deprivation fortifies life" (Jackson, 1965, p. 90), there is reason to hope that all children will have a preparatory experience.

The concept of immunization is illustrated in Kliman's description of a sequence which like medical immunization "enables the host to cope with a noxious agent without becoming seriously ill" (Kliman, 1968, p. 1). He draws a parallel between the death of a pet and that dosage of a noxious substance which, in medical terms, will immunize a child against disease. Speaking of gaining "mastery in advance," he sees the child's reflective thought about these occurrences as "trial action" (Kliman, 1968, p. 2). Carrying this further, R. Furman (1970) sees the child as understanding realistic discussion of these first preparatory deaths intellectually and then as being freed to devote full energies to the difficult affective task of the emotions caused by the parent's death when and if it occurs.

From another point of view, children may be coached in separation tolerance by brief trips away from home by themselves, to summer camp, or to visit friends or relatives for a night or two, and by the departure of parents on trips of their own, away from home. Children can gain independence with practice (Hilgard, Newman, \& Fisk, 1960). Even though most families foster independence only with the aim in mind that the child will grow into a fully functioning adult, the growth of the 
child's knowledge that independence is possible may protect that child from certain otherwise overwhelming fears in the event of the death of a parent.

Factors Influencing the Effects of Illness and Death on the Child

Illness or Death of Parent as Stress. There is some indication that the child of ill parents or the bereaved child may have a propensity to physical or mental illness.

In a study described in Rutter (1966), a group of children admitted for physical and psychiatric illness to Maudsley Hospital between 1955 and 1959 showed a significant excess of parent chronic or recurrent physical illness in their histories.

The study also showed an excess of delinquents among children whose parents had a chronic or recurrent physical illness. Rutter (1966), however, points out that this may have been due to a referral bias. The study did not isolate as variables child rearing practices in these families of delinquents, nor did it control for break-up of the home and separation from one or more parents, character of substitute caregivers, or methods of coping with and explaining illness in the home.

wolff (1969) states that while there is evidence to suggest that there is a higher incidence of behavior disturbance among children from broken families than among those from intact families, "bereavement is somewhat less important in this respect than family break-up due to failure of the marriage" (Wolff, 1969, p. 116).

In studies of wartime separation, the quality of the preseparation marital relationship is examined (Rutter, 1966). Good marital adjustment of husband and wife, family adaptability, integration and 
affection are seen to influence positively the course of bereavement as they do reactions to other crises. Likewise, in suicide situations, surviving children from what had been "happy" marriages before the suicide of a parent are seen to show less disturbance than other children (Hilgard et al., 1960). In sumary, according to Wolff (1969), the family broken through death presents a different situation than the family broken through divorce, perhaps because in the family where one parent has died, the surviving parent keeps the memory of the dead parent alive "with pride and with affectionate feelings" (p. 120). The literature also supports the idea, however, that pre-death marital stress, some of it illness-caused, may exist in some cases to a severe degree, and that it may affect the feelings of the surviving spouse and of the child during the period of bereavement. For instance, during illness, there may be discrepancies between the attitudes of two spouses as to treatment decisions, ways to inform (or not inform) children; in addition, the parents may be having increased sexual tensions, angry feelings against the medical profession, etc. The resulting strife may not be far different for the children in intensity or tendency to produce conflicting and arbitrary behaviors from the parents than the strife preceding divorce.

In long illness, the child may, for some months before the death of a parent, have been receiving less affection and less attention (contingent on adaptive behaviors) than usual. Psychiatric disorder after the death of a parent "may be as much due to a reaction to circumstances in the home consequent upon parental death or to the situation associated with the illness that led to the death" as to the death itself (Rutter, 1966, p. 66). 
During the illness, events are possibly weighted in the direction of honoring the ill parent's wishes because of his or her condition and nearness to death, and while the well parent may be inclined to take control, the conflict resulting may well be extremely difficult for the child (Kliman, 1968).

When a parent is ill with a life-threatening disease, he or she may be irritable with the child; it is difficult for the child to see this irritability as a symptom of disease (Rutter, 1966). Varieties in temperament and attentiveness, erratic hours, and physical tension in the parent constitute a form of non-verbal communication for which the child will have to provide an explanation through his or her own perception of the behavior.

sex of Parent. The sex of the ill parent, whether the ill parent was the same sex as the child or the opposite sex, was not seen by Rutter (1966) to influence the outcome for the child. Kliman (1968), however, found that "opposite sex bereaved children have prolonged periods of verbal expression of yearning for the lost parent" (p. 80), while the same sex bereaved children demonstrate this behavior less often. It is not clear what factors contributed to this difference, since Kliman did not control for contingencies such as the fact that mothers may have selectively reinforced verbal expression of yearning and recollection in daughters and not in sons who have lost fathers.

There have been some studies of adults who were bereaved in childhood that reveal differences in the quality of the bereavement period dependent on the sex of the surviving parent. In a study of 29 "healthy" female adults who lost a father in childhood, Hilgard et al. (1960) take as a criterion for "healthy" that the women's marriages are 
satisfactory, that they have adequate relationships with their children and have made a comfortable adaptation to social life. Factors seen as influencing the quality of their early bereavement were that (1) their mothers kept the home intact, (2) their mothers were what they describe as 'strong,' (3) there was a network outside the home and the mother used it. Hilgard et al. (1960) indicate that the threat to the integrity of the family was greater when the mother died than when the father died, but this conclusion is not supported in detail in this study.

Wolff (1969) does not distinguish between the male and female parent but finds that if the child feels assured that the remaining parent (of whatever sex) will take care of him or her, the expression of grief in 3-to 5-year-old children is greatly diminished. These studies raise provocative questions but do not resolve the complex issue of the relationship between the sex of the ill parent and the nature of the child's adaptation to the illness and death.

Single-parented Child Among Two-parented Children. The child who perceives other children growing up with two well parents or two living parents may make comparisons and be put into situations that make his or her loss obvious in a new way (Toomin, 1974). Although the single parent, single from choice, divorce, or from loss by death, is more common now than he or she was 25 years ago, the child has no way of knowing that he or she is a part of a large and growing group. The skillful and compassionate teacher can, for instance, make things clear and "normal" for the child of a single parent, but there are inevitably times when the unknowing person asks the child whose father has died why he or she hasn't included daddy in the valentine message (Schlesinger, 
1969). Children attempting to answer such a question may not be able, at age 4 or 5 , to explain why some questions just seem impossible to answer. One child might answer this by saying "because my Daddy died," but another, assuming that the question meant the dead parent should be included, might add "Happy Valentine's day, Daddy," because that was what was asked for, not necessarily out of any denial of the fact that the father had died or out of a strong lasting affection.

Role Transition and Changing Expectancy. Seeing the death of a parent as a form of role transition for the child sheds another light on the problem.

When a parent dies, role shock, or stress due to a disruptive role transition, can be acute (Minkler \& Biller, 1979). Cue familiarity is gone, there is a discrepancy between what is expected and what is encountered, and the non-holistic nature of the transition means that parts of a role will have to be relearned while others remain the same. For example, the oldest boy child, if his father dies, now may be the only male in the family older than his sisters; his role has changed in that respect, but still, his reponsibilities in the running of the household remain the same: His tasks may include taking out the garbage or feeding the dog but he is not the head of the household. Change in the active or passive nature of one's role, if unpredicted in either direction, is a source of shock (Minkler \& Biller, 1979). This may be especially noticeable for the child who held an active role in some particular activity with the parent who has died, and now finds that role gone or changed since the well parent has no interest in that same activity. Further, a child's relationship with a sibling which was a competitive relationship before the parent's death, for example, may 
change to a less competitive one after the parent's death.

The child's pre-illness-and-death relationship with both parents will influence the quality of the child's bereavement experience (Rutter, 1966). Rutter speculates on how much the child's affection for the surviving parent can offset the deleterious effects of the illness and death of the other. We could surmise that a major factor might be whether the parent who died was the one who offered the most spontaneous affection to the child.

The framework in which these drastic role transitions occur has been viewed in a theoretical study by Bain (1970). He sees the family that is undergoing a disruptive event such as the death of a parent as likely to experience less pathology if there is institutional support that the family can depend on and a social network functioning. These supports may influence the child's bereavement process as a function of their ability to provide role stability for the child.

Substitute Caregivers. Another side effect of illness of a parent arises in that most families where the parent is ill and dying depend on some household help from outside, people who often temporarily take the place of the real parents in care of the child. The social network, the extent of contact with kin and neighbors and the existence of a group of spontaneous helpers, will certainly influence the nature and quality of the substitute caregivers. These caregivers, in turn, can prove crucial in a positive or negative way in determining the nature of the child's experience at this time. Factors influencing the child's experience will include character of the caregiver, whether or not the child already had an intimate relation with the person, the location of care, whether it is in the child's home or in a new and unfamiliar place, 
and the length of time the care continues (Rutter, 1966).

Whether the caregiver begins giving care to the child before the death and remains afterwards may also be a factor in the child's adaptation (Kliman, 1968).

\section{Childhood Mourning}

Grieving Patterns. The various parts of what is generally looked on as a normal grief process include disbelief or denial that the death is about to occur or has occurred, anger, guilt focusing on "what might I have done," sadness and longing for the person and for the time before the death occurred, and finally acceptance that it really has happened and that the survivor's life can continue, changed but with joy (Parkes, 1973; Kubler-Ross, 1974).

Pathological mourning, on the other hand, includes a drastic extension of the first stages in degree and duration, the inability to arrive at any form of acceptance and frequently the misplacing of blame and responsibility (Parkes, 1973). Terminology is confused by the fact that in some cases psychologists refer to delayed mourning as a pathological condition. It will be useful to look first at Piaget's ideas of solidification and then at an example which might clear up this confusion.

Piaget speaks of solidification when he discusses the cognitive stages in adolescence. The adolescent can keep coming back to tasks or to concepts as they reappear in different guises, and can rethink the process whereby he or she accomplishes the task, according to the new developmental stage he or she has reached (Inhelder \& Piaget, 1958). In the case of the death of a parent (although that particular loss 
may, we hope, occur only once), other losses will occur which remind the growing person of the original loss, and the memory of the loss of the parent is ideally available for spontaneous recall at any time. New losses may involve departures of friends, losses of objects, or other deaths.

As an example, we will cite the experience of a young man, 17 years old, who remembers that when he was 7 and his mother was dying of cancer, he "knew perfectly well" that his mother was going to die, although no one had told him. (The mother insisted that no one talk with the children about her dying. The spouse, grandparents, and other relatives and friends honored this demand although they recall not feeling comfortable in that compliance.) When they told him at breakfast that his mother had died, he remembers not being surprised, but he describes the feeling as having been similar to one "you have when you've missed the train and you stand on the platform and see the train going away. There's nothing to do about it." He recounts his menory of going to school the next Monday and feeling "quite special" because a lot of people knew what had happened and talked about it.

He describes his impatience when he was given an enlarged picture of his mother the next Christmas. He didn't pay much attention to it and remembers the adults making a fuss about his rejection of the picture.

When he was in his early teens, his father and he were driving home one day and they began to talk about the mother and the marriage as it had been. The boy stayed in the car when they got home and wept heavily, as he remembers, for the first time. 
This would seem to indicate that the cumulative process of understanding does occur within each individual and makes possible, with each progressive stage, the fuller process of grief.

Changes in Behavior. We can speculate that children who do not acknowledge and respond directly to the facts of the illness and death that they are capable of understanding, because of a system of avoidance behaviors, may indeed begin to exhibit maladaptive behaviors. We may then have a partial explanation of the dysfunctions that occasionally occur during the illness of a parent and after the death. We should remember that children undergoing stress and prolonged periods of tension may begin bed-wetting, for instance, whether or not a parent is ill or dying, and it is very important that we not ignore the fact that even in the shadow of the crisis event, a whole range of contingencies is at work, any group of which may be maintaining maladaptive behaviors.

The changes in behavior in a child whose parent is ill or has died may range widely: They may include psychosomatic symptoms such as pains similar to those experienced by the ill parent, over-helpfulness, requests to share the bed of the well parent, behaviors similar to the mannerisms of the deceased parent, including those related to special interests of that parent, fearfulness, separation difficulty, difficulty in falling asleep, eating problems, weeping, learning disturbances at school, disciplinary problems, and verbally expressed, overt, and prolonged yearning (Kliman, 1968).

As with any study of grief, the line between seeing these as transient, normal, adaptive behaviors, and seeing them as a cause for serious concern is hard to draw. Even Kliman (1968), who suggests that these behaviors may be a sign of guilt on the child's part, does also 
aver that "some regression can be adaptive in transient and flexible ways . . a means for acquiring short-term increases in psychosocial sustenance" (p. 86).

In fact, we would hypothesize that there are probably many ways in which the well parent reinforces behaviors such as the child's imitations of the dead parent or requests to share the parental bed. It may be pleasurable and in some ways an affirmation of continuity to the surviving parent to see the young child carrying on traditions or even lesser behavior patterns that had been the wont of the now dead loved spouse. And a small warm body in the bed, even though not a sexual companion, may be a sign that if everybody stays loving and supports each other, all will be well. In most families, children occasionally, under non-crisis circumstances, come to the parents' bed briefly after a bad dream. It is possible that for both the parent and the child, these are transient and adaptive behavior sequences, and that they are maintained temporarily by the surviving parent.

The Use of Heaven as an Image. That adults, not only children, can deny the permanency of loss is pointed out widely in the literature (Parkes, 1973; Bowlby, 1960). There is some evidence to support the idea that using heaven and eternal life as an image in explaining death to a child is a way of denying death (Grollman, 1967) and of "maintaining a person alive and in communication" (Bowlby, 1963, p. 519). While at the same time reaffirming one's faith in a life after death, and in the everlasting qualities of one's love for a dead person and that person's lasting effect on the world, using the concept of heaven can also be a way of avoiding the child's natural curiosity about 
the fate of the body after death. This is painful for adults to explain to children. They may fear that the child will begin to have terrors about being buried and about the disintegration of the body. Adults may themselves not want to admit that the body disintegrates. And so they neglect to separate the spiritual, figurative, mystical sense of heaven and the physical sense, allowing the child to take literally what they say.

The effect on a child of an idealized dead parent who does not age, and whose faults are entirely de-emphasized, who resides in a heaven from which the parent can see what a child does is distinctly absent from the literature, although the phenomenon is described by children and parents, as we will see in personal accounts. We do find some indication (Jackson, 1965) that to tell a child that an illness or death is God's will may cause the child to consider God a killer in the earthly sense, and may mislead the child into blame and unresolvable anger.

Intervention and Therapy

Depending on one's view of what causes serious complications in the grieving process, one would look to various methods of intervention and therapy.

According to Hagin and Corwin (1974), intervention must be of such a nature as to keep the child from feeling isolated either by the adult's ignorance of what the child understands or by incomprehension of what the child still wants to know. Answering unspoken questions is possible by giving reassurance and by mentioning that sometimes people feel a certain way and sometimes they don't, recognizing that there are 
parameters a child may have wondered about but not spoken of. A good example of this technique is given in Eda LeShan's book Learning to Say Goodbye (Leshan, 1976).

Ramsay (1977) supports a theory that serious complications in the grieving process originate in the same way that phobias originate. This view of chronic grief, which sees distorted patterns of grieving as a type of avoidance behavior similar to that in phobias, has led Ramsay and others to use, as intervention and therapy, techniques similar to those used in the treatment of phobias: desensitization through flooding techniques, and the presentation of painful stimuli in the recalling of the illness, the death, and the events surrounding the death. The individual is prevented by the therapists from changing the subject or leaving the room and thereby attempting to avoid the painful memories. The unpunished expression of the emotion that is elicited by those memories then occurs. This type of therapy has been found to be extremely effective in alleviating the depression, the learned helplessness that is chronic grief.

Aims of Present study

The parents' and other adults' view of the deprivation caused to the child by the death of a parent is complex in that it may include a universal view of the child as an orphan; it sees the tragedy of the loss of all that could have been in the relationship between the child and the dying person, and it is very different from the child's view. We would hold that the child's view of the loss caused by the death of a parent is different from the adults' view not only because of the child's developmental stage but because with little foresight 
into what future years will bring, the child does not have the full sense of what might have been had the death not occurred. The child's sense of loss may be acute. He or she may be afraid and may weep for the loss of the security, the fun, the loving touch of a parent. But, not being able to envision all that might have occurred between him- or herself and the dying parent, the child does not grieve for that. It will only be later in the years ahead when the child has grown to an adult, that the full adult realization of the larger nature of the loss will be apparent and available to be contemplated and grieved for, as is illustrated in Figure 1.

There will be gradual changes in that, as the child grows into the teens and adulthood, he or she will grieve for each new part of the loss as it becomes clear. Until the child has been sexually attracted to and in love with another person, he or she will not be able to understand the sadness that the surviving parent must have felt. Until children have grown and have children of their own, or at least can imagine what is involved in that parent-child relationship, the full realization of the anguish involved in the earlier illness and death may not really be clear to them. Only as they grown older is the whole compass available to them. The 17-year-old in the account given above, for instance, could be said to have grieved that day for the mother he would never now know as an adult and for the anguish he could now see his mother and father had endured. They, and therefore the events themselves, are different to him now. This is quite a different picture of what we will call appropriate mourning than that given by Bowlby's view of delayed or repressed mourning, which is looked on as a pathological state (Bowlby, 1963). 


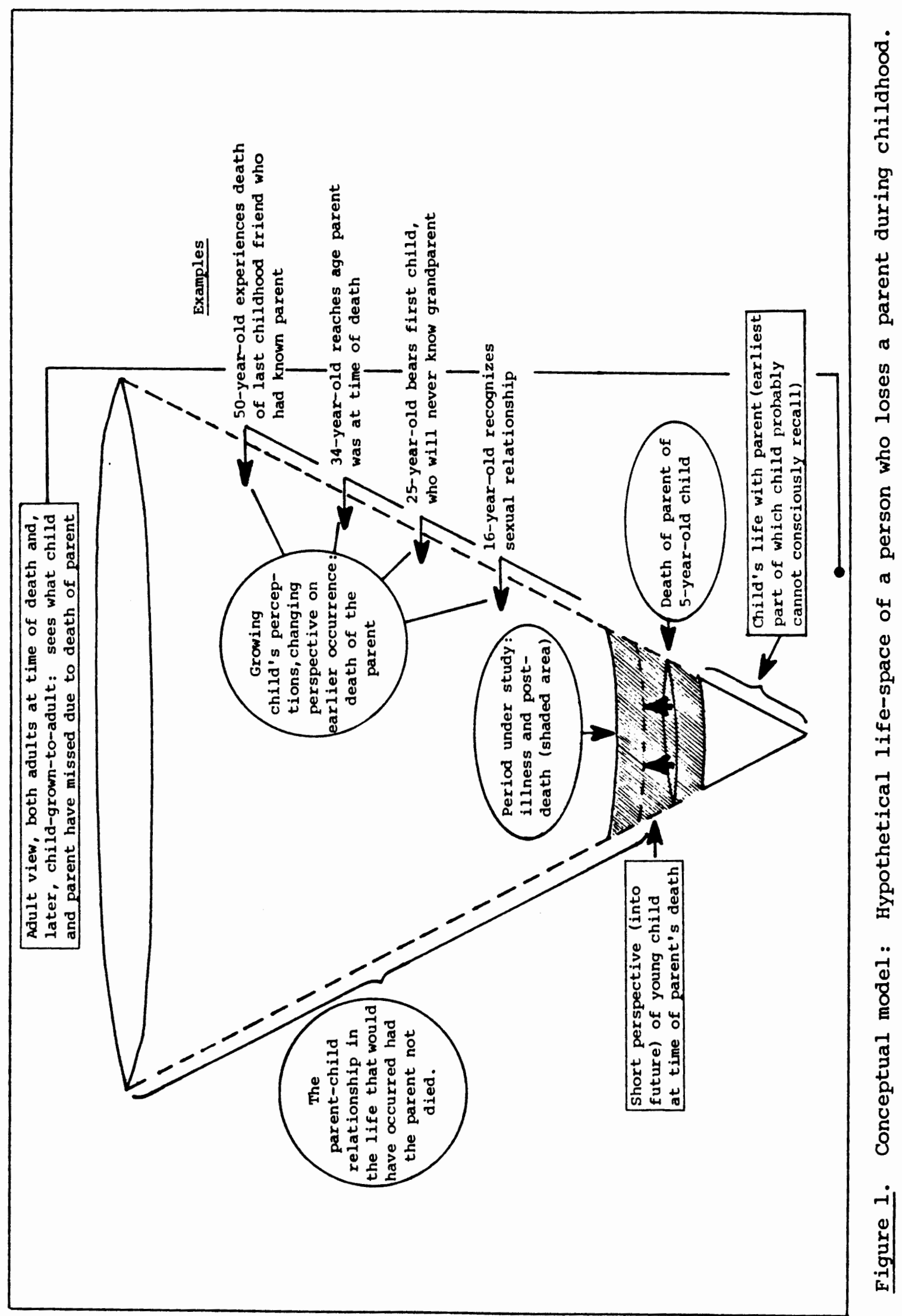


If this process of deepening realization is desirable, as we feel it is, we are led back to the importance of creating a situation around the death such that the growing child will be able to think about the loss without serious avoidance problems. The higher the incidence of aversive, painful circumstances (aside from the death itself) that surround the illness and death, the greater the probability that the child will avoid thinking about it, reviewing, asking questions or speaking directly of it at all. In "painful circumstances," we would include argument, deception of which the child is aware, physical pain, fear, lack of loving attention, isolation, and disruption of loved routines . Ensuring that as few as possible of these peripheral painful circumstances occur, one might increase the probability that the child would progress through the period around the death without laying the foundation for serious avoidance behaviors.

The purpose of including considerable detail in the accounts of the five families in this study is to show the infinite number of possibilities for aversive or positive qualities to emerge in all situations surrounding the illness and death. To give a few examples, during the illness, what might have been normal fluctuations in a well parent's moods take on increased importance, since the death that will occur leaves little room for apology, explanation, forgiveness, or joint retrospective review. The ability of one parent to explain and soften the effects of the other's perhaps angry outbursts may become crucial. Further, substitute caregivers may be warm, understanding people who provide support and information that the parent is incapable of giving, and may possibly function not just as a caretaker but as a psychological stabilizer. Without the intense emotional involvement that the well 
parent has in the events that are occurring, the substitute caregiver may be able to provide a dispassionate and at least partly objective point of view in answering the child's questions or offering information. On the other hand, due to pressures of time and availability of help, a family may be forced to accept or contract for assistance by people who are abrupt, careless or who totally disrupt routines that the child treasures.

Iastly, a family whose pet dies during the illness of the parent can turn the experience either into a chance to share tears and sympathy with each other or they can make it into a tense experience for the child, possibly full of baffling half-truths or recriminations.

A subsidiary aim beyond the main purpose of this study was to bring to light the adequacies and weaknesses of a method that combined informal participant observation, interview, and telephone conversation in creating a picture of family interactions with a focus on the child in relation to parent illness and death. As a follow-up, the researcher will return at several-year intervals to gather more information on the child's retrospective view. If the children are available in the area for interviews, if they are willing to participate, and if no other ethically prohibiting circumstances exist, there will be regular visits. It is possible that at those later times, the young people and the families concerned will offer suggestions of their own as to how the earlier efforts might have been conducted. 
CHAPTER III

METHOD

\section{Selection of subjects}

Subjects were contacted in several ways. Two families were contacted through an oncologist's office, one through a home health agency, although the patient never ultimately received care through that agency. One was referred through a cancer unit at a local hospital. The referring caregiver, in each case, explained to the family that the research was designed to study 5-to 8-year-old children of cancer patients, that the researcher was separate from the hospital or agency, that the study would involve home visits, interaction with children, and interviews with parents by telephone or recorded on tape, and that the study was for completion of a degree at Portland State University. Parents gave permission for the researcher to contact them, and subsequently made the decision whether to participate in the study and how to present the researcher to the children. None of the families contacted refused to participate.

The age range of children was limited to those who were between 5 and 8 years old. Some siblings in the families were younger than the focus child and in one family there was an older brother.

\section{The Arrangement of Visits}

The parents retained the right to restrict interviews to the telephone for a time when this was easiest for them. The parent giving 
the first permission also signed the informed consent form for the family. In the case of a school visit, the researcher obtained permission first from the parent and then from the child's teacher before making the visit. Except for introductory visits arranged with the oncologist's permission at his office, all other visits were made at the families' homes or at other places separate from the hospital or home health agency. Once the participation of the family had been established, the researcher always called ahead and arranged visits in whatever order or format was most convenient for the family.

The span of time over which observations and interviews were conducted, and the relationship of the time of the study to the time of diagnosis and/or death, varied among families due to individual circumstances. By referring to Table $I$, the reader will see that the period during which visits were made extended from the Fall of 1979 to the first three months of 1981. In the case of Family 1, Garrison, the mother had died before the start of the study. In Family 2, Lindstrom, and Family 3, McAllister, the parent died during the study. And in Families 4 and 5, Reutter and Neether, the ill parent is relatively well and the disease is in remission at this writing.

\section{Procedures}

The four procedures used for gathering date were: (I) the informal visit or participant observation, (2) the interview with a parent, (3) the telephone conversation with a parent, and (4) the school observation of the child. These procedures were not used in equal proportion in all of the five families, due to individual circumstances. 


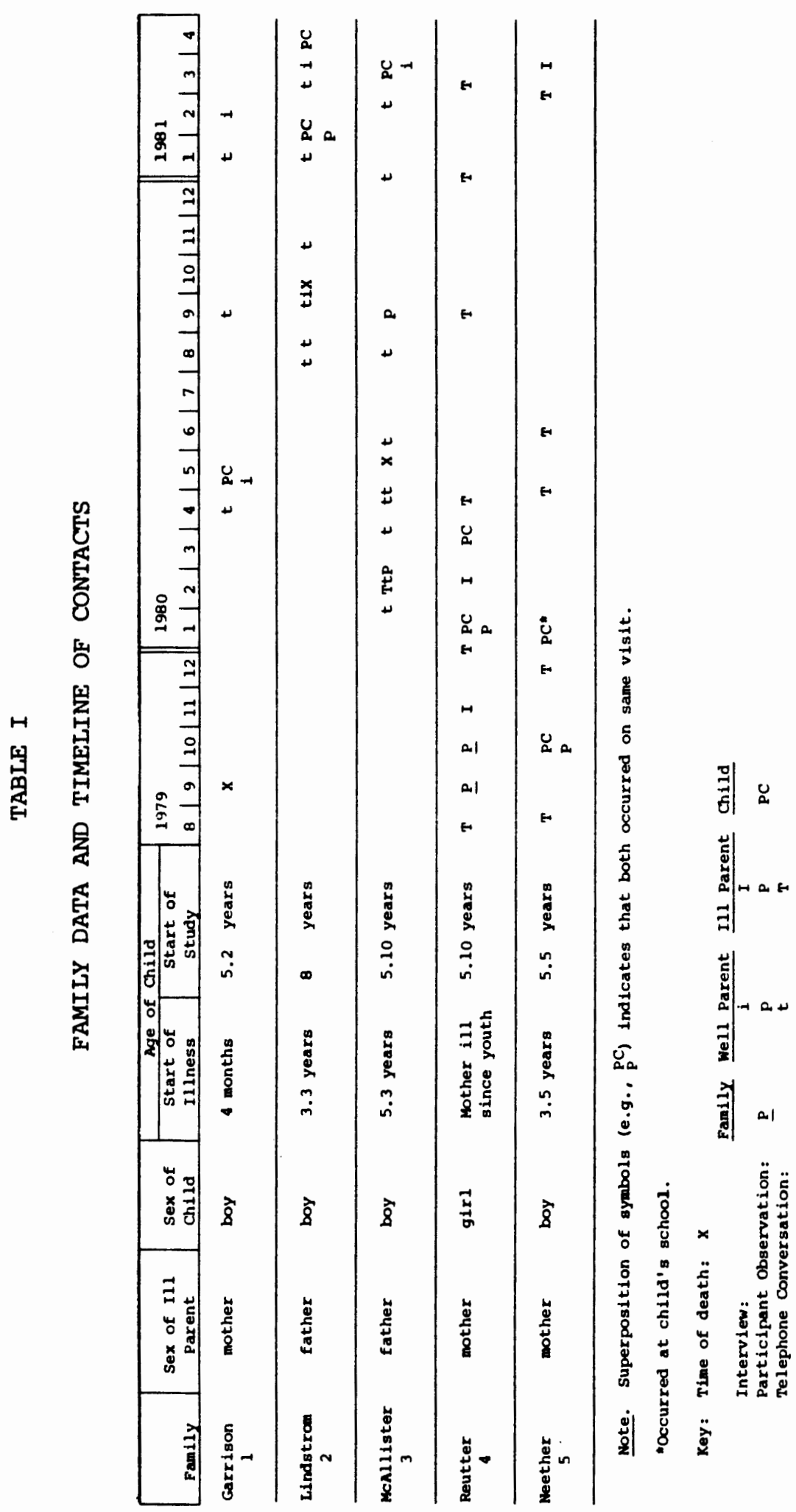


In introducing the researcher to the child, the parent used whatever explanation suited the situation for that family. The following conversation, with a child whose mother has been ill with cancer since her late teens, illustrates a response to a question that arose out of the parent's explanation of the study to the child:

[Name] asked me if I was going to school. I explained about taking courses and how I was now working on a project that especially interested me, that that's what you do when you've finished taking courses.

"What's it about?" he asked, and I said, "Well, it's about how families work."

And he said, "And that's us!" turning to me, smiling.

"That's right," I said, "that's you" (Excerpt from notes).

In all cases, the researcher followed the lead of the parents, not saying more than they had said to the child.

The Informal Visit or Participant Observation. In this type of visit, the researcher came into the home as a guest and behaved accordingly, at times sharing a meal, playing a game, going out to the store with the family, sitting and talking. All notes and comments were recorded after the visit.

The Interview. The procedure used in interviews was a simple one. Permission was asked to tape the interview. A set series of questions was asked. Interaction was Iimited to questions and occasional probes. The interview was varied occasionally if the parent had already discussed a question at length under other circumstances. The interview will be found in Appendix I.

The Telephone Conversation. These conversations ranged in length from 5-15 minutes. The parent spoke spontaneously in response to general questions such as, "How are things going?" or "How have you been 
feeling?" The researcher recorded notes during and after telephone conversations, quoting where possible and otherwise paraphrasing. Telephone conversations were not taped.

The School observation. The researcher used the school's accepted method of observation, a combination of using the observation room and later joining the group outdoors and in the schoolroom itself, but not participating with the children.

Stipulations Self-imposed by the Researcher

In order to diminish as far as possible the participant observer effect, the researcher made no recommendations to the parents or children concerning either verbal or non-verbal behaviors, nor did she make any criticism of any procedures the parents described or of anything that occurred. Furthermore, questions such as, "What do you think I should do?" were answered with such comments as, "I think the only thing you can do is what feels right to you." since this was the honest opinion of the researcher, she did not feel any ethical conflict in so answering.

The researcher carried on no discussion about past research in the field or about any hypotheses. She made a statement to the parents about the rationale behind the study, i.e., that the aim of the study was to discover as much as possible about the psychological and environmental factors surrounding the children of cancer patients. She did not take notes or do other things that set her apart from the others during participant observations. She recorded interactions later, including quotes only when they could be remembered accurately. Otherwise, paraphrase and description were used. 
Data sorting

When the data had been collected through any of the four procedures described above, they were transcribed (if on tape), copies were made, and then sorted according to topic. In some cases, the topics were suggested by the review of the literature; in others, topics emerged from the data themselves. In order to give the reader the most organized, least repetitive, and most absorbable information while retaining as much of the character and spirit of the speakers as possible, findings were reported under topic headings rather than in straight case histories, retaining the information as to which person said what within each category.

All of the demographic information on each family was collected into a narrative profile, describing the family constellation, facts about the ill parent's diagnosis and disease progression, dates, and a general picture of the sequence of events for that family. Data that illuminate the child's typical behaviors are included in these profiles.

All names have been changed. Families were coded by number for purposes of clarity, although names continue to be used throughout the Results section. During data sorting, each entry was numbered by family and dated. Since this exact dating was not relevant for the present investigation, it has been omitted in the text. Only the sequence in which statements were made has been retained so that the reader will know whether a person said something early in the study or later, whether it was before or after the death of the ill parent. 


\section{CHAPTER IV}

PROFILES

\section{Family 1: Garrison}

Chet Garrison was born in July, 1974, and three months later, Janie, his mother, began to have vision and balance difficulties. At first, this was diagnosed as multiple sclerosis but later was rediagnosed as cancer of the spine and eventually as a primary brain tumor. over the course of the next 5-1/2 years, Janie underwent a long series of hospital admissions, around 25 in all, for treatments and surgeries including a laminectomy and caesarean (when Chet's younger sister Andrea was born in 1976). The couple discussed a therapeutic abortion at the time of Andrea's conception but Janie wished to carry the child, who was born prematurely and in good health. The family moved from one side of the city to another part way through the illness, in order to be nearer the husband's place of employment. Janie remained at home about 808 of the time and died in the hospital in February 1980.

Everett Garrison, the husband, was the sole wage earner and continued in his health-facility administrative position throughout the illness. He and Janie, both in their early $30^{\prime} \mathrm{s}$, had had what he describes as a happy marriage, loving and open. He is an energetic, handsome man, clear about his goals, easy in talking about experiences and events over the whole period of Janie's illness and death. His emotions come to the surface occasionally and, he says, take him by surprise. 
Janie's parents live not far away but, as Ev recalls, an aunt and uncle were most helpful. Janie's parents "couldn't handle it," and Ev is now "not on the best of terms with them." Janie also had two brothers, one, a physician and one, a renal technician. Ev's parents live in Florida and made three visits over the space of those years. Friends and relatives provided what Ev considers a lot of help by letting the children stay with them during some of Janie's hospitalizations. This meant, however, some quite constant shifting around for Chet in the first years of his life, with two- and three-week stays in the homes of different people.

During the home visit, the researcher was able to interview Ev first, and later to visit with Chet as well. When Chet opened the door, he was welcoming, "My Dad is on the phone, but he'll be right here. You can come in." The house is in a suburban, newly built, and relatively treeless neighborhood with a vacant lot nearby. It was very pleasant inside, clean and neat. While the interview was going on, Chet and Andrea played in another room cheerfully and quietly, with only one interruption when a small car got stuck behind a piece of furniture.

Chet is sandy-haired, average height, with very big eyes. His birthday is July 1, 1974, so he was just 6 years old at the time of the visit. While we talked, he drew a picture of a sleek racing car--ivhat he said would be a "cool car." He said he couldn't draw people: "Their faces are too big." There was talk of that and about a camping trip he and his father and Andrea had taken. Afterward, the two made sone paper airplanes and went outside to fly them. He got his bike out, a twowheeler, and rode it up and down the street a few times with skill. 
He speaks easily, with a large vocabulary and has good large and small motor skills. Watching some carpenters jump down off the roof of a house they were building a few lots away, we commented that they must be going for a break. Ev said, "They're probably going for lunch." "That's a break," said Chet.

Chet started kindergarten in the Fall of 1979 and is now in first grade at the same school, to which he goes by bus, "except when I'm late and my Dad takes me."

Janie and Ev had had a strong church affiliation at the Seventh Day Adventist church in their old neighborhood. Ev continues to take the children back there to sunday school because "it was the only world they knew."

The family had had a dog, Peppy, who was there at the time of the first interview. She was later killed by some roving German Shepherds in January of 1981, so there are now no pets.

At a later interview with Ev, we discussed the fact that there is a young woman now in his life who "helps [him] with the kids." There is a strong mutual attachment, although it was unclear whether she lives all the time at the house. He spoke of a possible "permanent relationship" but seemed unsure.

\section{Family 2: Lindstrom}

Chris Lindstrom was born in July 1972. His parents Abby and George lived at the time in Puerto Rico where George was a pilot. They adopted Chris through an agency in New York, getting him when he was three days old but not completing the legal procedures until he was two, due to confusions between the courts of New York and San Juan. When 
Chris had just turned three, in October of 1975, George developed a brain tumor. From that time on he did not drive or fly although after surgery and radiation treatments he went into a long remission that lasted until August 1980. He was cared for at home entirely by Abby until his death in October of the same year. He died at home. Abby's parents live in Michigan and her mother spent some time with them during George's last illness. George's parents "have never approved" of Abby, she says. They did come to visit and stayed at the house, mentioning, not to Abby but to friends, that they planned "to stay until George died." She asked them to leave and they did. She says it was too difficult to keep things (as she and George had decided they would) as "normal as possible" with the other people in the household.

A neighbor couple (in which the husband is a nurse) was a great help. The husband came when George was finally unable to take showers or a bath and bathed him daily. They also took care of Chris at times. other friends and a cousin came when they could to give Abby respite so that she could get out occasionally.

The house is in a rural area, very near the city but with broad, rolling fields around it, and a lake below it. Abby and Chris have sold their tractor since George died and have bought a pick-up which they use to go collect firewood. They have a very bouncy, small puppy, which they acquired after George's death and which Abby described then as her "widow breakdown. We already have a great dane!" Actually since then, they have given away the great dane because it was chasing a neighbor's sheep. A year before the recurrence of George's disease, they had had a dalmatian that had to be 'put down' because of throat 
cancer.

Chris is 8 now, a dark-haired, talkative boy, who on the day of the visit, got off the school bus and ran down the bank to greet the researcher, whom he'd never met, and who had arrived early and was waiting outside. Abby wasn't home yet from a class, and Chris had forgotten his key, so the two spent a half hour playing and talking outside in the yard. Chris made several spontaneous mentions of his father. He spoke of the work he and his Dad had done on the shingling, showed the researcher the bus-waiting house by the side of the road, and they peered through the garage windows at the shop George had made in the basement. While they were looking at his baseball cards, he said quietly, "The reason I want to get in the house so much is because I have to go to the bathroom so bad!" At the researcher's suggestion, he went to pee behind a tree and came back saying, "Boy, that makes me feel better!"

Abby had begun taking classes at a nearby community college, one in small business management and one in career development. She also started a group for bereaved young adults, having found that there was nothing in the area for widows except older ones. She speaks with some amusement about the fact that in a class with many divorced women, she "felt out of place." After her return, on the day of the visit, we all went into the house and had tea. During the three-way visit over tea, Chris was part of the conversation. He showed a good sense of humor and a large vocabulary. He was excited about the snow that had started falling, hopped up frequently to look at it out the window and related the excitement at school when it had started a while earlier. There was laughter and a real sense of enjoyment between him and Abby. She 
had told him that if he got all A's in shcool, she would give him anything he wanted! He had first said, "A new Dad," they recalled and then, when they'd talked about how you can't buy that at the store, he'd chosen an indoor swimming pool, clearly a well-established joke between them.

In March of 1981 they took a trip together to Disneyland. Abby is about to go to Hawaii for ten days and Chris will stay with friends. He asked if he could go but doesn't seem to be overly concerned about Abby's departure. She does not plan to get a full-time job, nor has she worked in the past, although she says that now she senses that her friends ask her what she's doing, sounding as though they expected her to be working. She thinks maybe she only hears that because she feels guilty about not wanting to go out and "conquer the world."

\section{Family 3: McAllister}

Robby McAllister is the son of Karen and Pete McAllister. He was born November 20, 1974 and was almost 5 years old when, in August of 1979, Pete was diagnosed with acute leukemia. Robby's little sister Mary was $2-1 / 2$ at the time.

Karen and Pete had been married 12 years and were living in a pleasant house in a suburb of the city where Karen still lives. According to Karen's descriptions, Pete was an extremely hard-working young man, very demanding of himself and others. He traveled and was off early and home late from work, spending the weekend on yard work. He was at the height of his career in business when Mary was born so she "never really had a Daddy in the formal sense of the word." Pete went through a series of chemotherapy and radiation treatments and 
had a bone marrow transplant from his twin brother in October 1979. In January 1980 it was clear that the disease had not been arrested and he died on July 2,1980 , in the hospital.

Pete and Richard, his twin, were very close. Richard was also very close to Robby and Mary, taking the place of a father for games and roughhousing, at least before Pete's death. He has since withdrawn almost entirely from contact with the children. Pete and Richard's parents live in another part of the state and did not give him much support, although they at one time offered to take the children for a visit. Karen did not accept the offer because she says she didn't want Robby to feel they were sending him away. They did not come to the city at the time of Pete's death for the funeral service.

Richard is married and it was his mother-in-law who proved to be the greatest support for the family, taking care of the children and being a listener for Karen. Karen's own parents and grandparents live in the mid-west. Her mother came to stay for two weeks before Pete's death and stayed for the following week.

Pete had been the only wage earner. Karen did not at any time take a job although she considered doing so for a time after Pete's death. She, with the help of a home nursing team from the hospital, took care of pete at home for periods of some weeks during the illness between January and July 1980. She learned to give injections and said at the time, "I'm doing things I never thought I could do." She felt strongly that it was important to keep him at home as long as possible. Robby is a tall, blond 6 year-old. He speaks with a slight lisp and an accent left over from baby speech, but he has a large vocabulary for his age. He greeted the researcher at the entrance to the garage 
on her arrival and showed her into the living room. He is affectionate with his mother and observant. At one time he came in from play while the researcher and his mother were talking, and said to Karen, "Have you been crying? Your eyes are red." (Karen had been laughing and before that had been teary over something.) During the interview with Karen, while Robby played outside, he occasionally returned to report indignantly on what other children were doing. At one time everyone was at some one else's house and saying he couldn't play; the next, Mary was sitting on the hot wheels and refusing to get off; then someone was hitting Mary on the head. He expected Karen's intervention and sometimes got it, although once she sent him off with a suggestion for coping with it himself.

Robby started school in kindergarten of a nearby public school in the fall of 1980, having not been in any school before that. During the visit, he chatted with Karen and the researcher for a while and then asked if the visitor would like to hear him read. He ran off to get his reader and read very nicely, with lots of expression and chuckles, at an advanced first grade level. We talked about the tape recorder, and his eyes twinkled as we played back a bit of the interview with his mother. He then recounted (for recording) the sequence of what they all do in the morning to get ready for school, as part of the game of hearing his own voice on the tape. He spoke with descriptive skill, no silliness.

At one time he accepted a limit-setting direction from his mother with some tears and, during the discussion, the objection: "Mom, wait! I just want you to hear my weasons!"

There are no pets in the family, although they had had a dog who died several weeks before Pete died. 
The family has taken one major trip since Pete's death, to visit Karen's family in the mid-west. The trip was a great success and for a time made Karen feel she would move back there. She has since decided to remain here, which had been her original plan during the illness.

\section{Family 4: Reutter}

Mary Ann Reutter is a 5-year-old Korean child born on November 25 , 1973 and adopted by Christine and John Reutter when she was 1-1/2 years old. They also adopted her older brother, 9-year-old Jim, when he was a baby. Christine is now in her 30's, and, since she was a teenager, has had Hodgkins disease which has been under control. Recently, however, she has had a return of the disease which was detected in her lungs, and has been undergoing treatment. She has had a mastectomy in 1973 and lung surgery in 1978, followed by a year of chemotherapy. When she and her husband John were married in 1963 only he knew that there was a limit on her life, as she describes it, and she found out later through friends the real nature of her illness.

The Reutters live on a farm in a rural area about 25 miles from the nearest large city. Besides the raising of cattle, John has held several other jobs, including school bus driving, trucking, and working other farms in the area. This means that he has often been at home during the mid-part of the day and at other times has been away on long trucking runs. Christine runs a busy household, which includes her father who lives with the family, and two children she takes care of during the day, a boy about Jim's age and a baby. She grows vegetables and fruit and does the preserving. There are animals all around, dogs, cows, and horses. 
Christine's family, after whan the road they live on is named, was a pioneering family in the area. She has enjoyed researching her own genealogy and knows the whole neighborhood as well. Her aunt lives just down the road. Her mother died some time ago. She has been back to Sweden with this same aunt on a visit to relatives. John's parents used to live not too far away. His father is retired and they saw them quite frequently. As of the end of the study they had just moved to the eastern part of the state, his father having received a medical retirement.

Both the children attend a nearby public school, a very small school with two classrooms, grades one to three and grades four to six, but with excellent facilities, e.g., a gym and a library. At the time this study began Mary Ann was in kindergarten at another school but is now at the same school as $\mathrm{Jim}$. One of the teachers is a person who taught Christine when she was a child.

Mary Ann is an energetic child, bright-eyed, very friendly and verbal, quick to see humor in situations and able to put into words complex thoughts and ideas. She holds her own with her older brother, often looks at him fondly and admiringly, but stands up firmly against encroachment on her rights as she sees them. Observations were made (I) at home, several times, (2) at an evening back-to-school night at Jim's school for a Halloween performance and refreshments, which we all attended, (3) on an outing which Mary Ann and the researcher took alone, on a day when Christine had to come in to the city for doctor's appointments, and brought Mary Ann along.

Mary Ann is independent and secure in strange situations. She sat in a seat apart from the family at the school play so as to see the 
performance bettex, and she spent some time looking through the classrooms on her own when the whole group was invited to tour through them. At home she did puzzles very ably, played the piano well for a 5-year-old and can read simple music. She drew pictures and showed the researcher her room proudly, making comments on some of the things in it. She chatted with him and the other boy who was being cared for by Christine and was bouncy with enthusiasm when an excursion was planned to get ice cream cones, teasing the boys and saying, "Why don't you stay and I'll go alone with Joan?"

The family is very open with the children about the adoptions. There are nicely bound photo albums showing the arrival and various scenes and festivities that have occurred since. About Christine's disease the parents have been very open when questions were asked, for instance about the scar from surgery, but have not mentioned the word cancer because the children know "people die of cancer." Christine is feeling well at this time and her prognosis is good.

\section{Family 5: Neether}

Terry Neether, a boy, was born April 4, 1975. His parents, Diane and Jack Neether, in their mid-30's, have one other child, Court, born in 1977. In mid-1978, Diane contracted Hodgkins disease and over the following 19 months underwent surgery and a series of chemotherapy treatments. Jack is the only wage earner at present, although Diane had worked in modeling and sales before the children were born. They lived in Australia for a time, where she also taught home economics. They now live in a very attractive suburban house and Jack continues in the job he moved to not long after Diane's illness was diagnosed, a position 
in an investment firm.

Diane's parents are divorced. Her mother has remarried and the family considers her second husband as grandfather. They do not live in the same city, but the mother came to stay with the family and was closely involved, especially after the surgery, in helping out in the household. Jack's parents also live in anothex city at some distance, but came and "really stepped in and took over" during the time of the treatments, doing the housekeeping until the young couple hired a housekeeper, who then stayed for about six months, coming in daily rather than living in.

Neighbors helped by bringing food, cleaning house and by staying with the children when Diane went in overnight to the hospital for chemotherapy. She preferred to do this rather than being actively sick at home.

The family has no active church affiliation. Diane has been very active in a sorority which meets regularly and provides a network group of women her own age as well as older and younger women.

Diane is extremely well-organized, a fastidious house decorator and planner. The children each have carefully decorated rooms of their own. Toys are kept in a neat group in the hallway. The family has no pets.

Terry is an active 5-year-old, and when he was observed both at home, during lunch and in going down for a nap, and during an entire morning in preschool, he showed himself talkative, observant, and engaged in all the usual activities for the situation.

At home during the play time after lunch, Terry played in the kitchen with Court until it was time for his nap. They shared some red 
plastic building blocks. Terry generally ran the game which involved manning a space ship (out of the blocks) with the Incredible Hulk and Spider Man who were the people toys available. As Diane moved the children off to bed, Terry delayed in the hall for a few minutes to play with the magnetic letters on a metal board, but Diane was firm and counted $(1,2,3 \ldots)$ to move them along. By the time Court was tucked in, Terry had climbed to his bed; he got a kiss and was cosied under the covers, sucking his thumb.

Outdoors at school, Terry spent a good deal of time with a few friends playing dinosaurs, dinosaurs that walked and made noises rather like loud robots. He participated in a trip to the post office to mail valentines. Indoors, he painted, built with blocks, listened to stories and interacted with children and teachers in a friendly way, asking questions, planning games and pursuing a number of activities, moving from one activity to another quite fast but not unusually so. His pictures were not representational. He was experimenting with the materials (felt pen first, then later paint at the easel) and seemed more interested in them for themselves than in the shapes he produced on paper. Later, he asked questions about the story that was being read that indicated he was listening carefully and thinking about it. During the time of Diane's treatments, Jack did the family's share of car-pooling and also helped occasionally at the pre-school. Terry has now, at the end of the study, moved to a public school kindergarten, with which the family is very pleased. 
CHAPTER V

RESULTS

In compiling data from interviews and conversations, a division into topic headings has been made for purposes of clarity.

The first section considers the practical side of the care of the ill parent, the place of care, routines and outside influences such as substitute caregivers, counselors, siblings, and school influences on the child. Following are comments that center on interparental relations between the well parent, the ill parent, and the focus child. Whether the mother or father was ill, whether one or the other parent usually found it easier to talk with the child, and the particular stresses that existed between the two parents themselves constitute the major thrust of this second section. The third section examines the child's understanding of the illness, what the child was told, the child's behaviors, fears, and particularly, the child's participation in activities at the time of death. And finally, in the cases of the three families where one parent died, the possible effects on the child of the surviving parent's growing new identity as a single parent are examined.

\section{PRACTICALITIES}

\section{Place of Care}

The place of care is an important element, particularly in the families where the ill parent has become debilitated and has died. For 
the families where the parent is now in remission and has been in a place other than home only for short periods, for treatment, it takes on importance, too, but of a different nature.

For the Garrison family, over a period of five years there was constant alternation of home and hospital. Ev feels that the effect on Chet of the separation when Janie was hospitalized was dramatic and destructive (see also Children's Behaviors). "Probably the biggest thing for Chet was not the illness but the separation." He lost vocabulary, bladder and bowel habits changed, and Ev feels that had frequent hospitalization not been necessary, the illness and death (which did not occur until four years after the diagnosis) would have had less effect on Chet.

After many months intermittently at horne, Janie wanted to die in the hospital. Ev said he doesn't know if it was because "of the kids and not wanting them to see her getting worse." He added, "I couldn't keep things down her. I was worried about her hydration. So she went back into the hospital."

Visiting had already been a problem because of the pressure of time on EV who tried to get over to the hospital at his lunch hour. And it continued to be a pressure, taking him away from the children in the late afternoon when he would otherwise have been feeding them supper, right up through the time of her death.

Abby Lindstrom and George, with their one child, Chris, lover a five year period from when Chris was 3 to 9 years old) carried out all care at home, except during immediately post-operative recuperation. It was something they had agreed on early in the disease and it continued to be possible so that George could die at home. The most 
noticeable effect on Chris, according to Abby at the time and again in a later interview, was that having George at home meant that Chris was very aware of his father's gradual deterioration and that it affected both his desire to have friends came over and play and his reactions to his father's authority.

Karen McAllister, six weeks before Pete's death, described her efforts to keep pete at home as being based on his desires: "I just want to keep him out of the hospital. He's getting pretty sick of that." It also, though, was an advantage overall.

That was one of the very nicest things that went on with us, not having to make those every day trips to the hospital. Mike having to do it and me having to haul him around . . . just that little bit of support that we got from having the nurses come, knowing somebody was around.

She described "getting the routine down," getting to bed by midnight or one rather than by three or four in the morning. They had "scary times in between," one brought on by Pete's pain caused by heart burn that she "thought was a heart attack." But "the kids have been just great. There have been relatively few major clashes."

sudden trips to the hospital from home were of course part of the disadvantage. Karen describes one night when Pete's lung collapsed, having to "grab the kids and run," taking the whole family to the hospital, not getting home until 4:30 a.m. The children at that time were "really getting bored (at the hospital) having to be so quiet and so good while they're there."

Pete died in the hospital. The disease had moved so fast that there had been little time to adjust. With brain metastases he deteriorated very fast and they were still irradiating him almost up to the time he died. 
For Christine Reutter, the time at home after treatments were occasions when the children asked questions about her illness. When she returned home and vomited for the rest of the day, the children didn't understand why you went to the doctors to get sick. She also said, "I explained that medicine made you feel bad first but in the long run better." This was an element they would not have noticed had she stayed in the hospital longer at those times.

Diane Neether said, in an early conversation, that she was "laid low" by treatments that were to go on for another three weeks and that after that she would "live again." She was at home, with a substitute caregiver taking care of the children, and was feeling very much out of the picture; she also felt that she was putting increased stress on her husband.

I think probably for the first time in my life I really wanted some babying [laughs] at times. But, you know, it was really tough 'cause I'd always been a get-up and a doer and run the show so to speak and all of a sudden $I$ wasn't.

We see that the ill parent's presence at home kept the disease in slightly higher profile as far as the child was concerned than if the parent had been steadily in the hospital. The increased presence of both parents in the home when care was being given there was a positive factor in spite of the apparent fatigue of both parents. The fatigue, for the well parent, of frequent hospital visits seems to have been greater if anything, in a different way, than that of home care.

\section{Routines}

The maintaining of routines, both small (daily) and large (expected vacations, special events), is brought out in varying degrees. 
Ev Garrison mentioned it particularly in the ways that helping

relatives and friends maintained some routine for the children.

I think they offered a lot of companionship. Really close friends of ours and our family, my in-laws had the kids for the rest of the time. What was really good about that is that they kept them diversified enough with some activities that it wasn't such a heavy bang. You know "Mom's in the hospital, Dad's going back and forth to the hospital, they're not here to kiss us goodnight." I also think it's good for kids nutritionally [laugh]. I'm not a bad cook but I just don't have the time. When I was trying to run up to the hospital at my lunch hour, sometimes I'd go up in the morning and you go up in the evening. But that and a lot what it is: they had somebody around to really spend time with them.

They did try to establish, these people did, some normalcy, some routine. Iife isn't on superfast feed, not a treadmill. Iike Deb, who was her sister, a young couple, they were really sweet. The kids were a little more than she could handle.

Then we have some other friends. I think, you know, they got to see a lot of life different places and I think it kinda gave them a chance to analyze things. Iike 'this is what they've got and everybody is flying high and have no handicaps and, well we got something better than that at home. I think that was good.

Abby Lindstrom said routines were usually maintained.

I can't think of anything I would have done differently. And I'm not even sure with Chris whether I would have talked to him more about it. Only because he stayed busy, we got him to soccer, we stayed as normal as possible. So routines weren't interrupted. Not having this happen, I can't think of anything I would have changed other than it not happening at all.

About in-laws who had been visiting, she said they had disrupted

routines.

They left. They haven't talked to me for a year 'til this happened. They would sit all day and watch TV and I was going crazy. They'd bring George out and say, "Look how he's enjoying TV." Well honestly. He doesn't usually watch TV 'til the 5:00 p.m. news. And when he's up we try to do other things. We went to the beach this weekend.

Anyway, so they left. I wrote them a note today, saying I hoped they'd come back for short visits. I mean my mother has asked to come, too, and I con't want her to come either. 
I just feel as if I've got to keep things as normal as possible--that that's the only way I'll survive.

Karen mentioned deliberate attempts to maintain pleasurable routines and spoke of them sometimes laughingly as, "We had to get out!" She took the children to the park one day and said, "It was what everybody needed."

For Christine some routines were thrown off like "canning peaches, but not [routines] with the kids." During the treatments from May to the following April "small things" were disrupted "but not things like vacations."

\section{Diane said,}

Well, we didn't take trips. We didn't do, you know, the usual Saturday or sunday outings with the children that we would have ordinarily done. They were too young. They didn't realize they were missing it. I think it was just me, me and Jack particularly feeling guilty that we weren't doing the kind of thing we had always talked about that we would do with our children, at that age and it wasn't-Terry was still too young that you wouldn't want to involve him in this, that, and the other thing so it wasn't--we didn't feel we were depriving them that way, that they weren't into this lesson or that activity. But I think it was basically the family things that we weren't able to do. Even at that age, he never said, "So and so is going to do this, why can't we?" He was too young.

These parents seem to feel that routines are important, to have been aware of trying to retain normalcy, and to have succeeded at least in part.

Financial Worries

Financial problems caused by the illness and hospitalization, or by hiring home help, were mentioned by two parents and added to already existing stress.

Karen said in June, 
Our hospital bill came to $\$ 12,000$; that doesn't count August to May [it only included the hospitalization in Mayl. Pete's insurance pays $80 \%$. He does have that through his company.

Later, several months after Pete died, the hospital approved her for the Hill Burton Fund which meant the charges, at least a major part of them, above what insurance covered, were waived.

She thought of finding a job but found that she would lose her Social Security benefits if she did, so she decided against that. She had been drawn to working at the hospital where she had spent so much time and had felt "kind of a second home."

Diane spoke of the fact that Phyllis, the housekeeper got a lot of money for what she did, which killed me! I think that was it: looking at all this money going out and thinking, "Come on; if you got with it, if you could get with it, you could do it yourself," and yet, you know, I couldn't physically and during that three-month span, through March, mentally I was not...

Among the children, only Chris Lindstrom spoke of worry about money, and he actually spoke of getting a job hinself to help out. He being the oldest of the children may have been expressing something verbally that Robby McAllister did by starting to do yardwork: "somebody's got to do this work and the main wage-earner, yard-worker is out of the picture and that leaves me."

It is confusing and a cause for concern and anger among families who are young (and therefore not eligible for Medicare) that catastrophic illness such as cancer does not make them eligible for benefits to cover their costs. As a result, economic hardship is often a pressing reality for young parents in families where one is dying of cancer. The child's concern about the financial well-being of the family can 
often be a factor in the amount of worry he or she is experiencing, as we see fram Chris's questions, described in a later section, about whether he and his mother would "be poor."

Caregivers: at Home and Away from Home

People who have helped, parents, friends who lived at some distance, neighbors who were not necessarily close friends, relatives of the same generation, hired housekeepers--all of these people in some part became substitute caregivers for the children in the family. The caregivers in the hospital, as well, have a part to play in the family interactions, in the ability of the family to maintain an equilibrium. For Ev Garrison, who did not hire any help, the friends and relatives who took care of the children during Janie's hospitalizations were indispensable aides. They provided support and care. Partly perhaps because no one person took over the care of Chet and Andrea, the children moved from one household to another frequently enough so that Ev feels Chet suffered both from the separation from his mother and from the discontinuity of care. Although Ev made earlier statements in this regard about the effect on Chet of Janie's hospitalization, another series of comments on the same subject, said at another time, can be viewed in the light of substitute caregivers.

Ev spoke of his distress at the fact that Chet had been toilettrained three times, once at $9-1 / 2$ months, once at $2-1 / 2$ years and again at 4 years. He was trained at the time of the interview and had had a year in kindergarten. (This was five months after Janie's death.) Ev said it wasn't so much that Chet had forgotten things he'd learned but that his "mind had degenerated" and he couldn't learn things as 
quickly as he had been able to.

The fact that Andrea was born during Janie's illness and that Chet had had added stays with family friends during that time should be noted. The stress must have been increased for everyone, and there were more substitute caregivers. "We had three days there. I wasn't sure if I was bringing one home or none home or two home. And I guess maybe that's part of it."

Ev spoke of the circumstances and the decisions that had led up to Andrea's birth, mentioning the chain of symptoms that had occurred first.

What it was originally was a problem with her eyes. She couldn't see an "A" as big as that wall. She went to see a neurologist. The vision thing was before she was pregnant [with Andrea]. This was right after Chet [was born]. When she got pregnant the problems started and kept getting worse and worse and worse, and so we just sat down and I said, "Honey, I got to tell you about how I feel about this." I really didn't want Andrea. It's a terrible thing to say but it's really how I felt. I said, "Hey, you're sittin' here and you're takin' a chance that you're going to be able to complete the course of the pregnancy, that you're going to be able to have a healthy fetus in spite of what you've gone through and all that junk you've got in your body. I've almost lost my lady and Chet has almost lost his mother and we've almost lost our family. And you know, I just want you to know that's where I'm coming from. And if you really want that baby, I'll fight like hell to see that you can have it and if you don't or if you have these other concerns, stop." And she said, "No." And Andrea was not quite seven months. She was our little miracle baby . . . and we had Catholic people and people on the tumor board . . . there was science coming out and there was theology coming out.

And so we see that the substitute caregivers and visits to other families were not always due to the illness itself, but to an event which added further complexity to the family's situation. 
Ev was at the same time going through the strain of trying to make sure that what he felt should be done for Janie was done. The medical caregivers were a force in his thinking and general stress level.

The first time it happened, I read volumes and I knew enough what was goin' on. I run a nursing home. I knew what I wanted for my lady. There was no maybe. Dr. gave good medical direction. The nurses were good people. Things came up and I could say "Hey, you ladies aren't doing your job." I'd go down to ward or ward and pop a cork on one

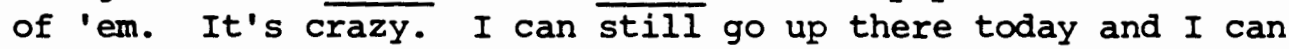
hug the nurses, "Hey, how are you?" You know, we love each other, but I just sometimes, just the waiting to get responses back on reports, uh you can't blame. . you can't hold anyone responsible. Just, why isn't there any more concrete explanation of what the, you know, what the tenor of this illness is going to be?

He said he'd gotten help when he asked for it but

well, not as concrete as I'm sure I could have handled and would have liked and I think Janie.. . That's one thing Dr. really. Well, we called him our real life Marcus Welby. I'd say, "Hey, this is a real gutsy lady and if you tell her up front what's goin' on, she'll follow you through hell and back. I says, "If you pull a trick on her and you don't tell her all. . . don't show her all the cards," I said, "she's not going to trust you, man." And he did. He laid it right on the line with her.

When she was first in, I finally took Chet up [to see her]. I had a nurse... I almost decked her. "You can't bring that child in here." I said, "Hey, this is that lady's life right here."

For Abby Lindstrom, who never had any hired aid, her main source of help was from neighbors and a cousin of George's. Neighbors brought food and asked Chris over to play. She said, in one conversation about George,

More and more he's going to be in bed. Our neighbor [name] comes now on his days off. He's an RN and he's been bathing George. Today I have to go to a PTA meeting and another neighbor will come in, and I'll do some errands.

About ten days before George's death, she said, 
His parents came last week. They didn't tell me but they told other members of the family that they were going to stay 'til George died. They were in the house all day. They'd leave about $90^{\prime}$ clock. It was too hard for me after a few days and I asked them to go away for a while and then come back.

When asked if that caused a flurry, she said, "Boy, did it ever!"

As mentioned earlier, she stated that she couldn't feel right about having things as changed as they inevitably were with other people in the house, doing things their way.

An interesting part of the help Karen's mother provided when she was with the family for the two weeks before Pete died and the week after was the toilet-training of the youngest child. Karen reported with some humor that her mother criticized Karen for not having toilettrained Mary. The grandmother proceeded to do the toilet-training successfully, in three weeks. There had been no regressions since she left. Karen had decided not to push Mary as she had Robby. "I worked hard with Robby. I was trained, not him. We fought, we cried. . ." Karen resented her mother's training of Mary a bit (she used a finger motion to show how "little bit"), "but not enough to worry about." Otherwise there was the sense that it had meant a lot to have her mother there, to her and the children. As for Pete's parents, they called during the illness and wanted to take the kids for a couple of weeks. Karen said, "I've put a veto on it because I don't want Robby to feel we're sending him away. He's very clingy." Pete's family, Karen says, could not deal with Pete's dying. They drank heavily. They did not spend time with the family during the illness nor did they come to the service. Karen said, "I was hoping they'd come for Pete's brother but they didn't. That's about par for the course." 
Her most steady long-range help was from neighbors who came in on weekends sometimes and vacuumed or cleaned up the kitchen, and from a substitute mother, Auntie Fran, who must have been a person of very solid temperament, warm and gentle, from Karen's descriptions. She was a steady hand when Karen needed someone to "take the children," and they loved her. She was the mother of a sister-in-law and helped very regularly, having the children to her house a few miles away or coming to stay with them.

Christine Reutter finds some support from her neighbors in the rural community where she lives. The community of experiences she shares with one friend seem more important than the actual aid the friend has given.

This friend in the neighborhood, we went to school together. She lived just down the road. She was starting a family; we started ours six years later. She lost her mother when she was quite young, too. Her father lived in a trailer with them so she knew how that was. She brought me over for treatments a couple of times. She brought me for lung surgery. I hadn't known I was going in the same day. I knew it was coming.

She's working full-time now, so we don't see each other as much now. Our husbands are quite compatible, too. We have an agreement to exchange kids some weekends. They adopted a partEskimo girl before we got Jim. She [the little girl] is very very inquisitive about her past life, her real mother.

Christine also, besides her father, has the aunt who lives down the road. She points out that concern about her health is appreciated but occasionally can be too much. When she gets back from a check-up, "Auntie comes rushing to the door wanting to know everything. One day, I said, 'I've found out I'm not going to die yet'!" In the case of the Neether family, a long section of the interview with Diane was taken up with spontaneous comment on the caregiver, a hired housekeeper, Phyllis, who was about to come and see the family 
that very afternoon after a 1-1/2 year absence. Although the whole discussion is not quoted, it was clear that this person had been a strong, helpful, but not always positive force in the family. She occupied much time in the interview.

Phyllis was a very dependable, conscientious, caring individual. She's in her early 50's, divorced, but she's also very strange. I mean she has some very, very different ideas, about--I mean, you know, she's very much into naturopathic and, you know, popping all kinds of vitamins and putting--what is that little thing you can put into a quart jar of water to purify it?--and--just real--of course, I was at my worst time and so I was not my usual headstrong, self-assured person and it was difficult. It was difficult on Terry because she was treating him like he was 14 rather than 4. And yet, I don't think we could have found any one better. You knew at $90^{\circ}$ clock she was going to walk through the door, and she was not really sick a day, and not a complainer, but, you know, some of the things she said--and there were days when I'd just as soon not talk to her and I think, too, it was a feeling that she was invading my privacy. Although she wasn't live-in, she was here enough of the time, but she ran the house very well.

When asked what things got in the way of handling her illness

and the children the way she would have liked to, Diane said,

Oh, just being tired, and I think Phyllis got in the way by her presence and her way of handling things, the way she would say things to the children, and there were times that, you know, lunch time--I mean now it's getting to be that lunch time, I mean, there are times when it's absolutely chaotic but this was something that she couldn't really handle. There were many times during lunch and of course, Court was at the stage where he spilled and everything [gestures] and, the yakking back and forth, would want this and that and the other thing and she would get up and take her lunch down to the utility room. And I didn't like that. You know, if she had started out there, fine, that's her choice, but to get up and leave...!

\section{Phyllis was with the family}

from January until June (1979) . . and so we have continued with the children to talk about Phyllis and it's amazing. She made--for the children--Valentine's day, two little felt, puffed hearts with the little felt hangers and, of course, we bring those out every Valentine's day, and this year, Terry 
said to me, "Who's Phyllis?" Now I don't expect Court to remember; I thought perhaps . . you know . . . I said to Terry, "You remember, Court used to call her [nickname]," and he gave me the biggest, blankest look. You know, I really wonder. I said to Jack, I said, "Do you think that other things have become more important in his life? It's not like we haven't continued to talk about her... or do you really think that maybe that's a point in his life that he wants to forget?" I really wonder because he is such a perceptive child and he doesn't forget, and there are things farther back than Phyllis which were really a shorter duration of time that, you know, that he remembers--that we haven't talked about at all. So I don't know whether at that young age...

Jack's parents had

really stepped in. His mother took over housekeeping until we got Phyllis. She was here . . uh . . . they arrived the day of my biopsy and stayed right through until surgery. And [they] stayed until my mother came down so they were here all during the seven days $I$ was in the hospital and then they left and my mother came, and then they came back again, I believe for a few days, so they really have been a big, big help. Mother was working, so she, you know, she could have taken the time but they said, "No." You know, they have the time, they're retired...

Diane's neighbors came to help, even ones she had not known very

well. "It's terrible to say that you have to meet or become close to

your neighbors [when a crisis arises].

And Jack's former boss's wife was like a sister. I mean I was feeling very guilty: all those things she was doing and and all the time she was spending. 'Cause she would take the children to give them a break from the situation here at the house and do some fun things, and she would bake goodies for Jack, 'cause he's got a real sweet tooth. Just, you know, she said to me, 'cause I'd go into tears and say, "You're doing so much and I can never do anything back," and she said, "Don't regard me as a friend, just--I'm your sister and I would do this for my sister and she would do it for me."

And then somebody else said to me once, another really good friend, "You probably won't ever be able to pay me back or any of the other people who are helping you, but some day there'II be somebody else that you will help." She said, "Don't even think about it." 
And I think a lot of people are afraid that, maybe they're going to intrude or they just don't know how. And I think for that reason it made me a better person to know how to help. That you don't ask somebody "can I bring you a dinner," even if they've just had a baby or you just call up and say, "Hi, how're you doing? I'm going to bring dinner tonight. If you don't want to eat it tonight, it'll stay a couple of days in the refrigerator or you can pop it into the freezer." You don't ask because people are going to say, "No, everything's fine." "Cause I did that when people would ask. It's just human nature.

These statements illustrate very clearly the dichotomies between needing help and not finding it easy to accept, between being dependent on caregivers and yet finding their ways of doing things very different from the familiar family ways. Illness may often be the cause of the sudden change from being a nuclear family and self-sufficient to being part of a larger mutually dependent group, a change which certainly thrusts the child into new relationships.

School: The Teacher's Comments, The Parent's Outlook

The question involving school was asked with the idea that the school might or might not prove to be a stabilizing factor for the child.

When Chet Garrison went to school the Monday after Janie died (on a Friday), he told the teacher about his mother's death. Ev had not called ahead. The teacher reported a couple of weeks later, when Ev had his parent teacher conference, that Chet had come in and said, "My Mommy died and we're going to bury her in the ground, so I won't see her anymore, but she'll always be with me in my heart." Ev reports that the teacher said she didn't know whether chet had made it up but thought he sounded so sure about it that she went and looked it up in the paper and found it was true. She also reported to Ev that when one 
of Chet's friends said, "Your Mommy is dead and you won't see her anymore," Chet replied, "Oh yes I will. I'm going to be good and then I'll see her in heaven."

Ev felt that he and the children had handled things well. His feeling was confirmed by the teacher's remark at the conference: "Tell me what you've done. I've taught a lot of kids and usually when something like this happens there are behavior problems."

In later conversations, Ev mentioned first, in January, six months after Janie's death, that Chet was reading and having a good time at school. Three months after that, he reported that Chet had been very "rambunctious," "me first," at home and at school. Chet's teacher described him to Ev's friend Elaine, when she went to talk with the teacher, about their concerns, at Ev's request, that Chet was "a very spoiled little boy." Ev said he was surprised because he saw that as meaning Chet got everything he wanted in the way of toys and clothes, and he doesn't feel that is the case. He said the teacher did mention that Chet always wants to be first, always wants to be right. Whether or not Chet received special treatment or was given special allowances at home and at school following Janie's death would be interesting to know. In attempts to reinforce cheerful, assertive behavior, the adults may have inadvertently contributed to what they now describe as "me first" behavior.

Chris Iindstrom stayed home from school the day George died. Abby Lindstrom reported two days after George's death,

I called the school yesterday and told them [that George had died]. I sent a note with him today, to tell them to call me if anything happens, if he cries or gets in a fight or does anything that isn't like Chris and I'd come get him. 
She had kept him home the day of George's death so that he could come with her to do errands and to see where the funeral home was and the social security office, which was where the money would come from. He had expressed concern about the problem of money. Since then, she has had particular knowledge of things he's said to people through his teacher.

They would be having a discussion. They were talking about the word "service." She meant the word "service" in terms of something you do for someone. And they were discussing it and Chris raised his hand and said, "There's another kind of service," and said, "You know, when someone dies, you have a service for them." Another time in science class they were talking about black widow spiders; [laughs] again he raised his hand: "There's another kind of widow," and said, "You know," he explained, "when someone's husband dies, the wife is a widow." So he brought out things like that. Some of his friends, his close friends, when he would visit their homes he would talk to the adults in the family and just tell them that his Dad had died, just that--I mean, he didn't discuss the illness or anything, just that he had died. He wrote about it, and I have the paper. They were writing about their animals, I think. And we had a dalmatian that died of throat cancer and we had him put to sleep because of the cancer [Chris was 7 years old then.] so this year, this little thing, he wrote that he had a dog who died of cancer and that his Dad died of cancer, and so he would bring it out in little things like that.

In the store when like at Christmas time we would go shopping, he would just say to the clerk, "My Dad died." You know, and here the poor person was . . . ! He told strangers; he told everybody.

At the end of the study, Abby reported,

It's harder on Chris now than it was in the first couple of months, because now things are coming out like school work. It has really dropped off. I mean his attention span is really very short. He's antsy. To get through a meal he has to get up and do something. Before, he would just sit down and he would talk like we're talking, but now he has to get up and move. He's always had a short attention span to some degree, but he could stay on task. He could concentrate to get the job done.

Abby says that she and Chris work on his homework together in the after-

noons. She says still though that "he doesn't have any emotional 
problems I can zero in on."

Robby McAllister went to public school kindergarten the fall after his father's death in July. In November, Karen reported that school was going well. She said she had explained to the teacher what had happened and that the teacher called in the evenings to keep Karen up on how things were at school. Nine months after Pete's death Karen spoke of school as a much needed supplement to what she could give Robby.

School has been great. Robby is bright--beyond me--I have to look up answers to some of his questions--like about astronomy. His teacher is very good. Robby could write his name when he was 3 . Has known his $A B C ' s$ forever. She keeps him interested and challenged at school.

School came up only in informal discussion with the Reutters. Judging by the frequent comment on it by Mary Ann, it plays a very important and happy part in her life, but her mother never discussed it in relation specifically to the illness. The visit to Jim's school made on the back-to-school night by the researcher in company with the family confirmed the impression that Mary Ann feels at home and confident in a very relaxed and proper way in a school setting.

Diane Neether spoke of Terry's school situation as follows.

Well, I think school helped for Terry 'cause it got him out of this situation into an environment that was fun, and with peers and with [teacher's name]. And, you know, it was a loving, warm atmosphere there and fun and exciting, something to look forward to everyday, which maybe, perhaps--what went on here everyday was not nearly as exciting to look forward to.

School seems to emerge not only as a stabilizer for some but as a place that affords the parent a sidelight on the child's overall behavior. We see it as a place that gives the child a change from the atmosphere at home, but do not see any particular differences brought out between school behavior and home behavior. 
The Younger (2-and 3-year-old) Child

The younger child in the family may, as several of the parents have said, have "rolled with the punches," not have "had any problems with this," or have been "too young to express himself verbally." What particularly interests us for this study, however, is the relationship between the older (focus) child and the younger child in respect to the death of the parent. Chet Garrison, for instance, began saying to his little sister, "You didn't know your Mom like I knew her. You're not as smart as I am." He may have been using a fact as he saw it to wield power over his little sister. He may have perceived that he knew his mother differently than did his sister, which was true, or he may have been repeating parts of what he had heard adults say about him and his sister, sensing that there was something important and repeatable in what he heard. Nonetheless he said it and we must assume that to him the aspect he described was noticeable.

This same little sister had said to her father one night that she wanted a "new Mommy or a new dog." He reports that he said that they might not come in that order. She had one day said, when a friend came over and was getting out her mother's sewing machine, "That's my Mommy's sewing machine."

This same child, according to her father, five months later, was no longer asking if every lady was her mother, which she had been doing. He said she had that "all figured out now," he didn't know how, he thinks from outside adults, that "her Daddy would get married again and get her a new Mommy."

In two sequences that involved visits to the cemetery, Ev and Karen remarked the difference in the reaction of the older and younger 
children. Ev said that the children now go with him to the grave "about [once] every four times I do." He had been going lately about every two months, and found that when the children came with him they played around and put flowers on the grave and were cheerful, while in the early days after Janie's death, Chet used to weep.

The McAllister's younger child, a little girl, Mary, was also cheerful in the midst of sadness. She, as Andrea Garrison did, played around cheerfully when her parent and older sibling took her to visit the grave. Karen described this, saying,

I hadn't been up to the grave until just recently. Robby said to me, "Let's go to the grave," and I thought, "OK, here it is." So we went and as we got out of the car, I just broke down, so we cried. Robby and I cried and cried. Mary just didn't do anything. She played around and was funny.

Karen does not feel that Mary will remember her father at all.

I was adopted when I was 2 years old and I don't remember my father at all. I doubt that Mary will remember Pete at all. So that's what's going on.

There seems to be a good possiblility that this may be a factor in the statement of superiority that the 5-year-old Chet made to his 3-yearold sister: The ability to remember a dead parent better than your younger sibling may take on importance, especially if the surviving parent has made it clear that this is a capability worth mentioning.

\section{Seeking Advice from a Counselor}

In four out of the five families, at least one parent, either during the illness or after the death of the ill parent, has been to a counselor.

In the case of the Garrisons, it was about six months after Janie's death that Ev felt he needed help, that the children were 
showing signs of stress and maladaptive behavior.

Andrea had destroyed several dolls. He found that during the time soon after Janie's death, before he had left his administrative job (he has since taken another one), he was coming home much too tired, with no patience, punishing the children when he did punish them not out of sensible disciplinary motivation but out of anger, "not beating Chet" but "really hurting him." He says he thinks that's why Chet "doesn't fight back with kids" now but "puts down his bike and runs." This is quite a different slant than the one he gave in July when he mentioned with pride Chet's refusal to fight a child. Ev reported at that time that Chet had said to a child who was pressing him to fight, "I could beat you up but I don't have time." Ev felt then that that seemed like a sensible, non-violent way to cope, that he had done his share of fighting himself as a young person and didn't much like it.

The whole family went to the counselor, including a young woman who has become part of the family although she and Ev have not married. They went for one group session and several separate ones, and Ev expressed satisfaction with what occurred. He implied that it has served to reassure him and make him more relaxed. At the end of the interview Ev suggested that it might be interesting to talk to the counselor. He said he wouldn't mind at all. Ev said [counselor] had taken "four pages of notes." They like him very much. He didn't try to tell them that he knew all the answers "like some others I've run into." Ev reports: "Like, on discipline, he said, 'I'd say you don't have to spank your children, but do I spank mine? Yes." (The researcher elected not to go to visit with this counselor or others as it would enlarge the research beyond the scope of this study. In 
future work, this would certainly be a logical avenue to follow.)

Abby has not been to a counselor but did go to take courses (as did Karen) after George died and started a small widow-widowers group in the area where she lived. She now finds that the widow-widowers group is not doing things together other than talking about being bereaved. She would like to have seen people engage in activities together like bowling, not having their bereavement remain their chief or only common interest.

Karen did go to talk with a counselor, both before and after Pete died, although she did not take the children. On July 15, two weeks after Pete's death, she said,

Dr. finagled me around to seeing [the counselor] about four months ago. I went to see him yesterday. I realized I have some feelings I didn't know I had. People keep telling me things I should do: get Pete's clothes out, get my wedding ring off. [Counselor] made me realize I was feeling more resentful than I'd thought. I talk big in the morning but about the time the sun goes down, I really bawl sometimes.

She spoke several times of the help the physician had given: "Pete and I handled it as best we could and, of course, with Dr. 's help. He's given us so much support."

Christine spoke about John's two hospitalizations the year before the study started, using the words "enotional breakdown," when she described the reasons for them. She and John both went to a psychiatrist for a while but stopped both because it was too expensive and because they didn't like him very much. She says that she feels, for John, that

it was partly me he was worrying about, maybe, but mostly my father, I'm afraid. It's just really hard, having someone else living in the house. My Dad has made over the cows and machinery to us now and half the land. Sometimes they can 
sit down and have a good discussion about the farm and then other times they'll start and they'll disagree, not so it's an argument, but they'll just go on and on and one will say, "Well, that's not the way I heard it," and I just go in the other room.

Diane never actually went to a counselor but one came to her in the hospital. Diane describes the person as

not my kind of person. She was dumpy, had frayed sleeves, kept her coat on the whole time she was talking to me. She wanted me to move up to the psychiatric ward. I'm not a nut and I wasn't about to be up there with the nuts!

Diane persuaded her husband to make sure the lady never came to see her again.

What seems important in the decision to contact a counselor is the desire to have an outside opinion, and to gain some perspective on what phenomena are taking place, either for the parent or for the child. This is in common with the motivation behind joining a group of others who have been through the same experience: the search for affirmation that one is normal, that the emotions and confusions one feels are not unusual. Where the parents found this affirmation, it seems certain that the reassurance gained must have helped them feel more confident and relaxed with the children.

MOTHER-FATHER-FOCUS CHILD

Mother III or Father III

The parents interviewed spoke of their feelings as to how it would be different for children depending on whether the father or the mother was ill.

For Everett,

as far as the bereavement goes, you miss the people having the time during the day. They miss their mom and having 
someone to sit down and read a story and someone soft to caress their head. I do it but mine's more of a pat, nothing impersonal, and of course it's very loving, but I think--that's one of the things in this. Janie had the time during the day and I don't have the time and most babysitters don't have.

If the roles had been reversed there would have been no problem. If something would have happened to me, if I would have died, Janie could still have required 24 hour-a-day nurses [for me] here and could have economically been able to afford it . . . She could have sent the kids to a Montessori School, she could have done whatever she wanted to. The house would be paid for, all our loans are paid off and we have life insurance. So, all she'd have to do would be function, you know, and live. Whereas I have to still make a living and provide an economic base. I . . plus... I like to try and play with them.. . and it's fun. We get rowdy. I say get rowdy--we haven't broken anything, but we like to roughhouse kicking, laughing, and giggling, and tumble and tickle each other. We go out and run. Where I think, you know, I can't tell you generally about parents, friends of ours, no particular strain runs through all of them, but I think the thing they would miss from would be that rollicking and frolicking.

Whenever she'd come home and be convalescent during the last five years. . . I don't know . . I think they get more of that acceptance feeling from the mother. . . more of a security, more of a superiority feeling, inferiority feeling from the dad.

If the father is ill, Ev felt (based on a family friend of theirs where the father has cancer) there are difficulties of a particular sort.

The one thing I think was hard on everybody was that he was around all the time and I think that's hard on families for the husband to be around. You need that respite, that eight hours while they're gone while they're at work. But then the problems that really came up . . . the kids pushed the mom . . . and I think it's more a feeling . . . but they're really trying to get on top of it. They don't behave and there's really a change in their behavior and they're really assertive-aggressive.

Abby said,

I just don't know in our situation. Had I been the one dying, I would not have handled it well at all. I just know I wouldn't because I thought about that--"Gee, what if this was me?" You know, here I'm being this cool 
because George was--it was easy for me if I can use that word--compared to what it would have been, because of George. He handled it so well, so very well. I would have been . . . bawling constantly . . woe is me!. . . It can't be . . And George went through those stages, but quietly. I'm afraid I would have been heard! [Iaughs]

When the comment was made, "That could have been a personality dif-

ference, not necessarily a male-female difference, too," Abby said,

Exactly. I think that it's definitely the personality that makes [the difference], not whether it is a male or female at all. Because I handled George's death and his illness and taking care of him real well and I was strong in that area. Had I been the one that was sick I wouldn't have handled it so well and I don't think it's because I'm a woman. A lot of women die who handle it extremely well. I think it's my personality.

I think some people handle their death so poorly that you'll just [a sigh to indicate "Whew!" relief] when they die. I mean, unfortunately but I really feel that way; you're just relieved. And I think that would have been my case [both laughing]. But I don't think nale or female has anything to do with it.

Karen didn't find any difference: "No, not really any difference.

They'd both be awful." Christine only said, "The kids are closer to me than they are to John," and then also mentioned her role as explainer, implying perhaps that it would not be as easy for John. She says,

Last sumer I thought "Gee, it would be interesting to write a book." I started and realized it wasn't that easy. I realized, too, it was really for my kids, for when they're grown up. I hope I'll still be around, but anyway if I'm not I'd like them to know how it was for me. Starts in high school when I had that bump on my leg and for two years my parents didn't want me to know. It's hard to get in all those details that other people don't know.

Diane, however, was quite explicit in the difference she saw.

I'm sure glad it's me and not you! I think all that stems from the relationship--that I had always considered that I was the strong one, that I was sort of the rock and that, no matter what, I would always be the rock, and all of a sudden I wasn't. And I think that was difficult for me to 
accept. And he was. You know, he was really the rock of Gibraltar. He wasn't cracking or breaking or showing. And he said he basically was not trying to hide his feelings. 'Cause we would have some really good discussions. It was just that I never saw that side of him. The opportunities never arose to put him in that light. What was the question again [laughs]. Oh, OK, if it were him rather than me. Well, if you want to look at the same thing with the age of our children, there would have been terrific financial burden. Because I would have had to be the one to go out and take the full-time job. We rould have still had to probably have someone in the home for the children.

In my situation, I think a lot of men--we know a couple-that do a better job as a homemaker than the wife would do. But I think Jack is a little bit old fashioned and I am, too, in our ways of thinking and doing. And yet I'm sure Jack would have handled it. I think it would have been more difficult on me than it was on Jack.

Because my whole life would have been changed around. I would have been out working, somebody would have been in my home and my husband would have been in and I still would have had to come home and cope with the whole situation of domestics and children and . . . whereas Jack--if this got spilled, it got spilled and it could wait 'til tomorrow--not that he's--he's very neat and clean, but a situation like that wouldn't bother him like it would bother me.

I know Jack's parents and mine would have stepped in to help out financially but I think that would have really made me feel uncomfortable. I don't know what we would have done-really I'm glad it wasn't him. I know when he's sick, he simply wants to be left alone. He doesn't want to be babied or pampered--special foods or anything. The . . . stay in bed, sleep it off, the world can go about its merry way. I think maybe our communications would not have been so open and I think probably, I would have shown it more, as far as the children were concerned. I think maybe they may have sensed the vibes from me more than Jack and yet, I don't know.

It is interesting that the opinion that it would have been very different for the child if the other parent had been ill is based partly on the speaker's own emotional reaction, how he or she would have felt. Partly too, though, there is an element of personality involved, of how the individual reacts to illness, how stoic the person is, and also how 
much the child depends on that parent for love and support.

Father or Mother as the Person who Talks Most Easily with the Child

In some cases, one parent talks more easily with the child than the other, but that was not true in all the families. In answer to the question, "Did you find that either of you found it easier to talk with him or did you pass it back and forth?" the following responses were made.

With Janie going in and out, we'd say, "Hey, you know, there's no written guarantees." Maybe the end of 178 we said, "Hey, here's where it's at. I could die. Mom could die. You could die."

I think we shared a lot. He'd ask us questions. I handled that. We talked about it. Janie was really cool. She laid it out for him. You'd try to teach him about love and about God. "Hey, where's my God, man?" [gestured]

We'd talk about certain topics in front of the children and we all had little fears. And we'd save that and we'd talk about those during the night time, and yet then once when we got understanding between ourselves then she could talk to Chet or Andrea the next day and then two nights later Chet would come up to me and say, "Dad, what if Mom gets another tumor?" And I'd say, "Well, you know, if she does we'll have to see what we can do . . . be cheerful and be gentle and we'Il still love her and we'Il take care of her and... I think we need to share. We did express love and . . almost a self-sacrificing love . . and you need to talk.

Abby Lindstrom remembers that George did not ever talk with Chris

about the illness or the possiblility of his death.

I don't recall him ever doing that. George and I talked about it constantly. I mean not every day but every time there was a change. I mean, we were really in tune to it, but I don't think George ever sat down with Chris and told him what was happening. I don't think George would have been able to get through it without breaking up. To my knowledge, I really don't think he had.

Karen McAllister said that she, mainly, had talked with Robby.

Not particularly that Pete would die but that Daddy was sick. pete skixted the question of what was happening. I was the 
one. When we were coming back from somewhere in the car

Robby and I would talk about it. Not in front of Pete.

In response to the question about whether the mother or father found it easier to talk with the children, Christine indicated that it was she. "Me, very definitely." She gave as an example the time when John was in the hospital last year. Christine described her going and sitting down with the children and explaining what was happening then and also made the comment that "the kids are closer to me than they are to him."

Concerning the illness, Diane said, "I think I told him what he wanted to know." She described the difference between the two parents, when it did exist, as depending on mood or situation: "To the children. . about the same. I think there were times that you . . that he was uptight where I was [more ready to talk]."

It is interesting that in all five cases here, the mother has found it easy to talk with the child, whether or not she is the ill parent. In the case of the Garrisons, the well father also apparently did a lot of talking with the children. We could suppose that difficulties might arise if the more open parent was in some way incapacitated and the more reticent parent could not bring himself or herself to answer the children's questions openly or to foresee fears.

\section{Interparental Relations}

There is a question as to what particular strains are placed on a couple during the illness that may have an effect on the child. No matter how strong a marriage, it seems probable that the changes in body image, the sexual tensions and the worry that accompany lifethreatening illness present great obstacles to marital harmony, and that 
this is perceived by the child.

Everett said,

probably we were really . . we'd worked a lot of things out . . Marriage is a kind of continual negotiation as

far as I'm concerned, but we'd really worked a lot of things out. Maybe around last part of 75 early part of 176 we really came together spiritually. Everyday I expected a miracle. Got a lotta little ones! Didn't get the big one. And they [the children] pick up on that. I'd say, "Let's hope that Mom'll have a great day so we can go somewhere!" There's that energy, you know.

Abby remembered that the hardest part was the inability to communicate.

It was very hard. I would rather he had lost both legs than the ability to speak. That caused a lot of tension. Tension on his part because I didn't understand what he wanted. Tension on my part for the same reason. He would go over and over it and I'd get sick of trying to guess it. Taking care of his personal habits, getting him on the commode and off, you know, the bedside kind, was a real job for me. And a couple of times I put him there and he really didn't have to do anything. Now, I don't know if I misunderstood him or what, but I got really angry because there I went to all that trouble and it was really hard [laughs] and with no results, and I let him know it. You know, I'd yell at him and... "you fool!" You know, I would really let him know. I didn't ever hold anything in.

One time he got really angry with me because, I don't know if I ever told you about that but, I was getting him off the commode and into his wheelchair and it was after I'd gotten, I think it was his third wheelchair and it was the kind that would recline and it was just really a nice thing to have. But, anyway, I'd gotten him in the chair and I was angry because here I was transferring him and I was tired, and some days I was stronger than others, and I was physically weak on this day. I got him into the chair and I was picking his legs up to put them on the footrests, wasn't paying any attention to what $I$ was doing and $I$ was angry and I was just getting it done. He was in the bedroom in the doorway with the wheelchair back facing out into the hall and I picked his leg up and pulled it up too high and he tipped over backwards. Well, needless to say that was very upsetting to both of us and I was just mortified. I couldn't budge him. I called vance [neighbor]; he was up up on the roof. He came tearing down here. They thought George had died because I was bawling and I couldn't talk 
or anything to tell them what had happened. But once we got him upright, and we got him back into the [wheelchair], he would not acknowledge me. He was showing me "I am angry because you put me in this position." And he was helpless. I was helpless. He was very indignant. It was really rough and so he wouldn't acknowledge me the rest of the day. And so that was his way of showing his anger just by . . . and so we did. We got angry with each other. And I can't say, you know, as things happened, that I wouldn't be angry again. Because it did get on my nerves, because he couldn't talk. That was so hard. So hard. And it was so hard for him, because we did communicate all those five years, about every aspect of his illness, about dying, about things I should do afterwards, about everything, and then, at the most important time. .

Karen and the researcher talked on the telephone in late May.

Karen volunteered,

He's been in a really rotten mood. Not depressed, just grumpy. I don't want to go up and get my head bitten off. So I spend a couple of hours [at the hospital] in the morning, a couple in the evening. I just never realized all the different feelings that you go through!

After he was home again, Karen reported,

Pete yells at the kids, sometimes just for being kids. I'd just like to say, "I think I'Il take off now and go [to the midwest] and visit my mother." All of a sudden things have changed drastically. I'm really getting mad at him now. He won't do exercises to strengthen his legs. He's not afraid to die. At least that's what he's told me all along. His religious background has been a big help to him. As far as the anger goes, he's really angry. He's taking a lot of his anger out on Richard, his twin brother, and me. [There was] a lot of "why me" for a while.

Ten days later, about a month before Pete's death, she spoke of things being

under control at home except outside [in the yard work area] - . Pete and I had a long talk. We decided Pete was never going to get stronger if he didn't try to help himself. He's been trying everyday to do just a little more for himself. His hands don't shake so much. He's going to help me pay bills. It's worked out real well and he feels better about himself.

Now, looking back, Karen says, 
We weren't very different from what we were usually, but [the children] may have sensed some tension. We didn't deliberately push them aside but they would do things sometimes, not just naughty--any kids will be naughty--but really, outright, to get our attention and it was probably because we were so absorbed in this thing that we were dealing with.

For the Reutter family there was a complex situation created by the fact that Christine's father is living with them. She said, "He's not easy to live with. Luckily, John and I feel the same way so we talk about it." She spoke of their ways of dealing with the illness,

I've dealt with it all my life. Just recently I've realized the seriousness of his thoughts about me. Just a few months ago I talked to [name]. I didn't know that they'd put a limit on my life. So when we were married, he knew that and I didn't. He has a very good friend; he'd talk to him and the friend would talk to his wife and then she'd let things slip. When we were first married he said he used to be afraid he'd wake up and find I was dead.

We had a conference in May 177 with Dr. __. He answered a lot of questions. John went away feeling better. I went away more afraid.

John is going through a funny time now. People think he's older than he is and that really bothers him. Once a while ago people thought he was older than I was; he's 36 and his friends think he seems at least 40 .

Christine said she worried about how he's going to react when his parents die. They're in their late 50's and have had open heart surgery.

Diane Neether spoke of her husband's strength and the complications of a job change in the middle of the time she was undergoing treatments.

Well, the whole thing at the time--I knew it was difficult for Jack and I was amazed at how he held up, his strength. He was not happy where he was. He knew the bottom was going to fall out of where he was, jobwise, 'cause the market just wasn't there, and so there was a lot of financial--and, of course, he's always handled the finances, not that I couldn't 
but I'm just very happy that he does, so there was that pressure, which we've never experienced before and not knowing if, you know, there was not the next month's salary to pay him, where he was going to go.

When she was asked, "Did he change jobs in the middle of that?" she said,

Yes, which worked out just fine, but it was still an awful

lot of pressure. You know, he didn't know when he was gonna come home whether he was going to have the usual dinners that he was accustomed to and, of course, the children being so much younger, they needed a lot more caring--just for their personal things.

Raising children in itself often prevents parents from finding sufficient time for themselves to nourish and enjoy their own relationship. With the added factor of physical illness, not only as "this thing that is absorbing" them, but as a preventor of loving, physical contact, they are, so to speak, in double jeopardy. A great deal must depend on their flexibility, their ability to enjoy to the full days that are better than others, and to transmit whatever elements they can of the good feelings to the children, at the same time acknowledging the bad times for what they are.

\section{CHIID}

\section{Child Behaviors}

Parents described children's behaviors that seemed problematic and that they had noted during the illness with some degree of humor and resignation. Ev, though, feels very strongly that the separation caused by Janie's hospitalization was in itself a very traumatic experience for Chet. Chet experienced a marked loss of verbal skills, and, Ev felt, learning skills. 
Probably the biggest thing for Chet, it wasn't so much the illness as the separation. Like when he was 9-1/2 months old, when she first went in, he had a vocabulary of about 30 or 40 words, toilet-trained day and night, and about seven-eight weeks later we bring him home, you know, two weeks here, three weeks there... gone." [Ev wept, the only time during the interview that he wept.]

[They were] people really close to us. He came home saying "wa-wa" and "da-da." I think he was born a little genius, I really do. And he a . . you . . goes up and down... it's one of the tragedies.

He mentioned this several times in different contexts. He

felt Chet simply lost a great deal of the capability he had to excel intellectually, due to Janie's frequent hospitalizations and the confusion they caused.

Abby, in an interview, reiterated the account of an incident

that had occurred earlier and which she had once mentioned on the phone, describing Chris's behaviors as George's abilities declined.

A few things just came to my mind. When George was in a wheelchair and couldn't feed himself, I mean, he was completely dependent on me for those things. Chris still wanted to have his friends over but he didn't want George to eat dinner with them. And that just came to my mind immediately because that was something he asked me. And I asked him if he was embarrassed and he said, "No." I think he just--he knew that George wasn't that way all the time and he didn't want his friends to think he was. I mean, that's how I got the impression, but he continued to have children over.

Abby had mentioned once that Chris was a little obstreperous and not doing the things that George asked him to do even though he could understand.

George didn't have the authority anymore; because George depended on me, Chris also made sure it was OK with me before he'd do something but also because when we were on a trip, George made a few statements that were very wrong. When we were in St. Thomas, they were in swimming and a storm came up and I asked them to get out of the pool and 
George made the statement, "Well, this is the safest place to be." You know, so things like that, and I had to talk to Chris about that later, and without putting George down, but explaining the tumor was making him think wrong, so he [Chris] began to wonder. . you know, and then just, he'd disregard a lot of things. I don't think he was ever out and out rude to the point where George was offended. I don't think he [George] noticed.

When Chris spoke of not wanting his father to eat with him and his friends, Abby solved the problem by letting the children eat first in the kitchen and then feeding George afterwards. When, at one time, Chris played dumb, pretending not to understand when his father asked him to clean up his room, Abby felt some anger that was clear in a conversation on the telephone. "It was perfectly clear what George wanted," and "He's having to watch his father turn into a vegetable," seem to say both that she was angry at Chris and at the whole situation, a very common and natural feeling in spouses of terminally ill people.

In a sequence during the last two months of Pete's illness, Karen mentioned behaviors of Robby's in this order.

Robby has--he's been awful good for about the last two weeks-Daddy's gone [to the hospital] so he is going to be the man in the house. Pete used to travel a lot. Robby used to kind of pretend that he was the man in the house.

Robby's a little insecure now and then. In June, during a conversation, she said, "We've encountered some new problems with our 5year-old. Pete is becoming very paranoid, very depressed. He's real angry and he won't share." This was explained by her saying that he had some felt pens which Robby wanted to use. Pete and Karen got into an argument over this and "he kicked me out of the bedroom."

Robby is becoming very protective of me. When I had to go to the hospital the other day he kept asking when I would get back, and when he heard I was on my way he was eating an ice cream cone and he just dumped the whole thing right into the garbage; he couldn't wait. He's very attentive. [He'd gone 
out and done a whole job with the wheelbarrow unasked.]

Not what a 5-year-old usually does.

Right before Pete's death she said that before the death Robby was having nightmares; he'd cry in his sleep and wake up. This was the only spontaneous mention of bad dreams among the five families.

When asked about whether she saw any behaviors on Terry's part that she attributed to her illness, Diane replied,

No, because I talked to [pre-school teacher] and they really didn't seem to--Terry talked about it very openly at school about what was happening, of course didn't go into it really in any great depth. They always listened. They were glad to see that he was open and talking about it. He wasn't going into his shell.

At one time during her treatment, Diane had mentioned on the phone that Terry was doing a lot of monster play, being a pretend dinosaur at school. When the researcher visited school, this was still continuing, although the teachers had limited the space in the play yard where Terry and the others who were being dinosaurs could carry on their play. The rule was that if other children went into that area, they would have to be ready to cope with or become themselves dinosaurs, a solution that seemed acceptable to everyone. At home, though, Diane said that when the uninvited dinosaur behavior occurred, he would be given a time-out; "Ostracizing him was the best thing, removing him from the scene; we don't condone that." Diane said then that she thought he had been a little bored in school.

He's always been very independent and yet he's loving and he goes through stages, now he's not in a real loving stage. I know that he's not pleased when he hears that I have to go for a doctor's appointment. That's what leads me to believe possibly that wasn't a really happy time of his life. And yet he loves to go to the doctor, you know, because he loves this doctor. And I don't know whether we were wrong at this time not really explaining. 
Christine Reutter mentioned no behaviors of Mary Ann's that she felt were caused by her illness. The illness has been in such a low profile in that household that there would probably be only the most indirect effects, and even those could be attributed equally to other stresses.

The shift in authority from two relatively equal parents to one well parent certainly seems important to the 8-year-old Chris, and is directly related to the father's illness. The child's becoming protective of one parent, though, as in the case of Robby McAllister, when one parent became abusive of the other, is something that might occur during any parental strife whether or not it involved the illness and death of one parent as it did for Robby. It is not always this easy to separate those behaviors which may have little relation to the illness from those which are closely tied to it.

Child's Understanding of Disease, Medication and Possibility of Death

The voices of parents sometimes quoting their children in answer to the questions concerning what they told their children, sometimes spontaneously describing how the children voiced their own understanding of disease, are best heard with very little interruption.

Everett Garrison said,

She would have chemotherapy and he'd say to his little friends, "We gotta be quiet, my Mom's got her special medicine in her. She's gonna be sick and she needs to rest." He understands IVs; "Yup," he says, "there's medicine and water going in her to make her well." The only problem he had, one time he saw the IV here and the catheter tube here and he wanted to know why we couldn't hook them together and forget all this in between stuff. He's seen her surgery scars, understands the stitches. I don't think he understood radiation. We were watching one time they were doing a contrast. The girl was just--well, 
Janie's veins they were scar tissue. Janie winced. I think he associates that with pain.

He's really very understanding of the problems of wheelchairs, blood pressure cuffs, thermometers. There were times when she got a shot . . . She was pretty unexpressive in front of the kids--he'd see her flinch. I think he got a lot of respect for what she was going through. Sometimes we'd have to yell at the kids, you know, "stay off Mon."

At one time, they had cut her hair off. [Ev looked for a picture in the room of Janie when she was first married.] Anyway she had long blond hair when we were first married. They'd cut her hair off and they'd painted blue lines for radiation all over and she had a bunch of IV's all over and . . he hadn't seen his Mom for probably three weeks and I took him in and held him down to her like I'd done a million times, and he just turned around and scrambled to stay away like a cat trying to stay out of the water! No. And he was crying. Finally I leaned over and kinda kissed Janie and he kinda curled up.

Abby Lindstrom says,

Maybe because George was sick so long and I don't mean the last few months but for five years.. . Chris was only 3 when he had surgery. He got used to the idea of something being wrong. I mean George never drove.. . when Chris was aware of it, and he would have seizures. He had a massive cytoma which Chris had seen and all this time I don't think he ever thought that the end result would be death, but - . and I'm not patting myself on the back, but because I could talk about it with Chris and I tried to make it seem, because it is, a normal thing, that he seemed to be OK. He seemed to be more OK than what I'd have liked; it bothered me because he seemed to be handling it so well.

Also being at home all the time meant that Abby could stay in touch with Chris's view of what was going on. Chris was playing in his "hideout" with the two neighbor children, on a day a few weeks before George died. One said to him, "You don't have to be embarrassed just because your Dad's doing to die." The children then talked about when they used to go to games together with George. The friend said, "He was such a neat guy." "He still is," said Chris. The friend replied, "That's right. I'm sorry. What made me say that!?" 
In answer to the question, "What particular things did you tell

Chris?" Abby replied,

After we found out, when we got back from our trip and George got to the doctor and they'd done another cat scan, it was so obvious, just telling him, you know, that George was very sick, that he wasn't going to get better and at that point, I didn't know exactly the steps that would occur to explain, so we just kind of took one phase at a time.

The thing that started out immediately was speech and the clumsiness. And that I had to explain so that Chris was aware of it. And so he would kind of talk for him, if he knew what he was trying to say; and then the various times when George would go into, I don't know what you would call it, a semi-coma or what, but he would be out for three or four days without waking and I never knew if he would wake up . . . various times like that, I said, "Gee, you know, Dad may not wake up." I never said he was going to die though. I didn't actually use the words that he was dying until two days before he died. Dr. came out. He hadn't had.. He'd been out five days by then, and he hadn't had anything, no IV's nothing, so he was getting diarrhea. On a Saturday night I told Chris that Daddy was dying, that he may not ever wake up and would never be well, and went through the whole thing, but I told him then that he was dying. And he died on Monday morning. But it was so obvious then that he was, because Sunday night he had [a temperature of] $106^{\circ}$. But that's the only time I can remember using the word death with him. I always kind of worked around it which I probably shouldn't have done. But because I didn't know the exact date I couldn't say George is. . . you know, "Daddy's going to die in four days."

Karen McAllister said that

Pete and I decided right away that we wouldn't lie to the kids. We don't use the big medical words and we say things like his "chest" because that's a word Robby knows, not "lung."

She reported in May, 1980, that "at the hospital Robby got visibly sick the other night." He asked Karen why Daddy had to be in the hospital. She explained that his chest hurt and he had to go and have x-rays. Robby wanted to know if the $x$-rays hurt. Karen said, "No, it was like having your picture taken."

In June, she said, "He's worrying about his Daddy shaking so 
much."

Sometimes at home Karen would say, "You go play for me and I'll do your worrying for you." "He shouldn't be having this to worry about, he should just be playing and catching frogs and running with his friends."

In a later talk on the phone, she repeated what she had told Robby: "It's the big people's job to worry. It's your job to play and have fun for us." She said, "it seemed to take the burden off a bit."

Robby really didn't know what was going on with Pete other than Daddy was sick. I didn't want to put any heavy big words--on the days we would go to the hospital or in the middle of the night, if we had to make an emergency trip, Robby just knew that Daddy was sick and we had to go to the hospital.

The two women whose disease is in remission now gave a sense of what they have said so far to the children and also what they would say if the disease worsened, or when the children found out that they have cancer and could understand the possible implications.

Christine Reutter had not mentioned the word cancer to the children because "they know that people die of cancer."

I realize it won't be too long before they realize that there's something seriously wrong and I hope there'Il be a way to talk about it with them so it doesn't frighten them too much.

Christine went on to describe a group of recent happenings that have brought death close to the children.

We've had some strange times lately. You know, that physician who killed another doctor and then killed himself and his wife? Well, they lived right up the road from us. The boy used to be in Jim's school. We didn't know them all that well. She spoke about how they heard of it--by a distraught friend, going in and telling the children in school. 
And now lately another neighbor has left home, leaving a note willing all his belongings to his son. Nagging wife went off to drive the tractor when the sheriff came continuing the search. The man took his gun with him and has not been seen since. John goes occasionally, thinking of another place he might be and hunts for him.

Christine spoke of how important she feels it is for children to have a sense that there is continuity in life, that poeple do die, and that life goes on. In working with a group at the school on the history of the old cemetery across the road, where many of her ancestors are buried, she felt she was contributing to that sense of continuity.

In the interview with Diane Neether, a question was asked about what particular situations she remembered where she discussed the illness with Terry.

Well, we always discussed at the dinner table the night that I was going to go in to chemotherapy, that after dinner Daddy was going to take Momny to the hospital and that Daddy-we had a neighbor lady who usually came in, one of two, and that Daddy would be back home sometime that night and then Mommy would be back home when they came home from school the next day, and that she'd be very tired and that she'd be in bed, not feeling well; and I think we probably, you know, I think as it went on a little bit like the second chemotherapy stint that he wanted to know what they did to me, so we told them that they put a needle in Mommy's arm and gave her chemicals to make her better. I think he may have asked, you know, "Will I ever have to have that done to me?"

Jack's father thought that he might be a possible diabetic or borderline so he went through the eight shots.. . first the hour interval with the urine specimen, etc., so at that point he did ask me, "Is that what you had done when you went to the hospital?" and I said, "No, not quite. I was having something put into me rather than just blood taken out."

About the possibility of death,

Terry has discussed probably in the last year, but not me singled out individually, who is going to die. He understands we're all going to die and that more than likely Grandma and Grandpa will die before Mommy and Daddy, and Momy and Daddy will die before Terry and Court do, and that people have children and that he will grow up and probably 
get married and have children and that that's how the world goes on.

She later mentioned that if she were close to dying, she "would have to start preparing [the children] earlier."

Attempts at helping the child to an understanding of the illness and of its seriousness were made by all the families. It was an undertaking that the parents accepted and carried on in varying degrees of detail and specificity. Whether they coached their children in learning to accept death through their own families' experience or through talking about other families, they do seem to have had a concern that the child begin to understand ahead of time what might happen and yet not worry overwhelmingly about the effects.

The families in the study uphold the premise that many children receive preparation in death or at least some experience with it through their pets and other animals.

Ev described a day, a few days before Christmas, when

our little dog, two big shepherds killed her, Peppy. Andrea had let her out in the morning. We didn't see it. Neighbors told us what happened. And so Chet, at his night time prayer, said, "And bless Peppy, wherever she is," and wept.

Ev said they then talked about how "someplace, somewhere a cow or a cat or a person is being born or is dying all the time."

According to Ev, the children volunteered details about the death of this little dog, Peppy. They had not even seen her afterwards but created a verbal picture of her, chewed to pieces, and told it to the counselor in great detail.

The Lindstroms, too, had a dalmatian who, a year before George's death, had cancer of the throat and had to be put down. At the beginning of the study, the Lindstroms had a great dane who had to be given 
away because he chased sheep.

Karen reported two weeks after Pete's death that

Our little black poodle died about four weeks ago. She may have done us a favor. Mary thinks Tammy's on the ceiling [where people had pointed when they spoke of heaven]. Daddy's with Tammy on the ceiling. The ceiling's pretty high when you're that little.

The Reutter family has always had animals around, living and dying. Mary Ann mentioned on one visit that their biggest dog had disappeared and that they thought it had died. There was some talk of it having dug up some buried smelt and gotten "salmon poisoning."

At lunch one day there was further matter-of-fact talk of an animal's death. John had come in from work just as the family group had risen from the lunch table. He smiled and said, "Hi," but went about his business otherwise almost as though nobody else was in the kitchen. He went to the closet and got out his .22 and a box of bullets and took them out to the front seat of his pickup truck. He came back in and got a bowl of soup, made a cheese sandwich, sat down and started to eat it.

Christine had mentioned earlier that he was feeling discouraged by this job, that the machinery was all broken down and that he was not being paid to fix it, but didn't like to leave it unusable. When it was mentioned that it sounded as though he had a lot on his hands, he said he wished there could be a happy medium. "One week I'm not busy enough, the next I'm too busy."

Christine asked, "What did you need the gun for?" John answered, "I've got to kill a cow. One of the cows calved and everything came out with it." The children didn't make any comment, nor did Christine. Christine had earlier described an explanation she had given the 
children of her own scar and stitches, using the dog's operation as a starting point, thereby making it understandable and not frightening to them. It is almost as though one can see the small doses of vaccine being doled out to these children: If animals die and people can talk about death in a calm way, then the child may gather that people around someone who dies do survive and are all right.

\section{Child Behaviors at the Time of Death and Shortly After}

When the parent dies and for a time thereafter, the surviving parent makes statements and explanations to the child, answers questions and shares to varying degrees whatever is being felt. The busy days around a death may be very different than those during the illness preceding it.

In this section are included reports about what was told to the child, what the child said and did, and what some of the varied circumstances were that occurred immediately surrounding the death.

Ev Garrison remembered,

I got home Friday afternoon the day she died and I thought I had the strategy all worked out how I'd tell 'em. And then they jumped and hugged me. . . it was a couple of hours before I told ' $\mathrm{em}$.

I told Chet what it meant to be dead--you don't drink, can't get up, nothing.

He reiterated his insistence that he was trying to get across to the children the idea of the difference between physical presence and presence of someone in your mind and heart.

I started with Chet because that's one thing, two things I want to do with the kids as a parent is to get him where - . so that he can understand life, things that were hassles to me and other friends of mine. My folks weren't really into that. My parents are beautiful people but quite conservative, and I wanted to give him the kind of God you can really love. You know, you don't go to him once 
a week and say, you know--he's your partner. We've really talked to the kids about life, the goodness of life and trying to establish a purpose and I think that Janie would spend time telling him--there's no guarantees. But we tried really hard to let 'em know that there was always going to be somebody to take care of them. And that we're the Garrison family and we're a good family and we're going to always be together. That's one of those little catch 22'si I said, "Hey, there's going to be times when Dad's going to have to be gone or Mom's going to have to be gone but we're all together still in our minds."

He mentioned spontaneously in an interview six months later.

The worst thing I did from a religious point of view was to tell 'em that Jesus will come, Mom will come back to life and go to heaven. I caused maybe six months lengthening of Andrea's coming to terms [with the finality of Janie's death]. I don't think you ought to do it unless they're six or seven.

Janie died in the hospital, but Ev took Chet to see his mother, after she had died, in the funeral home. Chet also went to the church service. There, he sat with his father and then went to the graveside ceremony as well. One night not long afterwards, Ev reports, he was sitting thinking "sad thoughts" and Chet came up and said, "I feel really sad about Mommy." Ev agreed.

For the Lindstrom family everything took place at home. George died early Monday morning, October, 1980. Abby had talked with Chris Saturday evening when George's fever had been very high.

I told him Daddy's going to die pretty soon and he's going to be dead and not wake up anymore. We cried a lot. A little later Chris said, "I hope next time you get married, you make sure that man lives a long time."

Abby was alone by choice when George died. She said,

The first few phone call I made to his parents, I hung up and thought, "He's not really dead and they're going to be mad at me for playing a joke on them."

She remembers a curious sensation as she saw herself thinking that.

When the undertakers came, they wanted to move George's body and not 
have Abby let Chris see him until he was in the funeral home and

embalmed. Abby said to them,

"No. He's not going to see him again after he leaves this house. I want you to wait while I wake him up and ask him if he wants to see him." He said he did, and when we went in and looked at him, Chris said, "He's not dead." "Yes, he is dead, Chris." "He is not, he winked at me." "No, it just seems that way," because his eyes weren't quite shut. "Why don't you touch his head and you'll know because he's cold." He didn't want to touch him. He said, "OK, I know he's dead." He went out in the living room. He still hadn't cried. The undertakers took George's body out in that thing [a gurney]. We sat there and talked in the living room. He said how sad it was; he wished it wasn't happening. I cried and cried and cried but he still didn't cry. We had had to put a catheter in George. Chris asked, "Is Daddy going to have that thing in his penis forever?" "No, they've taken it out already. It isn't there anymore."

I took him to the mortuary with me. His eyes got a little misty. I didn't want him to go off to friends to be taken care of and think this was something scary or bad. So we went together to finish up some arrangements. He wanted to know where the money was going to come from, so I took him to the Social security office with me too. We shopped and just sort of did ordinary things. In the car coming home, he said, "I wish this was a dream, Mom." We talked and I said, "Yes, wouldn't it be nice if it--if we could just go home and all this wouldn't have happened. But it isn't a dream and we won't just wake up and find it isn't true." Then he said, "Mom, my throat hurts." I said, "Mine does too. Sometimes I really want to cry and I don't and my throat gets tighter and hard and then I cry and it doesn't hurt anymore." Chris said, "I think I need to cry too." I said, "When you're by yourself or in a quiet place then you'll cry."

George is going to be cremated. Chris said a couple of times, "I don't want Daddy to be cremated." I explained that this is what Daddy wanted, and told Chris not too much about it but just enough to be truthful. We'll make a special place to bury the ashes so Chris will have a special place to relate to. George wanted to have his ashes scattered but I think that would be just too much for Chris.

In this account, recorded by hand as Abby talked that day, there are some phrases left out of what she said, due to inability to write fast enough, but what is here is verbatim. Chris's concerns and Abby's come through very clearly. 
Pete McAllister had been in a coma for a short time before he

died in the hospital in July of 1980. Karen had, just shortly before,

left at the urging of friends to take a breather. The doctor explained

to her that Pete had not regained consciousness and reassured her that

Pete did not know anything about what was going on around him. Karen's

account in an interview was as follows:

When Pete died of course my Mother was here; she'd come out and was living here with us--and I don't know, I guess it was Mom or maybe it was Auntie Fran that told sue, she's my neighbor, there [points across back yard] that pete had died, and sue very kindly invited Robby to spend the night so that he wouldn't be here. Now I don't know why, because I didn't fall apart you know that night. Robby came home the next day. I didn't tell him that night because by the time I got home it was dark and I didn't want to say anything. Night time's kind of spooky to a 5-year-old anyway without throwing something like that into it. So I waited until the next day. And it was about 11 or $120^{\prime}$ clock and I wanted to tell them so I took them into my room and I loved them, and if I remember right I think I just said that Daddy died yesterday. And, oh, Robby just had all kinds of tears. Mary didn't understand--uh--she hugged me, but I think it was only because she didn't know quite what to do. Robby cried and cried and cried, and then, it was real funny, because he asked me some questions about "Why did Daddy die?" and "Where is Daddy?" and you know some very general questions and then all of a sudden he said, "Can I go tell Kelly?" (Kelly's his little girl friend down the block) and I said, "Yes, if you want to." Because I felt like he was saying to me, "I have to get out and get away from this and talk to somebody my size." So he went out and told Kelly and then he played for the rest of the day. And then that night, of course, he was, well, we've always been real close and real huggy and lovey, but that night and for a couple of nights afterwards, he was very Iovey.

Robby didn't attend the funeral. I didn't want them to attend. I thought that would be a little rotten for them. Funerals are just not too neat anyways. I remember my first funeral, and I didn't want them to have that yukky memory. So they stayed with Sue. And then we brought them back here. You know how everybody always comes back home afterwards. And flowers were being delivered and people were wandering in and out and Robby knew that there had been a funeral for Daddy, and he asked me, "Do the people come to the funeral?" and "Did the minister say nice things?" But that was really the only participation the children had, afterwards when we came 
back over.

When Robby asked Karen what was going to happen to Pete's body,

she said,

We talked. OK first of all he asked me where Daddy was. And I said, well, that Daddy had died and that--he knew the part about the body and the soul, the difference between the two, so I said that Daddy's body is still at the hospital and that they were going to move it over to the place on the hill. He knew that location and--that was fine with him. He understood about the burial. I did not tell Robby that Pete wanted to be cremated. That's something that I think would be too hard at this stage of his life to understand, so I didn't mention anything about the cremation. Afterwards, after he got that through his head that Daddy was dead, that his body was, and that his body was being moved--then he asked about his real Daddy. "Where is my real Daddy now?" Well, he knew that Daddy was in heaven. Mary had a real hard time with that; she still does. When you're 3 , heaven is about as high as the ceiling so that's where Mary has placed it. To my knowledge, I don't think he has any bad thoughts about it. He took it very well.

He really feels that pete is looking down on him watching him from above. He's got a--Robby's got a great religious background and I can't take all the credit for it. A lot of it he has just picked up. I don't know how. He doesn't have any bad or scary feelings.

Other comments Karen made at the time about the period right after

Pete's death were

It's hard to watch a child deal with this.

[Robby's] drawing pictures of Daddy with his halo. He says he loves Daddy very much and misses him very much. He says he knows Daddy is in heaven and that's a nice place to be and he doesn't hurt anymore.

[Robby's] still got some pretty lonely feelings. I hope I'm interpreting his feeling correctly because he does, you know, he'll say, "I miss him. I wish he was back," but at the same time it's not a mad or a scary feeling. It's a fact with him.

At first my tendency was just to pick up and run. Last year I had decided I would stay in Oregon if anything happened to Pete. Now something has happened and I first wanted to go home. But that isn't really home anymore. High school girl friends wouldn't be girl friends anymore. 
Today [13 days after Pete's death] we're going to have all kinds of people in. The insurance man is coming. I've ordered a new bed for Mary.

We have not been normal for so long that we don't know what normal is. But we're trying to get a normal routine started.

I'm checking out schools. They need that. The kids are driving me crazy. They have a kind of seventh sense. It seems the more upset I am the more they act up to get my attention.

Eight months later she said, about that period of time,

And you know I don't remember anything about those first three or four months. I remember that I took the children to the coast. I don't remember what we did though. There's just big blank spots. I don't remember how we spent our evenings here or our days. Just little islands stick out in my mind.

The child takes on responsibilities, during the illness, beyond what would be expected, as seen in Karen's description of Robby's work with the wheelbarrow, his being "the man in the house." These activities undoubtedly receive recognition and certainly give the well parent a kind of unspoken support, quite different from other activities children may engage in such as "being naughty" or wetting the bed. It would be interesting to know whether the helpful behaviors and the "naughty" behaviors received different reactions from parents or whether, in the general confusion, they received similar reactions in terms of reinforcing behaviors from parents.

The well parent gives responsibilities to the children in a purposeful way as well. Ev Garrison pointed out that

The kids here, they've worked [things] out. And that's one of the things, you know, the house has to be cleaned. The kitchen has to be done, rooms need to be clean, beds need to be changed and . . . I mean, I say, "Chet... ." I mean little success things that I knew he could do, but it's really made him sometimes grow up too fast. I watch him sometimes even now, you know, sometimes he'll be six going on thirty. 
In a family where there are several children, the taking on of responsibility by any one of them may serve to bring that child closer to the remaining parent; thereby the activity undertaken may in itself become intrinsically reinforcing.

Responsibility of another kind, that in which the child sees himor herself as guilty of in some way causing the illness, may underlie these activities of helpfulness on the part of the child. The child may feel that it is necessary to repair the damage done, by doing good deeds. It seems more likely, though, that it is the parent's behavior that maintains this activity in the child.

Only one child in the study asked outright if he was responsible for his mother's return to the hospital. Part way through the illness, when Chet had jumped on Janie one day, hurting her a little, and she had to return to the hospital the next day, he asked Ev if the hospitalization was because he had hurt her. Ev was able to say that it was not his fault and to reassure him. The child's asking of questions such as, "Was it my fault?" gives the parent the chance to reassure the child.

\section{Fears}

In two of the five families, a parent had heard the 5-year-old express fears about the well parent's possible death. Those who had not heard that fear from their children, explained it in different ways. Abby said about Chris that

the main fear that he had wasn't even about dying. It was would we have money. He asked that right off the bat, so I explained to him where we were getting money and talked a little about life insurance. He would understand that.

To date, he has not expressed directly any fear about Abby's safety or possible death. 
Christine Reutter had not detected any fear in Jim and Mary Ann about John's illness when he was hospitalized last year, nor about her illness.

Diane Neether said that she had not sensed any in Terry: "'cause even nightmares that he'1l have have nothing even similarly related."

Ev Garrison, though, said that Chet had expressed the fear

a couple of times. It was more like, "Dad, what if you get in a wreck and get killed." I think more like, I mean with Chet and even with Andrea, I started with "There's no written guarantees that I'm going to be a millionaire, I'm going to be a pauper, I'm going to be a success or a failure, that I'm going to live to be 90 or a 100 or I'm going to live to be 30 , I'Il have happy love or I'll have sad love."

At night Chris would say, "What's going to happen if you get wrecked?" "Chet," I said, "Daddy's set up . . . it's a piece of paper. It's called a will. If something happened to me, you'd go to stay with Uncle and Aunt___ and, I said, "Daddy has insurance, and a couple of projects that I'm doing and there's going to be enough money so you can do whatever you want to do. You know, if you want to be a welder or if you want to be a psychiatrist, there will be dollars there so you can do that."

Karen said, in March, 1981, that Robby expressed fears about her possible death

all the time. Robby asks, "Will you die?" And I say, "Yes, we all will die," and he understands that. Mostly old people die. Robby thinks of me as old, so that's no help. But he knows my grandfather who is 84 ; so we've talked about "that's what I mean by old." And he checks in on me several times in a short period when he's playing, specially at first. And during the night, when Pete first died, he would peek in just to see if I was there. When I go out, I have to say just where, why, when I will return. I go in and wake him up when I come home. He asked, "If you die, what will happen to Mary and me?" I explained that my sister would take care of him and that was fine. He loves her.

Robby is afraid to do new things, to go places he hasn't been before. And in the car, I'm always getting lost. He'Il say, "Have you been on this road before?" 
These concerns of two 5-year-old boys, centered as they are on personal safety, could be interpreted and in a way discounted as egocentric, typical 5-year-old reactions to deprivation. It is curious, though, to note that this is a very similar question to that asked (of themselves if not of others) by older people who undergo a major loss: What will become of me?

These questions and the responses they received lead us directly to the speculation that, if the questions are answered as these were, the children will be free later to contemplate the hours and weeks surrounding these events without prohibitive terror and thereby rethink and continue to grieve in whatever new way is possible for them. Or are these answers that have to do with wills and insurance only something which make the parent feel better and simply close off more questions from the child because the language is so far above them? The tendency is to see the former as the interpretation the child makes. The child can sense that that is language that counts, that the parent has confidence in wills and insurance, and that confidence is what matters.

Karen added another aspect of this in her description of her own fears.

There's a lot of yucky feelings that go along with this. There's your own fear, your fear of losing somebody that you love, and then there's the fear that "Well, gosh, if Pete got this, who's to say that I won't or that Robby or Mary won't... . creeping into your head, and it kind of snowballs sometimes. I don't know whether that's a natural reaction or not. Kind of like watching your neighbor's house burn down and you think, "Hey, that could happen to me."

It is interesting that Karen's house had figuratively already burned down, but the next step always is, "that could yet happen to me, myself. I must reckon with the fact that I could die before I'm ready." 
The Idealized Dead Parent

The problem involving a child's idealized memory of the dead parent was mentioned spontaneously by Ev.

The biggest spin-off I can see is the "sainthood Mom!" I said to Chet, "Hey, I can remember one day I came in and there was Mom whaling you on the behind." "My Mom did... ." "My Mom didn't . . .." "Hey, she did, too!" Chet has memories and reminiscences and will speak of how "my Mom taught me how to clean cherries."

We were doing something else down on our trip and he comes up to this lady and says, "My Mom could do that better than anybody in the world."

Ev felt the children used this device in different situations and that the current one was with Elaine's cooking, stating that Elaine didn't do it right, the way Mom did.

Chris Lindstrom, Abby said, carried a little picture of a man and a boy in his velcro key holder. She said the two had their arms around each other. Chris told her, when she saw it and asked about it, that someone gave it to him, that he liked it, and had two of them. She said she wished she had given him a chance to talk then by asking him, "Do you wish Daddy was here?"

I was surprised to see them and disappointed with myself because Chris is doing so nicely. I forget that he still has thoughts. He has no outward behavior problems or anything.

Later she mentioned that

He misses not doing things with a father. Like, oh, later afternoons sometimes, when the weather's nice, he'll say, "Dad and I would probably be fishing now," this type of thing. So, he's thinking about it.

He had singled out certain traits in his father, it seems, the friendly, comradely side that he perhaps misses most. 
No one among the five families in the study mentioned a child's saying, "I wish it was you who had died, not " although a family contacted in the preliminary work did describe this. The child who does say this may sense that this is a powerful thing to say since it may bring a strong reaction. The child may also really have idealized the dead parent into someone who did not punish and whom the child would really prefer to have around.

Robby McAllister's comments about how Pete was in "heaven," was "looking down on me so I know everything's OK," or was "proud of me today when he found out what I did," described by Karen at the end of the study, would fall into this category, as well, reflecting a memory and a desire to preserve the approving happy side of his dead father.

It is not surprising that these thought processes occur: They are intrinsically reinforcing and when the child mentions them, the surviving parent probably smiles and says something encouraging and loving. The question of whether it will be startling and possibly harmful to the child if one day the child does things that cause shame or embarrassment, and then finds this image of the approving parent shattered, is a curious one. With a live parent, punishment can occur and be completed, and also the child can make explanations to a present parent. The image of the perpetuated heavenly parent may be much less manageable.

\section{PARENT}

Surviving Parent: Time Alone, Growth Possibilities, and New Relationships.

The well parent, during the illness of a spouse, became fatigued, 
angry at times and sad, and in varying degrees was aware that time alone for themselves was necessary. We have discussed interparental relations. It is interesting to look further at how the well parents looked at the necessity for privacy for themselves, at the possibilities for growth that were inherent in the situation and eventually, after the death, at being alone, and at their friendships and new relationships. Of particular interest is the influence on the child that these aspects of the well parent's life may have had.

Ev Garrison speaks of a time about a year after Janie's diagnosis that he and she felt spiritually very close. He says now, "I do miss my wife but I also miss my best friend." He went away on a trip by himself for a few days several months after Janie died.

I've taken off since. Oh, when was it? May, I think it was. I took off for a three-day weekend, just me. I was going to work everyday, taking the kids to the baby sitter, going to work, comin' out, spendin' the weekend together I just. . I don't know. Anyway when I came back, it was a neat reunion, and they were just so . . all over me you know, and I said, "Hey, what's going on?" and they said,"Oh, we missed you so, Dad!" I said, "Well, I missed you too," and I said, "You know you were right there with me, and I went over there and skipped rocks on the Columbia and you almost splashed a rock and got me wet!" 'Cause he's done that a couple of times.

The children may have been aware that he needed to get off without them. This occurs even with well parents, couples who continue, after the children are born, to make sure that they get time alone together as a pair. However, necessary as it is for the single surviving parent, it may have been hard to do.

For a few months, whenever a woman would come to the house (e.g., friend, babysitter or anybody), Andrea would ask if that lady was her Mormy . 
There was now a new friend, Elaine, a young woman: "She has some feelings about me. I have some about her." It was not clear whether she was living completely at the house. Ev reported the children were saying a lot, "I love you Elaine, I love you Elaine." He is not sure whether he and Elaine will have a permanent relationship or not, whether they may marry. He says he's talked to the children about how "when you lose your partner and your best friend you don't just go right out and find another one." But he mentioned that if this relationship is not permanent, the children will have another thing to get used to - . this lady's going away after they've gotten attached to her.

Lately, the children in Chet's class have been writing letters home from school, and Chet has just lately changed from "Dear Dad" to "Dear Dad and Elaine" to "Dear Elaine and Dad," in starting his letters. Chet said to the counselor that it was lonesome in the afternoons without his Mom. Elaine, Ev says, was hurt at that. "I'm there," she said. Ev told her not to let it get her down, that Chet was very close to his Mom and loved her very much.

Abby Lindstrom, in speaking of her own life as a young woman newly widowed, spoke of her own feelings and her friends' attitudes. She had had a "few bad nights" just before the conversation and said she'd had trouble sleeping. She had started taking two seminars at the nearby community college and had found most of the women in the class bitter, divorced, down on men. "I felt like a displaced person. I feel terrific about myself, I had an excellent marriage and I love men! My feelings towards myself were different." 
She said she found it difficult to listen to long complaints from other people. "I could never be a counselor! I would just say, 'stow it." In a later interview she mentioned that a friend had called her describing a woman whose husband had left her ten years ago and who is now

running four branches of an escrow company and on and on and on and on: She went to PCC, she took classes... I'm getting guilt camplexes because my friends will call . . . "What are you doing?" "Well, gee I'm getting ready to go to Hawaii--uhhh ..." "We1l, what classes are you taking?" "Oh, I didn't want to take any this term. Uh."

That's just not for me. And I have the opportunity to get out and conquer the world but I don't know--that's just not for me right now. You know, I can't say that I'm a career person. I like to be busy. I like to get things going and then do something else, and someone told me one time that was the sign of insecurity!

Abby went on to talk about the widow's group she had started.

We're all so different. Some of them really get on my nerves because they handle it differently than $I$ do, and I don't necessarily agree with them, but that's not wrong for them. That's how they have to do it. I'm bored with it. . . urmm ---but, you know, it's a necessity for a lot of people. I don't enjoy sitting around with that type of thing. I would prefer to go out and do fun things--go bowling or a movie or whatever. But again, see that's--I like to get on with things. I don't like to dwell on it. I think it's nice to form a friendship and then if that is in common, that's sad, but then it is in common. But I don't like to have that in common the main thing. I don't form friendships because that is - . something you have in common and I don't think they should either... I don't think they should hang on to that. I think they should just.. . "I'm single now and it was awful, and I didn't like it.. . but you know, tomorrow is coming."

Like many young women now, the new widow may be under unusual

pressure to have a career.

I think people, acquaintances especially as well as friends, tend to expect a lot of me because . . . now George has died - . now had George been alive they thought nothing of me being a homemaker, but because he has died--and I think this happens to a lot of widows--people expect them to get 
out and do things. And it's not that I'm not capable. It's just that I'm not very ambitious [laughs]. I love a challenge . . . and this fall I will probably get a job, but it will be a job that will end before Christmas. You know, to me that's great--and then I'Il have some free time. But in a while, I'll amount to something. I just know it. [laughs]. But, you know, being a widow, even if I had three children, no one would think anything of me being home, but because I have this gorgeous child who is so easy: "Why don't you do something?" But again see, that's my hang up, I feel guilty 'cause I'm not doing something, I'm sure, too.

Abby and Chris took a trip to Disneyland in the spring. As of the end of the study they were about to take a weekend mountain trip with friends, and then Abby was planning to go to Hawaii for ten days by herself.

During Pete's illness, Karen found that she could get out of the house occasionally and knew it was good to do. She let Auntie Fran keep the children and Pete for a bit sometimes but said, in May,

I feel guilty. And I don't stay very long. I have this impression, because pete is so fussy, that I'm the only one who can do things right for him. But it's good to get out for a little. I wish I was more than one person. At the hospital, I want to be with Pete and I want to be with the kids and I just want us to all be together!

She then went on to say, in June,

I'm doing his shots now. I just finished a course of chemo for him Friday. I'm not the dummy I thought I was. I'm just doing things I never thought I could do. I mixed his medicine, his IV, even though they [the home care nurses] were not thrilled with it. The chest tube is draining a lot; the dressing change I can do.

She spoke of how "all these years" she'd "gone along with the line that mothers can't do anything but make peanut butter and jelly sandwiches. Late, in November, four months after Pete had died, she said, "All those 12 years, I was a Dresden doll that Pete put on the shelf; he'd take me down and play with me and then put me back." 
She had been "mousey;" she said and had dusted, cleaned house, and cooked superlatively because Pete demanded it, and now she was finding that of herself and Pete's twin, Richard, she was the stronger of the two. Richard was angry that she slept so little at night "but he's the one who has black circles [gesture] under his eyes." She said she slept three to four hours a night. "A friend called last night at about $120^{\prime}$ clock and we talked for four hours."

Eight months after Pete's death, when asked what kind of a frame of mind Richard, Pete's twin, was in, she said,

You know, I really don't know. He doesn't come around anymore. I've only talked to him twice since I got back from the [midwest]. And he just stays away, which is hard on the kids. [They ask about him] often. Fran stays in a little more contact with him than I do, and according to Fran, he's been having nightmares and problems dealing with the situation--and, of course, with [his wife] being gone he's sort of carrying it all himself. And his health has sort of gone downhill, too. He has an ulcer and [not clear]. He keeps everything inside and I just wish he'd come over and if he wants to get mad or if he wants to cry, I wish he would do it--at me or with me. He can't. I guess everybody has to work it out in their own way but I feel real bad. I can understand how he feels. I mean Pete and he were like this [intertwined first two fingers]. They're not separate. I mean they were basically one person, and now he's lost that half and his best friend and his brother. I know that Richard's concerned about his own physical well-being. His aunt had melanoma. And their Aunt susie has had one lung removed and has skin cancer. And then their grandmother had leukemia. And he's feeling--now he hasn't come right out and said it but I'm sure that's what's going through his head.

During the third and fourth months after Pete's death, Richard

had been angry about Karen's dating.

He's been polite but icy. He doesn't think. I'm mourning enough. I did my mourning all those 18 months. I'm not going to just weep and sit around.

A month later she reported that Robby had been obstreperous lately and hitting his sister. Robby said [about Ben, the man Karen is now 
dating), "Ben is old and he has a mom. So does that mean when I'm old you'll still be here?"

It is interesting that Robby voices indirectly here a worry about Karen's possible death but words it in connection with a person she is dating.

Karen mentioned that privacy was hard to come by. She reported that "Mom's bedroom becomes the gathering place for everybody, cats, kids . . " but added "I still do keep Wednesdays for myself. I get out all day, away from the kids." Again, at the later interview, she reiterated her desire to be a person in her own right.

I don't want to be classified as a widow. I'm not a widow. I'm still me. I mean, it's just that I'm not altogether what I used to be. I don't like that classification of widow. You know, a widow is somebody who's 85 and all wrinkled and grey and a widow's not somebody who's young.

She looked into groups for single parents.

There's "Parents Without Partners" but that's for divorced people, and in most of the widow/widower groups that I've encountered there are still older people--not people with young children. There's a big gap. So, I don't know but anyway.

At first she said, "I felt like a third wheel."

I'm not single. I'm not married. I wasn't sure how my class would be. I've made new friends, Joan; it's just great! Mary's birthday is tomorrow and I have to come home to get ready for that.

Later, when asked about what friends were most help currently, she stated,

There are no friends. Fran has been great. Sue was great. She's moving away. "Our" friends don't come; pete's friends don't come. I've called some of them and asked them for supper, but I can't keep doing that. They don't reciprocate. They find excuses. My new friends who only know me as I am now are the fxiends I count on most now. 
And she had been writing a lot and had kept a journal, "written

a lot of poems about Pete,--no, not poems really. They're more prose." She said, "That's been a tremendous help."

Some divorced friends had said, "You're lucky. It's better to have somebody dead than be divorced." "That hurts," she said. Of Richard and his wife, who had separated, she added, in the interview at the end of the study,

They are separated. She moved out in october, is living in a separate house. He's got [their daughter] in the house. It's working out for them. I don't understand--of course, I get real upset 'cause I feel they're giving up something that I wanted. I get real angry with them, you know, I mean not outwardly but, because they're throwing away something that I wanted and couldn't keep so--but it's working out for them. They're real good friends.

The complicated circumstances that these statements reveal, the uncle who used to be close and jolly and a frequent visitor and who now no longer is, the mother who is feeling herself emerge as quite a different person than she had been, a new set of adult friends introduced into the family life, all are factors that touch the child in this family very directly. The sense the researcher gathered in the telephone interviews and in the home visit was that there was a very equal balance between concern for the child's welfare and the young woman's concern for her own well-being.

Overall, in these three families, there seems to have been a long period of adjustment to the changing family structure. It started during the illness when the ill parent's capabilities and authority began to wane, the well parent discovered sometimes unsuspected strengths, and the child had to adapt gradually to all the shifts implied in these transitions. The adjustment continued into the period after the death 
with departures of certain adult family friends, arrivals on the family scene of new and different friends corresponding to the new interests and self-discoveries of the surviving parent.

Whether the child felt redundant in this changing picture was never clearly apparent in any of the families. It would be surprising if some of the children had not occasionally had a glimpse of the other side of the coin: one side says, "I don't know what I would have done without the children." The other may at least fleetingly say, "If I didn't have the children, my life would be so much simpler."

\section{Recommendations to Others}

The question of what they as parents would recommend that others say and do with their children when they were going through this same experience brought responses that centered mainly on love and honesty.

Ev's words, over a period including several different conversations, were

Oh, yeah. I think the biggest thing you've gotta do . . . I think a word I haven't really used a lot is love. That's what makes it all . . love and a positive attitude. I'm still not through thinkin' it over.

And I think probably one of the biggest things I learned - . We have one day to live at a time. I had these big plans for my life and I had big plans for my lady. our plans have been either delayed or altered, or I've started to change my mind. Maybe I don't want to do what I wanted to do back then. You've got to love each other.

Abby said,

I don't think I could tell them anything other than to be honest and not pretend that nothing is wrong. Because that's my personality. I want to know what is happening and when. But I don't think anyone could handle that the same way. It again is a personality thing. In speaking with someone whose son faced death.. . that person didn't want to know. Now see with George, every year I needed a brain scan to find out. 
So I think as far as the children are concerned, they need to know. I don't think that should be hidden from them if they're old enough to see and to understand. And, I mean, even 3 years old, you know.

Karen said, briefly, "Just be open and honest with them and give them a lot of love." Christine, whose disease is in remission and whose children do not know, as far as she can tell, that she has cancer, said,

It's different for different children. Just reassure them that everything's going to be all right. 'Course when they see that you're not all right. . . !

The family's aim may be to reassure children, but not falsely, and the line may be hard to draw. Diane Neether advised, Well, I think probably to be open and honest, you know as much as they can handle, but there's no point in sitting them down and giving them a father to son or whatever talk if they're not going to be able to handle it, because they're going to digest or ingest a lot of things just through a process of osmosis. And I think basically just let them know that they're loved, and they're still wanted and that they're loved.

I think we don't give credit, as much credit to what children understand and what they can handle. And life goes on for them. I don't think there's as long a healing process.

The tacit recognition that children understand a great deal of what may seem to adults to be beyond their ken is an appropriate way to end these statements. That children deserve credit for some complexity of understanding and for the ability to prevail is a good stepping-stone into the nature of what Diane calls "the healing process," the long continuation of the adaptation that will go on for the rest of their lives. 
CHAPTER VI

\section{DISCUSSION}

In conclusion, we will first review some of the difficulties and unavoidable problems that arose in the study, both from the nature of the question and from the methods chosen to study the question. Subsequently, we will review a few aspects of the data that deserve special attention.

Factors that limit generalizability of these data start with the small size of the sample. Within the sample, too, there was variability as to place of care and place of death, length of time since diagnosis, family constellation, and sex of child in relation to sex of parent. However, all three children whose parents died were boys who experienced extended periods during which care was given at home and could therefore witness the increasing physical disability and deterioration of the parent during illness. The ill parent, the person who had been "in charge," strong, the person on whom the child had depended for love and support, play and structure became weak, out of control, physically disfigured.

There is good reason to suppose that these children who saw the parent's disability increase may have found the death congruent with the perceived inability of the parent to live, and may therefore have attached less mystery and misplaced blame to the occurrence than a child who was not close to the care. We also, however, can conclude from these data that seeing a parent disfigured and disabled had some 
aversive, fearful qualities for the child.

A subsidiary aim beyond the main purpose of this study is to bring to light the adequacies and weaknesses of a method that combines informal participant observation, interview, and telephone conversation in creating an accurate picture of the child in relation to parent illness and death. The chief source remained, throughout the study, the parent's account. In the cases of Families 4 and 5 , the interviewee and main contact was the ill parent. In Families 1, 2, and 3, the well parent was the interviewee and main contact.

The participant observations, informal visits in one case over a period of time, accomplished one chief aim. Since the researcher could observe the child firsthand, could see the physical setting in which the child functioned and could meet some other members of the family, the general setting and the tone of the family were made clear. Overall, this information provided a touchstone to which the parent's accounts could be referred to test their validity, and the method is seen as a useful method of gathering data.

The informal visits also provided a chance to talk directly with the child, although this was never done through a formal interview. One school visit was done as a participant observation, not in a regular school session, but at a back-to-school night with the whole family. The school visit in Family 5 was done as a non-participant observation; it also yielded data that contributed to the overall picture of the child's general behavior.

One unavoidable problem arose in that the asking of a particular question by the researcher or the presence of the new person in the home (i.e., the observer), may have introduced to the parent ideas for 
behaviors or areas of concern which he or she might not otherwise have had or may have altered the character of the family interactions. Some alteration might have been possible following any interview. As to the participant observer effect, it was diminished as far as possible by the stipulations outlined in the Method section and also by the fact that the observer had had experience for many years in work and play with children and families and did not feel constrained. Both of these possible alterations, moreover, were seen as a constant investigative problem and one that would apply to all subjects equally. The mere fact that a family had been asked to and had consented to participate in the study presents the same type of possible alteration to some degree. In examining the effects of being included in a study and, in another case, the effects of a single initial interaction between a therapist and a patient, we may gain another insight into the effects of the interactions between this researcher and subject families.

Levinson (1978) found in working with couples in therapy that there was a significant alteration in the behavior of the couples caused by the initial contact and observation. In another study (Malan, Heath, Bacal, \& Balfour, 1975), it was found that what had been considered spontaneous improvement of 11 neurotic patients who had not undergone treatment, but had had one single interview, was actually partly the result of that interview. Followup interviews were done 2 to 11 years after the initial one, and it was concluded that major changes had occurred which the patients attributed largely to the effects of the initial interview. Inclusion in the study, then, can be seen as a modifying factor for all the families. It is a moot point though as to whether the participant observations had any greater effect than an interview or a 
telephone conversation.

To ask families to participate in a study as part of a control group, giving some fictitious rationale for the study, would present serious ethical problems, particularly given the emotional and stressful situation the families were in (Koocher, 1974).

The unpredictable nature of cancer means that families were in certain suspense which was difficult to handle. This suspense or uncertainty was in fact a variable in the child's surrounding and part of the question under study. The unpredictability of the disease meant that although the aim was to observe the child before and after the death of the parent, this was not always possible: In one case, the picture of the period before the death was given entirely by telephone; the meeting with the surviving parent and the child occurred only after the death. In another, the researcher met with the well parent before the death but with the child only afterwards. The use of the telephone was unusual in that, other than in telephone questionnaires, the instrument is not usually thought of as a useful one for research. Repeatedly in this study, however, it served to relay to the researcher long, spontaneous accounts of events in the home, at times when a visit might have placed undue burdens on the family. In future work of this kind, it might be helpful to obtain permission from the families to tape these conversations so that they could be included as verbatim accounts, rather than forcing the researcher to paraphrase in cases where it was impossible to write fast enough.

Another limitation was that the child's behavior before the illness could only be known through retrospective account. Short of studying a large group of children from birth in some sort of general 
survey, one cannot expect to have any firsthand pre-iliness data on children of cancer patients other than by chance. It may be a next step in a long range studies aimed at preventive therapy to gather data on large groups of children in schools, for instance, based on the probability that a certain percentage of their parents will undergo serious illness and death.

Other problems arise from a desire to protect the child from added worry, very much the way parents avoid talking with their children about impending death. There was a possible bias caused by not wanting to ask children questions beyond what the parents indicated they had already talked about. This added another dimension to the participant observer problem. It was felt to be sufficient and proper for this study to accept, as a major part of the body of data, quotes, transmitted by the parent, of statements and questions the child had voiced. As we have seen here, children at the age of 5 to 8 years do talk directly about the death of a parent, but not necessarily to a short term acquaintance. It is much more likely to occur spontaneously, over a long period of weeks and months, to the adults who happen to be present, while the child is putting on a coat, getting ready for bed, washing the dishes, or getting off the toilet. Unless the researcher is in a position to be present over that long a period on a 24-hour-aday, seven-days-a-week basis, he or she must accept secondhand accounts and risk inadvertent distortion by the parent.

We felt there were some areas where it was more likely than others that distortion would occur. For instance, the parents of Chet, Chris and Robby, in speaking of how "well" the boys were doing, could be voicing their own hopes as facts, wanting the boys to support their own 
determination to do well, to be hopeful. They also, however, cited instances when the boys were angry, wept, had problems in school. It seemed, based on firsthand observation of the children, that the picture of a wide range of behaviors was accurate, and that the boys were doing well. The exact quotes from the parents upheld the claim that the boys spoke openly about the parent's death and about their sadness, a start in what should be a continuing chain of recollection and increased understanding.

Rather than try to generalize, we will look at a few aspects of these data that stand out. We will leave the rest to create their own conclusions in the reader.

In some ways, these are portraits, albeit stratified by topic, of the experiences of five different children. Just as one would not deaden the impact of several painted portraits by stating that they each have a nose, two ears, one is done from the right, four from the left, ad infinitum, we will make a minimum of generalizations or groupings from the data. More than that would only serve to take away the force of the individual voices, the vividness of the personalities of the parents and the children.

It is revealing though to look at some aspects of the nature of the data. There are interesting qualities about one-point-of-view descriptions. The reader can speculate on the other parts of the iceberg. For example, the well parent's comments on interaction with in-laws can only leave us to wonder what the in-laws were feeling. In two cases, it was their son who was dying. They may indeed not have been able to handle it very well. They may have felt angry or sad at being excluded. The important point for us is, however, that this 
conflict existed and that it was an element in the child's experience. It is not for us to call "foul" in either direction, even if we could. This leads us to another question: How much noticed by a child was any one factor? How high a profile did it have on the child's horizon? Some of the determiners may have depended on the timing of emotional outbursts, the loudness and intensity of the conversation overheard, and the acuteness, for instance, of the tension between the parents. Did competing behaviors in the child, i.e., playing outside with friends, listening to and watching television, cause the child not to hear or notice events occurring in the home?

In some instances, we know events were noticed, such as the child's being gotten out of bed and hurried to the hospital in the midale of the night. We know when a child commented or asked a question about a scar that it was noticed. But there may have been other instances where the specifics of the situation were lost to the child and only the mood or unspecific tension was apparent.

We can be sure that at least major parts of the actual giving of care by the well parent were noticed by the child. It has been suggested, (Virginia Sponsler, in conversation), that witnessing the well parent giving care in the home may have been important for the child in that the child saw that the well parent worked hard, did the best he or she could. This may lead the child not to place blame on the well parent for the death of the ill parent. It could, of course, have the reverse effect: "You did all those things and they must have been the wrong things since they didn't keep from dying." It would seem that the verbal explanations of the progress of the disease that were given by these parents were likely to make the inevitability of death 
more nearly comprehensible to the child, and the care given by the well parent seem sufficient.

Fears voiced by children ranged from fears about the surviving parents' safety to fears about financial security, all rooted probably in the child's concern over personal security. It is interesting that all the parents confronted with these fears chose to use reassurances that included legal or financial terms such as "wills," "pieces of paper that say . . .," "insurance," "Social Security," as well as assurances that people the children knew would take care of them if anything happened to the surviving parent. What these legal reassurances meant to the children is hard to know. Two parents said directly that their deaths were possible, with the emphasis that even then the child would survive. There is a certain strong credibility in these reassurances since they come from young parents who did, perhaps, take joy and health for granted once, who have experienced "the unthinkable," and who have survived, are all right, as the child can clearly see. The child who voiced the fear "What will happen if Mom gets another tumor?" heard that same strength: The family would stick together and do the best they could.

In all five families, we saw high hopes and demands for excellence in the children on the part of the parent, sometimes in extremes. One child speaks of his mother's wanting him to get all A's in school. In another family, the child prays that he will be a nice person, one that people like to be around. One little boy, when we were talking about a school that had a system whereby each student wrote his or her own report, said, "I'd say, 'I'm perfect."" He laughed as he said it. He may like many of us have seen the ridiculousness of ever expecting to be 
perfect, but also may have felt the desirability of not being pushed too hard to meet others' expectations and our own.

The demands placed on the child by the surviving parent may rise after the death of one parent. But it is also possible that that is not an appreciable change brought on by the death. High expectations are evident in the two families in this study where the ill parent is still living. There may have been high pressure to excel all along on all members of the family. This striving for excellence shows itself in the determination of the three couples in which one died to accomplish the work of caring for the ill person in a way that accorded with agreements the two parents had reached early in the illness. They had already reached agreements, too, on how they would talk to the children. These goals were high and explicit: What they would tell the children would be truthful; they would aim for autonomy for as long as possible. The goals are indicated by the Reutter and Neether mothers, too, as ones they would pursue if and when they came closer to death.

It is possible these pressures are related to a child's difficulties in school or to a child's always wanting to be right. They are, however, part of a broad spectrum of behaviors on the part of the parent in relation to the child, and not necessarily dependent on the occurrence of the death of a parent.

There was a difference in the amount of time the Garrisons and Lindstroms had to attain their goals, as opposed to the McAllisters who were pushed by the speed with which the disease progressed. The McAllisters could just barely stay ahead of it in their abilities to agree, to take in fully what was going on. 
Whatever the amount of time, whether it is many years as it has been for Christine, with a minimum of visibility of the disease for the children, or whether it is only months with dramatic and rapid changes as it was for the McAllisters, the period can be seen as a continuum, all of which will form the basis for the child's future recollection and increased understanding. The post-death time, separated from the illness time only by a moment of realization, has differences in that the ill parent is no longer there, the surviving parent's emotional states may vary in different ways, the routines of the day have changed. But it is part of the same continuum, one long event sequence which the growing child will view in a certain way at the age of 10 , in another way at 25 and yet another at 50 , as life experiences shape and reshape the viewing. 


\section{BIBLIOGRAPHY}

Agree, R. H., \& Ackerman, N. J. Why children must mourn. Marriage, 1973, LV, 55-59.

Anthony E. J., \& Koupernik, C. (Eds.). The child in his family. Vol. I, The impact of disease and death. New York: Wiley, 1973.

Anthony, S. The discovery of death in childhood and after. New York: Basic Books, 1972. (Originally published as The child's discovery of death: A study in child psychology. Keegan, Paul, Trench, Trubner \& Company, 1940.)

Archibald, H., Bell, D., Millex, C., \& Tuddenhar, R. Bereavement in childhood and adult psychiatric disturbance. Psychosomatic Medicine, 1962, 24, 343-351.

Arnaud, S. Some psychological characteristics of children of multiple sclerotics. Psychosomatic Medicine, 1959, 21, 8-15.

Astrachan, M. Management of a staff death in a children's institution. Child Welfare, 1977, LVI (6), 380-386.

Atwood, G. The loss of a loved parent and the origin of salvation fantasies. Psychotherapy: Theory, research, and practice, $1974,11,256-258$.

Bain, A. The capacity of families to cope with transitions: A theoretical essay. Human Relations, 1970, 31, 675-688.

Barnes, M. J. Reactions to the death of a mother. Psychoanalytic Study of the Child, 1964, 19, 334-357.

Bauer, D. Developmental changes in children's fears. Journal of child psychology and psychiatry, 1976, 17(1), 69-73.

Beck, A. T., Sethi, B. B., \& Tuthill, R. W. Childhood bereavement and adult depression. Archives of General Psychiatry, 1963, 9, 295302.

Becker, D., \& Margolin, F. How surviving parents handled their young children's adaptation to 10ss. American Journal of OrthoPsychiatry, 1967, 37, 753-757.

Becker, H. S., \& Geer, B. Participant observation and interviewing: A comparison. In W. J. Filstead ( $E d$.$) , Qualitative Methodology.$ Chicago: Markham Publishing Co., 1970. 
Bendiksen, R., \& Fulton, R. Death and the child: An anterospective test of the childhood bereavement and later behavior disorders hypothesis. OMEGA, 1975, 6, 45-59.

Benoliel, J. Q., \& McCorkle, R. A holistic approach to terminal iliness. Cancer Nursing, 1, 2, 1978, 143-149.

Bertman, s. The arts: A source of comfort and insight for children who are learning about death. OMEGA, 1979, 10(2), 147-162.

Blum, A. H. Children's conceptions of death and an afterlife. Dissertation Abstracts, 1960, 36(10-B), 5248.

Bok, S. Iying: Moral choice in public and private life. New York: Pantheon Books, 1978.

Bowlby, J. Grief and mourning in infancy and early childhood. Psychoanalytic study of the Child, 1960, 15, 220-239.

Bowlby, J. Childhood mourning and its implications for psychiatry. American Journal of Psychiatry, 1961, 118, 481-498.

Bowlby, J. Pathological mourning and childhood mourning. Journal of the American Psychoanalytic Association, $1963,11, \overline{500-541}$.

Brent, s. Puns, metaphors, and misunderstandings in a child's perception of death. OMEGA, 1978, $8,289-294$.

Britchnell, J. The possible consequences of early parent death. British Journal of Medical Psychology, 1969, 42, 1-12.

Bugen, I. Human grief: A model for prediction and intervention. American Journal of Orthopsychiatry, 1977, 47, 196-206.

Caplan, G. An approach to community health. Iondon: Tavistock Publications, 1961.

Caine, I. Widow. New York: Macmillan, 1974.

Coles, R. Children of crisis: A study of courage and fear, migrants, sharecroppers, and mountaineers, Vol. II, Children of crisis. Boston: Little Brown \& Company, 1967.

Crook, T., \& Eliot, J. Parental death during childhood and adult depression: A critical preview of the literature. Psychological Bulletin, 1980, $87(2), 252-259$.

de Beauvoir, S. A very easy death. New York: G. P. Putnam \& Sons, 1966.

Deutsch, H. Absence of grief. Psychoanalytic quarterly, 1937, $\underline{6}$, $12-22$. 
Eliot, T. D. Bereavement: Inevitable but not insurmountable. In H. Becker \& R. Hill (Eds.), Family, marriage and parenthood. Boston: Heath, 1955.

Erikson, E. Identity: Youth and crisis. Iondon: Faber and Faber, 1968.

Fassler, J. Helping children cope. New York: MacMillan, 1978.

Ferguson, F. Children's cognitive discovery of death. Journal of the Association for the Care of Children in Hospitals, 1978, 7(1), 8-14.

Filstead, w. J. (Ed.). Qualitative methodology. Chicago: Markham Publishing Company, 1970.

Flavell, J. H. Cognitive development. Englewood Cliffs, N. J.: Prentice Hall, 1977.

Fleming, J., Altschul, S., Zielinski, V., \& Forman, M. The influence of parent loss in childhood on personality and ego structure. Paper presented at meetings of the American Psychoanalytic Association, May, 1958.

Freud, A. About losing and being lost. Abstract in International Journal of Psychoanalysis, $1954,35,283$.

Fulton, R., \& Gottesman, D. J. Anticipatory grief: A psychosocial concept reconsidered. British Journal of Psychiatry, 1980, $137,45-54$.

Furman, E. A child's parent dies. New Haven, Conn.: Yale University press, 1974 .

Furman, E. Helping children cope with death. Young Children, 1978, $\underline{33}(4), 25-32$.

Furman, R. A. The child's reaction to death in the family. In B. Schoenberg, et al., (Eds.), Loss and grief: Psychological management in medical practice. New York: Columbia University Press, 1970.

Furman, R. A. Death of a six year old's monther during his analysis. Psychoanalytic study of the Child, 1974, 19, 377-397.

Gottsegen, M. G. Management of mourning of a dead or dying parent. American Journal of Psychotherapy, 1977, XXXI-I, 36-40.

Gregory, J. Anterospective data following childhood loss of a parent. Archives of General Psychiatry, 1965, 13, 99-109.

Grollman, E. Explaining death to children. Boston: Beacon Press, 1967. 
Grollman, E. Talking about death: A dialogue between parent and child. Boston: Beacon Press, 1976.

Hagin, R. A., \& Corwin, C. G. Bereaved children. Journal of Clinical Child Psychology, 1974, $3(2), 39-41$.

Hansen, $Y$. Development of the concept of death: Cognitive aspects. Dissertation Abstracts, 1973, 34 (2-B), 853.

Hare, E., \& Shaw, G. A study in family health: A comparison of the health of fathers and mothers and children. British Journal of Psychiatry, 1967, 11, 467 .

Harris, M. The complexity of mental pain seen in a six year old following sudden bereavement. Journal of Child Psycho-Therapy, 1973, $\underline{3}(3), 35-45$.

Henry, J. Pathways to madness. New York: Random House, 1965.

Hilgard, J. R., Newman, M. F., \& Fisk, F. Strength of adult ego following childhood bereavement. American Journal of Orthopsychiatry, $1960,30,788-798$.

Hine, V. Dying at home: Can families cope? OMEGA, 1979-80, 10(2), 175-187.

Hoffman, Y. Learning about death in a preschool. Review, 1974, Cleveland AEYC, 15-17.

Inhelder, B., \& Piaget, J. The growth of logical thinking from childhood to adolescence. New York: Basic Books, 1958.

Jackson, E. N. Telling a child about death. New York: Channel Press, 1965.

Kaffman, M., \& Elizur, E. Children's bereavement following death of the father. International Journal of Family Therapy, 1979, 1 (3), 203-229.

Kastenbaum, R. Childhood: The kingdom where creatures die. Journal of Clinical Child Psychology, 1974, 3, 11-14.

Klein, M. Mourning and its relation to manic depressive states. Contributions to Psychoanalysis 1921-1940. Iondon: Hogarth Press, 1948.

Kliman, G. The psychological emergencies of childhood. New York: Grune and stratton, 1968.

Kohlberg, L. Moral stages and moralization. In T. Tickona (Ed.), Moral Development and Behavior. New York: Holt, Rinehart, Winston, 1976. 
Koocher, G. P. Childhood death and cognitive development. Developmental Psychology, 1973, $\underline{9}(3), 369-375$.

Koocher, G. P. Conversations with children about death: Ethical considerations in research. Journal of Clinical Child Psychology, $1974,3(2), 19-21$.

Kubler-Ross, E. On death and dying. New York: MacMillan, 1969.

Kubler-Ross, E. The languages of dying. Journal of Clinical Child Psychology, 1974, 3(2), 22-24.

Kutscher, A. H. Caring for the dying patient and his family. New York: Health Services Publishing Corporation, 1973.

Langmeier, J., \& Matejcek, Z. Psychological deprivation in childhood. New York: John Wiley \& Sons, 1968.

LeShan, E. Learning to say goodbye. New York: Avon Books, 1976.

Ievinson, D. J. The seasons of a man's life. New York: Knopf, 1978.

Lewis, 0. A death in the Sanchez family. New York: Random House, 1969.

Lindemann, E. The symptomatology and management of acute grief. American Journal of Psychiatry, 1944, 101, 141-148.

MacDonald, M. Helping children to understand death: An experience with death in a nursery school. Journal of Nursery Education, $1963,19,19-25$.

Malan, D. H., Heath, E. S., Bacal, H. A., \& Balfour, F. H. G. Psychodynamic changes in untreated neurotic patients. Archives of General Psychiatry, 1975, 32(1), 110-126.

Maurer, A. Intimations of mortality. Journal of Clinical Child Psychology, 1974, $3(2), 14-17$.

Melges, F. T., \& DeMaso, D. R. Grief-resolution therapy: Reliving, revising, and revisiting. American Journal of Psychotherapy, $1981,34(1), 51-61$.

Menig-Peterson, C. , \& McCabe, A. Children talk about death. OMEGA: Journal of Death and Dying, $1978, \underline{8}(4), 305-317$.

Miller, J. Children's reactions to the death of a parent: A review of the psychoanalytic literature. Journal of the American Psychoanalytic Association, 1971, 19, 697-719.

Minklex, M., \& Biller, R. Role shock: Stresses accompanying disxuptive role transitions. Human Relations, 1979, 32, 125-140. 
Mitchell, M. E. The child's attitude toward death. New York: Schocken Books, 1967.

Moss, S., \& Moss, M. Separation as a death experience. Child Psychiatry and Human Development, 1973,3 (3), 187-194.

Nagera, H. Children's reactions to the death of important objects: A developmental approach. Psychoanalytic Study of the Child, $1970,25,360-400$.

Nagy, M. H. The child's view of death. In H. Feifel (Ed.), The meaning of death. New York: McGraw Hill, 1959.

Parkes, C. M. Bereavement. New York: International University Press, 1973.

Patterson, J. Children, death and dying: An annotated bibliography. Catalog of Selected Documents in Psychology, 1979, 9, SS, MS 1876.

Patton, M. Q. Qualitative evaluation methods. Beverly Hills: Sage Publications, 1980 .

Piaget, J. Judgment and reasoning in the child. New York: Harcourt, Brace, 1928 .

Pincus, I. Death and the family. Iondon: Faber and Faber, 1974.

Ramsay, R. W. Behavioural approaches to bereavement. Behavior Research and Therapy, 1977, 15, 131-135.

Reed, E. I. Helping children with the mystery of death. Nashville, Tennessee: Abingdon Press, 1970.

Roy, A. Parental loss in childhood and onset of manic depressive illness. British Journal of Psychiatry, 1980, 136, 86-88.

Rutter, M. Children of sick parents. Maudsley Monograph. Oxford: Oxford University Press, 1966.

Schlesinger, B. The one parent family. Toronto: University of Toronto Press, 1969.

Schnathorst, S. Sudden infant death syndrome. Waverly, Iowa: Iowa Guild for Infant Survival, 1976. (Pamphlet)

Schoenberg, B., Pettit, H., Carr, A., \& Goldberg, M. R. (Eds.). Teaching psychosocial aspects of patient care. New York: Columbia University Press, 1968.

Schoenberg, B., Carr, A. C., Peretz, D., \& Kutscher, A. H. (Eds.). Ioss and grief. New York: Columbia University Press, 1973. 
Schor, A. Acute grief in adulthood: Toward a cognitive model of normal and pathological mourning. Dissertation Abstracts, 1974, 35(5-B), 2447.

Schowalter, J. E. Parent death and child bereavement. In B. Schoenberg, I. Gerber, A. Wiener, \& L. Kutscher (Eds.), Bereavement: Its psychosocial aspects. New York: Columbia University Press, 1975.

Schulz, R. The psychology of death, dying, and bereavement. Reading, Mass.: Addison-Wesley, 1978.

Sheets, s. Children and dying. New York: Health Sciences Publishing company, 1974 .

Sponslex, V., Ph.D., Psychologist, Portland, Oregon. Personal communication, 1980.

Toomin, M. K. Counseling needs of the child of divorce. In J. Cull \& R. Hardy (Eds.), Deciding on divorce. Springfield, Illinois: Charles C. Thomas, 1974 .

Torrie, A. When children grieve. CRUSE, National Association for Widows and their Children. Richmond: Surrey, 1978.

Vachon, M. L. S., Formo, A., Freedman, K., Lyall, W. A. L., Rogers, J., \& Freeman, J. J. Stress reactions to bereavement. Essence, $1976,23-33$.

Vachon, M. L. S., Formo, A., Freedman, K., Lyall, W. A. L., Rogers, J., \& Freeman, J. The final illness in cancer: The widow's perspective. Canadian Medical Association Journal, 1977, 117, 11511154.

Whitehead, L. Sex differences in children's responses to family stress: A re-evaluation. Journal of Child Psychology and Psychiatry and Allied Disciplines, 1979, 20(3), 247-254.

Wigginton, E. (Ed). The foxfire book. Garden City, New Jersey: Doubleday (Anchor Books), 1972.

wolfenstein, M. Effects on adults of object loss in the first five years. Journal of American Psychoanalytic Association, 1976, $24(3), 659-668$.

Wolff, S. Children under stress. London: Penguin Books, 1969.

Wolfson, R. A time to speak. In B. Schoenberg \& L. Kutscher (Eds.), Bereavement: Its psychosocial aspects. New York: Columbia University Press, 1975.

Zeligs, R. Children's experience with death. Springfield, Illinois: Charles C. Thomas Publishing Company, 1974. 


\section{APPENDICES}


PARENT INTERVIEN: Version for III Parent, Families 4 and 5.

(Wording varied according to whether the interviewer was talking with the well parent, the ill parent, or the single surviving parent. Personal pronouns and tenses were different.)

I'd like to ask you a few questions to help me understand better what's involved for children in families where one parent has cancer. If you think of ideas or problems that I don't touch on, you just bring them up yourself if you want to.

1. How do you think the fact that you are ill has affected (child) most noticeably?

2. What particular situations do you recall in which you've discussed the illness with them? (PROBE: and what was said?)

3. Do either you or (spouse) find it easier to talk with (child) about the illness, and answer questions? (PROBE: in what ways do you handle it differently?)

4. What do you see as any evidence that (child) has had fears? (PROBE: When you've been in the hospital, when you've been actively sick?)

5. How have you handled those fears?

6. What are some of the things that get in the way of your handing this the way you'd like to?

7. What particular strains between the two of you do you notice, that seem to be because of the illness, that affect (child)?

8. How do you see the effects showing in (child)?

9. In what ways have particular friends or other people been a help as regards the children?

10. (If child is in school...) what effect has school had in helping (child) cope with your illness, if any?

11. What has (child) said about your illness when describing it to someone else?

12. Has (child) ever mentioned fear of your dying?

13. Let's think of the routines or special events that have been thrown off or maybe canceled because of your illness. Would you describe what happened and what you feel the consequences were for (child)?

14. What differences do you see for children between a situation where the father is ill and one where the mother is ill?

15. If you had a couple of families to advise about how to help their children when one of the parents has cancer, what would be the first most important things you'd tell them? 


\section{Appendix I}

Continued.

Adaitional questions in Families 1,2 , and $3 . *$

(In families where one parent had died, additional questions were asked either in the interview or informally. The information obtained in these additional questions included the following.)

Where the parent died.

What the child was told, exact wording when possible.

Child's participation in ceremonies, activities at the time of death of the parent.

Whether the child had asked what would happen if the surviving parent died, and, if so, what had been said.

*The questions in the interview were asked of these three well parents after the death of the ill parent. 


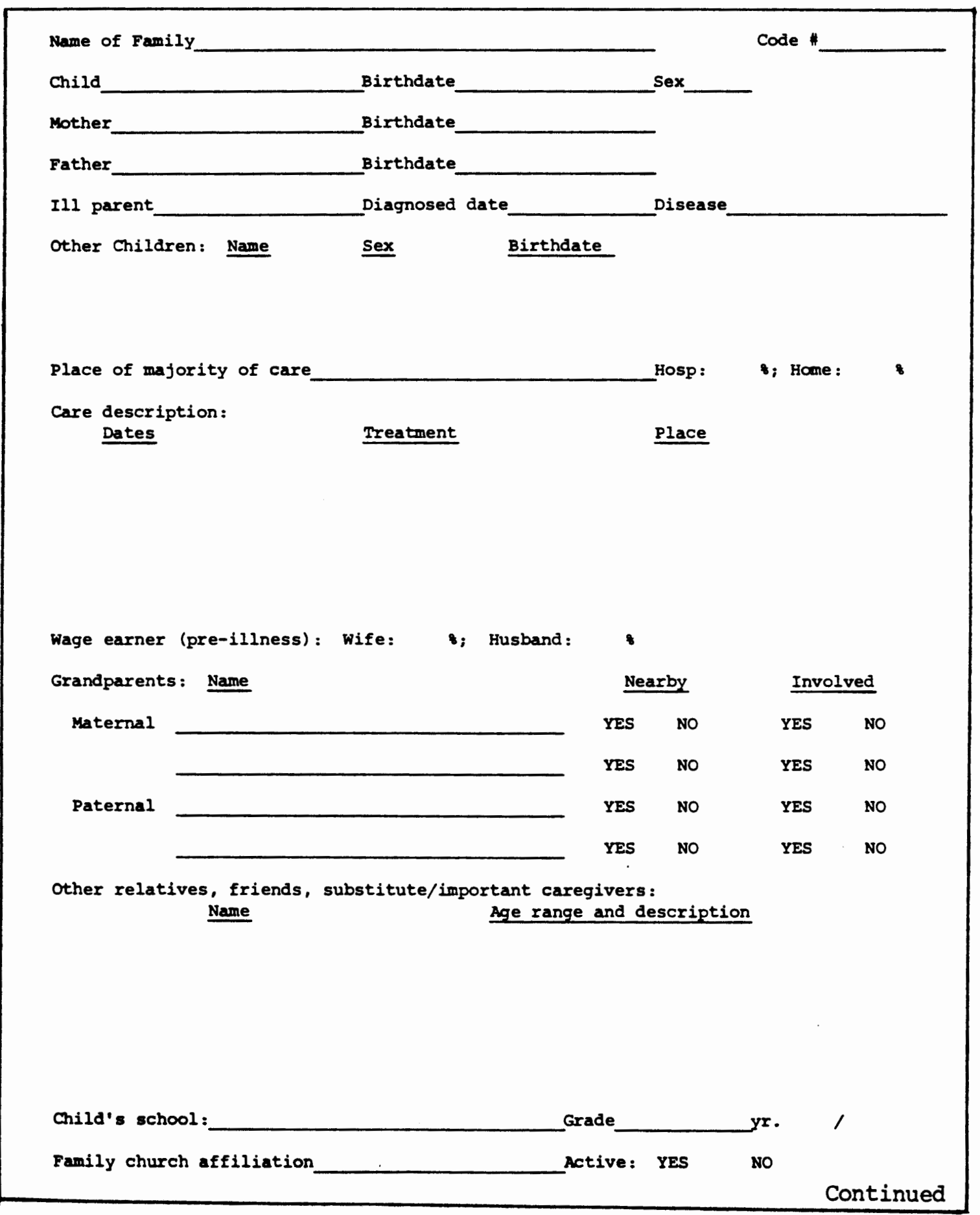


Appendix II

Continued.

Date of death

Place

Age of child at time of death

Preparation: Long-range Thorough Very little None

Description :

Child's participation in ceremonies at time of death:

Wording of what child was told:

Comments : 